AN INTERNATIONAL FORUM FOR THE RAPID PUBLICATION OF ORIGINAL SCIENTIFIC ARTICLES DEALING WITH CHEMISTRY AND RELATED INTERDISCIPLINARY AREAS
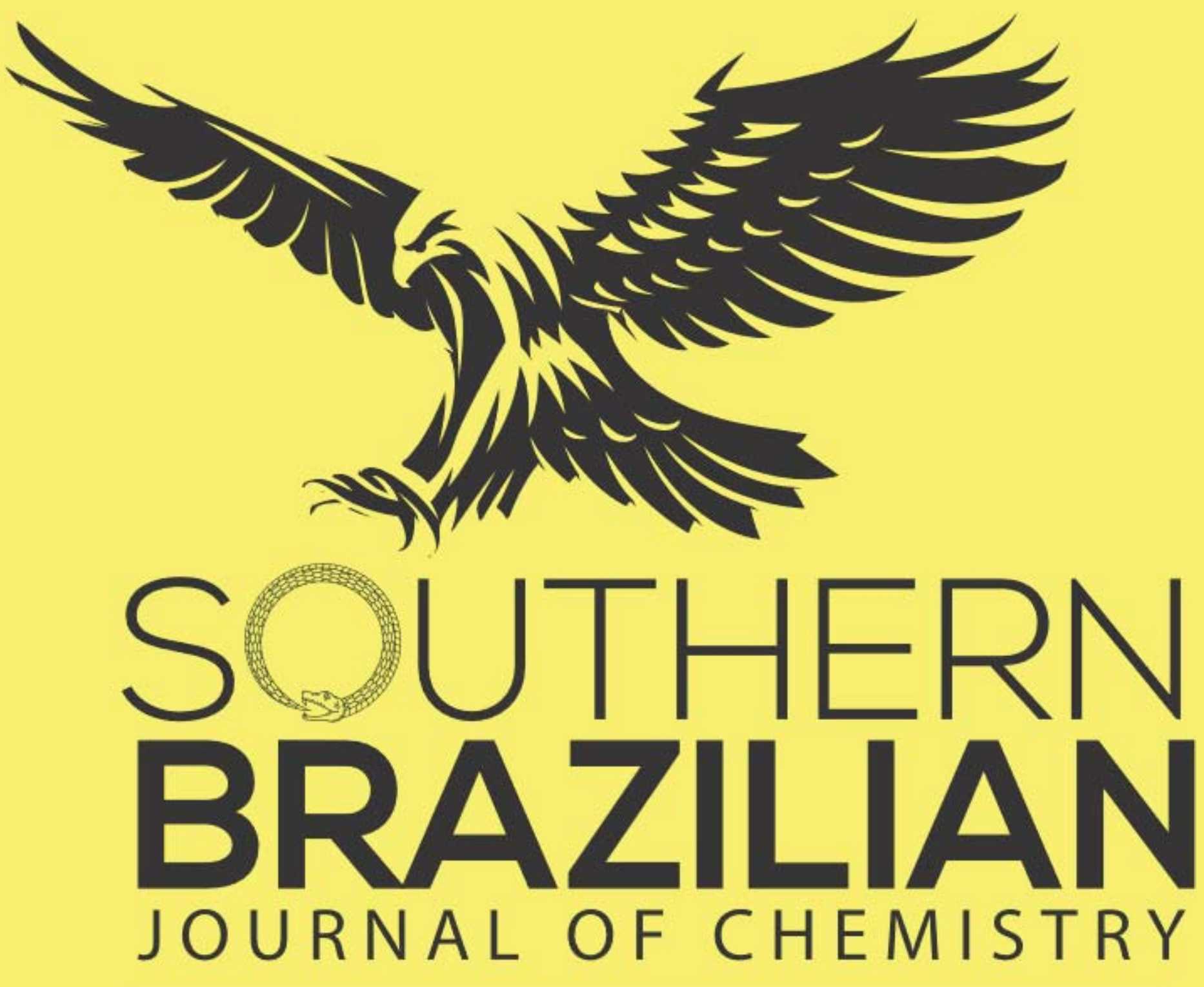

ESTAB L I S HE D IN 1993

VOLUME TWENTY-EIGHT, NUMBER TWENTY-EIGHT

Printed ISSN: 0104-5431 - E-ISSN: 2674-6891 


\section{SOUTHERN BRAZILIAN JOURNAL OF CHEMISTRY}

\section{International Cataloging Data on Publication (CIP)}

SOUTHERN BRAZILIAN JOURNAL OF CHEMISTRY: órgão de divulgação científica e informativa [recurso eletrônico] / SOUTHERN BRAZILIAN JOURNAL OF CHEMISTRY - Vol. 25, n. 25 (Dec. 2017)- . - Porto Alegre: Grupo Tchê Química, 2017 - Anual.

Sistema requerido: Adobe Acrobat Reader. Modo de acesso: World Wide Web:

$<$ http://www.sbjchem.com>

Descrição baseada em: Vol. 25, n. 25 (Dec. 2017).

ISSN 0104-5431

1. Química. I. SOUTHERN BRAZILIAN JOURNAL OF CHEMISTRY.

CDD 500 


\section{SOUTHERN BRAZILIAN JOURNAL OF CHEMISTRY}

\section{Volume 28}

\section{Number $28-2020$}

ISSN 0104-5431

\section{Editor-in-chief}

- Dr. Luis Alcides Brandini De Boni, Brazil, CORSAN, deboni@tchequimica.com

\section{Technical editors}

- Dr. Eduardo Goldani, goldani@tchequimica.com

- Ketevan Kupatadze, Dr., kupatadze@tchequimica.com ,Geórgia, ISU

\section{Editorial Board}

- Rafael Rodrigues de Oliveira, Dr., oliveira@tchequimica.com, Brazil, Neoprospecta.

- Teresa M. Roseiro Maria Estronca, Dr., roseiro@tchequimica.com, Portugal, UC.

- Marcos Antônio Klunk, Dr., marcosak@edu.unisinos.br, Brazil, UNISINOS.

- Dr. Francisco José Santos Lima, lima@tchequimica.com, Brazil, UFRN.

- Monica Regina da Costa Marques, Dr., aguiar@tchequimica.com, Brazil, UERJ.

- Rodrigo Brambilla, Dr., brambilla@tchequimica.com, Brazil, UFRGS.

- Gabriel Rubensam, Me., grubensam@tchequimica.com, Brazil, PUCRS.

- Andrian Saputra, PhD., saputra@tchequimica.com, University of Lampung, Indonesia

- Zhanar Zhumadilova, Ph.D., zhanar85@mail.ru, Satbayev University, Kazakhstan.

- Roberto Fernandez, Ph.D., rfernandezm@unicartagena.edu.co, Universidad de Cartagena, Colombia.
- Andrey Vladimirovich Sevbitov, avsevbitov@mail.ru, Ph.D., Russian Federation.

\section{SOUTHERN BRAZILIAN JOURNAL OF CHEMISTRY}

ISSN - 0104-5431 (Print)

ISSN - 2674-6891 (Eletronic)

JOURNAL DOI: 10.37633/sbjc

Available at

http://www.sbjchem.com

\section{Mission}

The SOUTHERN BRAZILIAN JOURNAL OF CHEMISTRY is a double-blind peer review, open access, multidisciplinary journal dedicated to publishing high-quality content and is intended to fill a gap in terms of scientific information for Southern Brazil. We have set high standards for the articles to be published by ensuring strong but fair refereeing by at least two reviewers. The Journal publishes original research articles in all the fields of Engineering, Mathematics, Physics, Chemistry, Biology, Agriculture, Natural resource management, Pharmacy, Medicine, and others.

Occasionally the journal will include review papers, interviews, and other types of communications. It will be published mainly in English, and at present, there are no page charges.

We hope that this journal will provide a forum for the dissemination of high-quality research in Science and are open to any questions and suggestions.

The responsibility for the articles is exclusive to the authors.

\section{Correspondências}

Rua Francisco Schneider, 292/302.

Bairro Centro. CEP: 95320-000

Nova Prata - RS. Brasil.

Skype: tchequimica

www.sbjechem.com

southbchem@gmail.com 


\title{
HEAT DISSIPATION AT CEMENT HARDENING
}

\author{
ZHANAR ZHUMADILOVA ${ }^{1 *}$; KENZHEBEK AKMALAIULY² \\ ${ }^{1,2}$ Satbayev University, Institute of Architecture and Civil Engineering, Department of Civil Engineering and Construction Materials, 22 \\ Satpayev Str., zip code 050013, Almaty - Republic of Kazakhstan
}

\begin{abstract}
During the construction of concrete structures of small cross-sections, the release of heat during cement hardening has no harmful effects. With the increasing temperature of the hardening cement mass, the rate of cement hydration increases. This increases the rate of release of its heat of hydration of cement. The consequence of the accelerated process of hydration of the binder is a more intensive increase in the strength of cement stone than in the case of hardening under normal conditions. This fact is widely used in practice for the intensification of the hardening of concrete. When structures with small cross-sections are being built, the heat released during hardening is relatively quickly transferred to the surrounding space and does not cause a significant increase in temperature. In structures made of massive concrete (with a large cross-section), this heat is stored in the interior of the array for a long time, which causes a rather large rise in temperature and its slow drop. This is due to the fact that heat transfer to the external environment is hampered here by the considerable thickness of the massif and the rapid rate of concreting, mechanized laying of large masses of concrete. As a result, a temperature difference is created between the internal and external parts of the structure and harmful internal stresses arise that can cause cracking in the hardened concrete. This leads to a violation of its solidity. The faster cement hydrates, the sooner and more heat is released. The types of cements with a high content of tricalcium silicate and aluminate emit more heat and rather than types of cement with a high content of dicalcium silicate and tetra-calcium aluminoferrite. However, the latter has a lower strength. The increase in strength resulting from the hydration process is inevitably associated with the release of heat into the environment.
\end{abstract}

Page - 1

\section{QUINOLINE DERIVATIVES AS GROWTH REGULATORS FOR ORNAMENTAL PLANTS}

\author{
VOSTRIKOVA, Tatiana V. ${ }^{1}$; KALAEV, Vladislav N.2; MEDVEDEVA, Svetlana M.; \\ LEDENEVA, Irina V. ${ }^{4}$, SHIKHALIEV, Khidmet S.;
}

${ }^{1,2}$ Voronezh State University, Botanical Garden, Russian Federation ABSTRACT

\author{
$3,4,5$ Voronezh State University, Department of Organic Chemistry, Russian Federation
}

It is investigated the effect of synthesized organic compounds of 6-hydroxy-2,2,4-trimethyl-1,2-dihydroquinoline, its derivatives, and hydrogenated analogs. These compounds affected the height of seedlings when they were used for pre-sowing seed treatment of the following ornamental plants: annual ornamental grass - scarlet sage (Salvia splendens) and woody plant - yellow rhododendron (Rhododendron luteum). Prior to the sprouting process, the seeds of Rh. luteum and S. splendens were soaked in water solutions of compounds with concentrations of $0.01 \%, 0.05 \%$, and $0.1 \%$ for 18 hours. Dihydro- and tetrahydroquinolines with a concentration of $0.05 \%$ proved to be the most effective for both plants. For Rhododendron luteum, the compounds of 6-hydroxy-2,2,4-trimethyl-1,2-dihydroquinoline, its derivatives, and hydrogenated analogs with a concentration of $0.1 \%$ proved to be the most effective. Dihydroquinolines at concentrations of 0.05 and $0.1 \%$ proved to have the strongest effect when applied to the studied perennial woody plant (Rhododendron luteum). Dihydroquinoline at the concentration of $0.05 \%$ also proved to be effective when applied to the annual grass (Salvia splendens). For annual S. splendens, tetrahydroquinoline at concentrations of 0.01 and $0.05 \%$ appeared to be the most effective. The pre-sowing seed treatment of grass Salvia splendens and woody plant Rhododendron luteum with the studied compounds demonstrated that their effect on the height of the seedlings is species-specific. The pre-sowing seed treatment of $\mathrm{Rh}$. luteum and S. splendens allows increasing the height of the seedlings by $3-61 \%$ and $17-25 \%$, respectively. It is suggested using the compounds of 6-hydroxy-2,2,4-trimethyl-1,2dihydroquinoline, its derivatives, and hydrogenated analogs as effective growth stimulators for ornamental grasses and woody plants. 


\title{
COMPARATIVE STUDY ON ANTIOXIDANT ACTIVITY OF SALVIA NEMOROSA L. FROM TWO DIFFERENT LOCATIONS
}

GHAFIYEHSANJ, Elham"; DILMAGHANI, Kamaladdin²; CHAPARZADE, Nader³; SAADATMAND, Sara4;

\author{
1,4 Islamic Azad University, Science and Research Branch, Faculty of Science, Biology Department \\ 2 Islamic Azad University, Marand Branch, Faculty of Science, Biology Department \\ ${ }^{3}$ Azerbaijan Tarbiat-e-Moallem University, Faculty of Science, Department of Biology
}

\begin{abstract}
In order to investigate the antioxidant activity of Salvia nemorosa L. collected from Ahar and Urmia regions in Iran at different growth stages, aerial parts of sage after collecting were dried, and for measurement, the ability of scavenge DPPH (2,2-diphenyl-1-picryl-hydrazyl-hydrate) radical in different concentrations $(0.025,0.05,0.07,0.1,0.2$, 0.04 and 0.6 ) of methanolic extracts were prepared. The result showed that the ability to scavenge DPPH radical and amount of inhibition percent of vegetative stage leaves, flowering stage leaves, and flowers increased with increasing concentrations of methanolic extracts from 0.25 to $0.6 \mathrm{mg} / \mathrm{ml}$. In the region of Urmia, the highest amount of DPPH inhibition there was in vegetative stage leaves, and the lowest amount of DPPH inhibition was seen in flowers. In Ahar regions, unlike the Urmia region, the highest amount of DPPH inhibition there was in flowers, but the lowest of DPPH inhibition was seen in flowering stage leaves. Also, the content of inhibition of DPPH in Ahar and Urmia regions similarly increased between two phenological stages (vegetative stage leaves, flowering stage leaves, and flowers) in $0.4 \mathrm{mg} / \mathrm{ml}$ and $0.6 \mathrm{mg} / \mathrm{ml}$ concentrations.
\end{abstract}

Page -17

\section{ANTIBIOTIC SUSCEPTIBILITY OF ESCHERICHIA COLI ISOLATE FROM URINARY TRACT INFECTION OF THALASSEMIC PATIENTS IN THI-QAR PROVINCE}

OKAB, Alaa Abood Yasir"i; SALIH, Manal ${ }^{2}$

${ }^{1}$ Ministry of Health-Thi-Qar health office.

${ }^{2}$ Department of biology-College of science-Thi-Qar University.

\begin{abstract}
Escherichia coli (E. coli) is the most common type of pathogen that causes Urinary tract infection disease. It can be presented as pathogenic or non-pathogenic strain and found not only in the animal but also in the human intestine. This bacterium can cause opportunistic infection when the human host comprised of thalassemia patients or changes the healthy hemostatic flora. This study aimed to analyze the presence of bacteria in thalassemia patients with urinary tract infection. A total of 303 samples were collected during the period from August 2019 to January 2020 from thalassemia patients who suffered from urinary tract infection. The results showed that there were $6.9 \%$ of patients infected with $E$. coli, $2.6 \%$ of patients were infected with S. aureus, $0.7 \%$ with both Proteus and Klebsiella, while $89.1 \%$ of patients had a negative sample for bacteria. Also, the incidence of urinary tract infections in females is higher than in males. Besides, its occurrence in rural areas is higher than in city residents. Moreover, among 16 antibiotics tested to sensitize bacteria to antibiotics, Imipenem showed $100 \%$ efficacy on all isolated bacteria. In contrast, Netilmicin showed $80.1 \%$ efficacy, Gentamycin 80.1\%, and Amikacin 76.2\%. Ampicillin, Aztreonam, Amoxicillin-Clavulanic Acid, Tetracycline, and TicarcillinClavulanic Acid, did not show any effectiveness toward the bacteria while other antibiotics showed different activities. Furthermore, the isolated microbes from thalassemia patients were the highest resistance to antibiotics in comparison with other studies, and this antibiotic-resistant may be due to the weakening of the patient's immune status and frequent blood taking and the antibodies it contains.
\end{abstract}




\title{
STUDY ON THE DPPH FREE RADICAL-SCAVENGING ACTIVITY OF SALVIA NEMOROSA L. AT TWO GROWTH STAGES
}

GHAFIYEHSANJ, Elham ${ }^{1}$; DILMAGHANI, Kamaladdin²; CHAPARZADE, Nader³; SAADATMAND, Sara ${ }^{4}$

\author{
${ }^{1,4}$ Islamic Azad University, Science and Research Branch, Faculty of Science, Biology Department \\ 2 Islamic Azad University, Marand Branch, Faculty of Science, Biology Department \\ ${ }^{3}$ Azerbaijan Tarbiat-e-Moallem University, Faculty of Science, Department of Biology
}

\begin{abstract}
This study was designed to examine the DPPH free radical-scavenging activity, in different concentrations $(0.025,0.05,0.07,0.1,0.2,0.04$ and 0.6$)$ of methanolic extracts of Salvia nemorosa $\mathrm{L}$. collected from the northwest of Iran (Zonouz and Ardabil regions) at two-stage of growth (vegetative stage leaves, flowering stage leaves, and flowers). The result showed that the mean of inhibition percentage in the Zonouz region increased in various concentrations and between flowers, vegetative stage leaves, and flowering stage leaves, compared with the plants of the Ardabil region. In each of the regions of Zonouz and Ardabil, the highest amount of DPPH inhibition was observed in the vegetative stage leaves in comparison with flowering stage leaves and flowers. In addition, in the effect of DPPH radical trapping in different concentrations of methanolic extracts of Salvia nemorosa L. was observed that from each of the collected region, methanolic extracts from sage plants were dose-dependent and acted very effective and useful and the best antioxidant activity was in the high concentration of extracts, So in Zonouz and Ardabil regions, the content of inhibition of DPPH increased significantly, by increasing the concentration of $0.025 \mathrm{mg} / \mathrm{ml}$ to $0.6 \mathrm{mg} / \mathrm{ml}$ and in Zonouz region the content of inhibition of DPPH similarly increased in $0.2,0.4$ and $0.6 \mathrm{mg} / \mathrm{ml}$ concentrations. In the Ardabil region, the most content of inhibition of DPPH was seen in $0.4 \mathrm{mg} / \mathrm{ml}$ and $0.6 \mathrm{mg} / \mathrm{ml}$ concentrations, but in this region, the content of inhibition of DPPH in $0.2 \mathrm{mg} / \mathrm{ml}$ concentration there was only in vegetative stage leaves and flowering stage leaves.
\end{abstract}

Page -35

\section{USING SYNTHESISED ORGANIC COMPOUNDS AS ENVIRONMENTALLY FRIENDLY RETARDANTS FOR ORNAMENTAL PLANTS}

\author{
VOSTRIKOVA, Tatiana V. ${ }^{*}$; KALAEV, Vladislav N².; POTAPOV, Andrey Yu. ${ }^{3}$; VANDYSHEV, Dmitry Y. \\ SHIKHALIEV, Khidmet S. ${ }^{5}$; \\ 1,2 Voronezh State University, Botanical Garden, Russian Federation \\ ${ }^{3,4,5}$ Voronezh State University, Department of Organic Chemistry, Russian Federation
}

\section{ABSTRACT}

The pre-sowing treatment of scarlet sage (Salvia splendens Ker Gawl.) seeds with 4-methyl-2-piperidin-1-ylpyrimidine-5-carboxylic acid at concentrations of $0.01,0.05$, and $0.1 \%$ proved to have an obvious inhibiting effect. Prior to sowing, the seeds of Salvia splendens were soaked in a water suspension of 4-methyl-2-piperidin-1-yl-pyrimidine-5carboxylic acid and 4-methyl-2-morpholin-4-pyrimidine-5-carboxylic acid with concentrations of $0.01 \%, 0.05 \%$, and $0.1 \%$ for 18 hours. On the 42nd day of the experiment, the seedlings, having been preliminarily hardened for 12 days, were removed from the greenhouse and planted on the field. The pre-sowing treatment of Salvia splendens seeds with 4methyl-2-morpholin-4-pyrimidine-5-carboxylic acid proved to have the inhibiting effect at concentrations of 0.01 and $0.05 \%$. The height of the seedlings decreased by $13.3-43.7 \%$. It was revealed that 4-methyl-2-piperidin-1-yl-pyrimidine-5carboxylic acid at concentrations of $0.01,0.05$, and $0.1 \%$ decreased the growth of the seedlings by $30.4-43.7 \%$, and $4-$ methyl-2-morpholin-4-pyrimidine-5-carboxylic acid at concentrations of 0.01 and $0.05 \%$ decreased the growth of the seedlings by $13.3-22.2 \%$. By contrast, the effect of pyrimidinecarboxylic acids on seed germination and plant height of another annual flower - spreading marigold (Tagetes patula L.) was stimulating. It was investigated some different concentrations from 0.01 to $0.05 \%$. The same concentrations of identical compounds were tested, but effects from them were opposite for Tagetes patula, and Salvia splendens seedlings. Consequently, the species-specific effect of pyrimidinecarboxylic acids on seed germination and plant height for ornamental grasses takes place. Therefore,4-methyl- 
2-piperidin-1-yl-pyrimidine-5-carboxylic acid and 4-methyl-2-morpholin-4-pyrimidine-5-carboxylic acid are recommended as growth retardants for Salvia splendens.

Page -40

\title{
MISUSE AND ABUSE OF DRUGS: A CROSS-SECTIONAL SURVEY AMONG PHARMACY PROFESSIONALS IN SAUDI ARABIA
}

\author{
ALSHAYBAN, Dhafer ${ }^{1} ;$ JOSEPH, Royes $^{1 *}$; LUCCA, Jisha ${ }^{1} ;$ ALJISHI, Fatimah ${ }^{1} ;$ ALSADIQ, Yara ${ }^{2}$ \\ 1Department of Pharmacy Practice, College of Clinical Pharmacy, Imam Abdulrahman Bin Faisal University, \\ Dammam, Saudi Arabia \\ ${ }^{2}$ PharmD student, College of Clinical Pharmacy, Imam Abdulrahman Bin Faisal University, Saudi Arabia
}

\begin{abstract}
Prescription and non-prescription medication misuse or abuse is a global problem that has a negative impact on all human life aspects, including health, social, economic, and security status. According to the United Nations Office on Drug and Crime reports, over 5\% of adult people used drugs at least once in the year 2015, and 29.5 million of them were suffered from the consequences of inappropriate use of drugs. Information on the knowledge and perception among pharmacists regarding the misuse and abuse medications in Saudi Arabia are limited, and therefore, a study was conducted among pharmacy staff to assess their knowledge and awareness on drug misuse and abuse. A crosssectional study was carried out in Eastern Province, Saudi Arabia. Pharmacy professionals with more than three months of experience were included in the study. A structured questionnaire was used to obtain the participant's responses. A Chi-square test was used to evaluate the association of socio-demographic factors with the participant's responses. Ninety pharmacy professionals were responded. Overall, $69(76.7 \%)$ participants agreed that misuse and abuse are two different terms. In addition, the study showed different responses for patients who suspected to be medication abusers. In conclusion, this study provides an initial picture of pharmacy staffs' knowledge and opinion regarding the misuse and abuse of medicines in Saudi Arabia. Participants' reactions toward such behaviors were different and not consistent. Therefore, there should be a clear policy to define the role of the pharmacy staff toward the misuse and abuse of medication in Saudi Arabia.
\end{abstract}

Page -45

\section{CLINICAL AND LABORATORY TESTING OF A NEW MODIFICATION OF TWO-LAYER "SILEP" DENTURES USED IN PROSTHETIC DENTISTRY}

TIMOSHIN, Anton'; MITIN, Nikolay²; OLEYNIKOV, Alexander²; TIMOSHINA, Maria'; MITINA, Evgeniya²

1 I.M. Sechenov First Moscow State Medical University (Sechenov University) ${ }^{2}$ Ryazan State Medical University named after academician I.P. Pavlov

\section{ABSTRACT}

Dentistry is a part of medicine, where various polymer materials were used for the first time. Many factors forced researchers to find more stable, versatile, and hygienic materials for the manufacture of dental products. It is important to note that the search for the ideal polymer dental material is still ongoing. This is because modern polymers, in some cases, do not meet the specified requirements for chemical, physical, strength, and elastic properties. Based on the data on the method of creating and using silicone material for the base of the removable prosthesis "Gossil", an improved silicone material for two-layer dentures "Silep" was developed, as well as a special primer for better connection of the lining with the rigid acrylic base of the prosthesis. To evaluate the most suitable compound, materials were tested for several parameters, such as tensile strength, elongation, and shore hardness. In addition to selecting a suitable material 
for modification, the selection and testing of an adhesive that allows the chemical bonding of the acrylate surface to the siloxane surface were carried out.

\section{Page - 53}




\title{
SOUTHERN BRAZILIAN JOURNAL OF CHEMISTRY
}

\author{
HEAT DISSIPATION AT CEMENT HARDENING
}

\author{
ZHANAR ZHUMADILOVA ${ }^{1 *}$; KENZHEBEK AKMALAIULY²
}

1,2 Satbayev University, Institute of Architecture and Civil Engineering, Department of Civil Engineering and Construction Materials, 22 Satpayev Str., zip code 050013, Almaty - Republic of Kazakhstan

(phone: +77771388677)

* Corresponding author

e-mail: zhanar_85@mail.ru

Received 16 February 2020; received in revised form 27 April 2020; accepted 04 June 2020

\begin{abstract}
During the construction of concrete structures of small cross-sections, the release of heat during cement hardening has no harmful effects. With the increasing temperature of the hardening cement mass, the rate of cement hydration increases. This increases the rate of release of its heat of hydration of cement. The consequence of the accelerated process of hydration of the binder is a more intensive increase in the strength of cement stone than in the case of hardening under normal conditions. This fact is widely used in practice for the intensification of the hardening of concrete. When structures with small cross-sections are being built, the heat released during hardening is relatively quickly transferred to the surrounding space and does not cause a significant increase in temperature. In structures made of massive concrete (with a large cross-section), this heat is stored in the interior of the array for a long time, which causes a rather large rise in temperature and its slow drop. This is due to the fact that heat transfer to the external environment is hampered here by the considerable thickness of the massif and the rapid rate of concreting, mechanized laying of large masses of concrete. As a result, a temperature difference is created between the internal and external parts of the structure and harmful internal stresses arise that can cause cracking in the hardened concrete. This leads to a violation of its solidity. The faster cement hydrates, the sooner and more heat is released. The types of cements with a high content of tricalcium silicate and aluminate emit more heat and rather than types of cement with a high content of dicalcium silicate and tetra-calcium aluminoferrite. However, the latter has a lower strength. The increase in strength resulting from the hydration process is inevitably associated with the release of heat into the environment.
\end{abstract}

Keywords: concrete, hydration, minerals, temperature, strength.

\section{INTRODUCTION}

It is known that the hydration reactions of cement minerals are exothermic, and the interaction of cement with water is accompanied by the release of heat.

According to S.D.Okorokov (Volzhensky, 1986), clinker minerals are characterized by heat release indicators at different hardening periods.

According to D. Verbeck and C. Foster (Bazhenov, 2002), the heat release of three calcium silicate $\left(\mathrm{C}_{3} \mathrm{~S}\right)$ and two calcium silicate $\left(\mathrm{C}_{2} \mathrm{~S}\right)$ is much lower, and three calcium aluminate $\left(\mathrm{C}_{3} \mathrm{~A}\right)$ and four calcium alumin-ferite $\left(\mathrm{C}_{4} \mathrm{AF}\right)$ more.

The heat release of various portland types of cements varies widely depending on their mineral composition and fineness of grinding. The presence in their composition of an increased amount of $\mathrm{C}_{3} \mathrm{~S}$ glass and especially $\mathrm{C}_{3} \mathrm{~A}$, determines the intense heat release during the hardening of such types of cements, mainly in the first terms, due to the rapid interaction of these minerals with water. Cements characterized by a high content of $\mathrm{C}_{4} \mathrm{AF}$ and most of all $\beta-C_{2} S$ are characterized by a reduced heat release. Heat generation can also be reduced by introducing active mineral additives into Portland cement, in particular, finely ground granulated blast furnace slags (Volzhensky, 1986).

\section{MATERIALS AND METHODS}

Heat release during hardening of cements is of great practical importance. In particular, in 
the process of concreting conventional structures at low temperatures, increased heat generation plays a positive role. On the contrary, the construction of massive structures, for example, hydraulic structures (especially in summer), from concrete on cements with increased heat generation leads to their heating to $50{ }^{\circ} \mathrm{C}$ and more. Subsequent cooling of concrete masses at the outer surfaces causes significant temperature differences in the outer and inner zones, the occurrence of tensile stresses in the surface layers, and the formation of cracks in them. This reduces the bearing capacity and durability of structures, therefore, when erecting massive concrete structures, low-heat types of cements are used, for example, with heat release after three days no more than 168-188 and after seven days $210-230 \mathrm{~J} / \mathrm{g}$.

The experiments of many researchers have shown that heat from a mixture of Portland cement and water is released stepwise during the first days of hardening.

Based on their data, as well as the data of V.Lerch, T.Powers, and others (Mikulsky, 2002), the time of initial hardening of the cement test can be divided into four periods according to the intensity of heat release. The first period of 30-40 min can be attributed to the first period of the interaction of cement with water, when there is a strong heat release in the test (especially during the first 5-8 $\mathrm{min}$ ) with its subsequent decrease to small values.

The second period - the period of low heat, sometimes called induction, occurs during the second to fourth hours. Its duration depends on the properties of cement and gypsum content.

The third period, starting 3-5 hours after the moment of cement mixing with water, is characterized by the beginning of setting and a gradual increase in heat generation, reaching a maximum after 6-10 hours. At this point, the setting of the dough is usually marked.

The fourth period begins after the heat release indicator passes through a maximum and is characterized by a decrease in the amount of heat by the daily time to approximately $4.19 \mathrm{~J} / \mathrm{h}$ per $1 \mathrm{~g}$ of cement. At this time, an intensive increase in the strength of the system is observed, and the heat release in ordinary cements after a day of hardening reaches 15$20 \%$ of the total (Volzhensky, 1986; Bazhenov 2002). At the same time, according to the data of Yu. S. Malinin and others, there is a stepwise change in the concentration of calcium hydroxide and silica in an aqueous solution of cement paste. A curve with sharp kinks is also characteristic, illustrating the growth of the ultimate shear stress measured by a conical plastometer. Here, the moments of decrease in the indices of the ultimate shear stress coincide in time with the onset of strong drops in the concentration of calcium hydroxide in the liquid phase of the test (Mikulsky, 2002; Dvorkin, 1991; Solomatov, 1989).

The presence of an induction period with low heat generation is explained by the formation of clinker particles of helium shells of hydrated compounds, which almost cease water access to unreacted inner zones of binder grains. But the presence of a saturated solution of $\mathrm{Ca}(\mathrm{OH})_{2}$ and other compounds in the gel formed, and on the unreacted surface of the cement, particles create the conditions for the diffusion influx of water from the intergranular space with a low concentration of the solution. As a result, the osmotic pressure gradually increases in the gel shells, leading to rupture at certain values. In this case, there is the possibility of direct access to water to exposed fresh surfaces and its reaction with cement. This moment is the end of the induction period of low activity and the beginning of the third period with increasing heat dissipation (Krivenko, 1989; Neville, 1972; Reichel, 1979).

The data obtained by M.I. Strelkov (Reichel, 1979), during observations under a microscope, confirm the possibility of rupture of the gel shells that arise on the surface of cement grains. He also believes that the phenomenon of rupture of the shells on individual particles contributes to their movement into the grain space, which, due to this, is filled with cementing neoplasms.

The rate of heat release and the formation of particles of a new solid phase during the hydration of binders has a great influence on the formation of a bound structure with the formation of a "hardened stone". For example, the formation of calcium hydroxide from oxide usually proceeds very quickly with the release of a new substance. Theoretically, they are able to increase its temperature by $878: 1.17=750{ }^{\circ} \mathrm{C}$ (here $1.17 \mathrm{~J} / \mathrm{g}{ }^{\circ} \mathrm{C}$ is the heat capacity of the hydrate) (Artyukhovich, 2011).

Hydration ( $\alpha$-semi-aquatic gypsum comes with the release of $112 \mathrm{~J} / \mathrm{g}$. In this case, with stoichiometric ratios of the reacting components, the resulting two hydrates can theoretically heat up only by $112: 1.09=103{ }^{\circ} \mathrm{C}$. It is important to note that hydration of calcium oxide or gypsum proceeds practically within 1-2 hours with the 
release of all the heat.

Of the clinker minerals, only $\mathrm{C}_{3} \mathrm{~A}$ can be compared to some extent with $\mathrm{CaO}$ and semiaquatic gypsum. With its full hydration, $1082 \mathrm{~J} / \mathrm{g}$ is released, or in terms of $\mathrm{C}_{3} \mathrm{AH}_{12} 600 \mathrm{~J} / \mathrm{g}$. If we allow the possibility of a fairly rapid interaction of this substance with water even in half, then in the absence of heat loss, the temperature of the reaction product can reach approximately 300: $1.26=237^{\circ} \mathrm{C}$.

Hydration of semi-aquatic gypsum with relatively small heat release proceeds quietly only with a moderate increase in the external volume, while hydration of three calcium aluminates, according to some researchers, causes an insignificant strength of the formed stone, and according to others its zero strength.

It is characteristic that the presence of $3 \mathrm{CaO}-\mathrm{A}_{2} \mathrm{O}_{3}$ in clinkers in an amount of $5-10 \%$ is useful, while its higher content already leads to a temporary decrease in the strength of types of cements. This phenomenon can be partially explained by the peculiarity of hydration $\mathrm{C}_{3} \mathrm{~A}$ (Shevchenko, 2004).

Of the other clinker minerals, $\mathrm{C}_{3} \mathrm{~S}-500$ $\mathrm{J} / \mathrm{g}$, according to V.Lerch and R. Bogg (Puliaev, 2011), is distinguished by high heat release during full hydration. However, this process. it is relatively slow, and even under favorable conditions at ordinary temperature during the first 12 hours, the degree of hydration barely exceeds $15-20 \%$. In this case, heat generation can reach $100-126 \mathrm{~J}$ per $1 \mathrm{~g}$ of the starting substance, and even less per $1 \mathrm{~g}$ of neoplasms. These heat dissipation indicators are close to those characteristics of semi-aquatic gypsum, which interacts with water for 1-2 hours. Thus, one can not be afraid of significant heating of $\mathrm{C}_{3} \mathrm{~S}$ hydration products and deformations inherent in $\mathrm{C}_{3} \mathrm{~A}$.

The two calcium silicate $\mathrm{C}_{2} \mathrm{~S}$, as well as the four calcium aluminoferrite $\mathrm{C}_{4} \mathrm{AF}$ in terms of heat during the initial hydration periods, cannot have a significant effect on the heating of the system, in which dangerous deformations can occur.

Thus, it is necessary to evaluate the true astringent properties of certain substances with due regard for the factor of heat release, which from a certain threshold exerts a sharply negative effect on the hardening effect of the system. It should be emphasized that the above applies to stoichiometric mixtures of binders with water. The hardening of concrete and mortar mixtures is less affected by the factor of the intensity of heat generation due to the presence of aggregates and excessive amounts of water preventing the system from overheating (in the absence of artificial heating).

\section{RESULTS AND DISCUSSION:}

The most significant influence on the rate of hardening of concrete is exerted by the mineralogical composition of cement. According to the intensity of the increase in concrete strength at normal temperature, modern types of cements are divided into four types (Table 1).

At the same time, type I and type II types of cements, which provide a faster increase in concrete strength, at an early age, sharply slow down the increase in strength during long hardening periods, while type III and type IV cements, slowly hardening at the beginning, show a noticeable increase in strength over a long time. Under favorable conditions, the strength of concrete on these types of cements by the half-year age increases by 1.5 to 1.8 times compared with the strength at the age of 28 days, and there is also an increase in strength over the next several years, although at a slower pace.

A noticeable effect on the rate of hardening of concrete is exerted even by relatively small fluctuations in air temperature.

To determine the temperature of cement hydration during hardening of concrete, thermometers of the TM-1288/1 type are installed in the structure. Thermometer readings were recorded in an eight-channel TM-5103. The arrangement of thermometers in the structure is shown in Figure 1.

From Figure 1, it is seen that on the first and second foundations, thermometers No.1 and No.6 in the center are installed, respectively, thermometers No.2, No.3 and No.7, and No.5 are installed along the edge of the formwork at different levels. Thermometers No.4 and No.8 are installed to control the outside temperature or air temperature.

Figure 2 and Table 2 show the change in temperature of concrete over time in various places of structures. Therefore, when concreting massive structures, especially in the springautumn period, it is necessary, if possible, to take into account temperature fluctuations and its effect on the hardening of concrete.

Analysis of the results of changes in concrete temperature shows that 5 hours after 
pouring, the temperature of concrete began to rise markedly and amounted to $37.1-38.3{ }^{\circ} \mathrm{C}$ (Table 2). Such a relatively slow rise in temperature is due to the regular process of cement hydration.

This process is very intense. Since, at this stage, the number of hydrated phases is relatively small, in the space between the cement particles, there is free growth of thin plates of calcium hydroxide and calcium hydrosilicates and ettringite in the form of long fibers that form simultaneously.

In the process of intensive hydration of clinker minerals $\mathrm{C}_{3} \mathrm{~A} \quad \mathrm{C}_{4} \mathrm{AF}$ and $\mathrm{C}_{3} \mathrm{~S}$, after 22 hours and 30 minutes, thermometers No.1 and No.3 (structures No.1) respectively reached a maximum temperature of 76.3 and $69.1{ }^{\circ} \mathrm{C}$ (2017/08/12, at 08:30 h).

In construction No.1, the maximum temperature was recorded by thermometers:

- No.1 - after 22 hours 30 minutes - 76.2 ${ }^{\circ} \mathrm{C}$;

- No.3 - after 22 hours 30 minutes - 69.1

${ }^{\circ} \mathrm{C}$;

- No.2 - after 29 hours $-49.6^{\circ} \mathrm{C}$.

In construction No.2, the maximum temperature was recorded by thermometers:

- No.7 - after 23 hours 30 minutes - 68.8 ${ }^{\circ} \mathrm{C}$;

- No. 5 - after 24 hours $-60.7^{\circ} \mathrm{C}$;

- No. 6 - after 26 hours 30 minutes - 79.0

${ }^{\circ} \mathrm{C}$.

The preservation of the reached maximum temperature of concrete can be observed from 4 to 9 hours, depending on the location of the thermometers. This fact confirms that the third stage of the hydration process, occurring after 5 hours 30 minutes, lasts up to 27 hours.

After 27-30 hours, a uniform, and a slight decrease in temperature is observed at all studied points of concrete structures (Figure 2). This confirms the completion of intensive hydration of $\mathrm{C}_{3} \mathrm{~A}$ and $\mathrm{C}_{4} \mathrm{AF}$, as well as the end of the crystallization of calcium hydroxide through the liquid phase.

The degree of hydration depends on the water-cement ratio, and reaches its maximum value only after $1-5$ years (Evlanov, 2002; Krasnovsky, 2004; Shifrin, 1985; Sychev, 1974; Lukyanov, 1972; Lukyanov, 1971; Velichko, 1972).

The degree of hydration (Figure-3) is determined in various ways: by the amount of $\mathrm{Ca}$ $(\mathrm{OH})_{2}$, by heat, by the specific gravity of the cement paste, by the amount of chemically bound water, by the amount of non-hydrated cement
$(18,19)$, or indirectly by the strength of cement stone (Shifrin, 1985; Sychev, 1974; Lukyanov, 1972; Lukyanov, 1971; Velichko, 1972; Solovyanchik, 1985; Shifrin, 2007).

Hydration products vary in strength. The main carriers of strength are calcium hydrosilicates (Krivenko, 1989). In the process of hydration of clinkers $\mathrm{C}_{3} \mathrm{~S}$ and $\mathrm{C}_{2} \mathrm{~S}$, in addition to calcium hydrosilicates, hydrated lime $\mathrm{Ca}(\mathrm{OH})_{2}$ is formed, which is stored in the cement stone and prevents corrosion of steel inside the cement stone (Solovyanchik, 2015).

Since the thermal conductivity of concrete is relatively low, hydration leads to a significant increase in temperature inside massive concrete structures. At the same time, the outer part of the concrete massif loses a certain amount of heat, so that a sharp temperature gradient is established.

Like many chemical reactions, the hydration reaction of clinker minerals is exothermic, with cement emitting up to $120 \mathrm{cal} / \mathrm{g}$ (Solovyanchik, 2015).

Strictly speaking, the total heat release is the sum of the heat of a chemical reaction and heat as a result of the sorption of water by the surface of a gel formed during hydration. The heat of sorption is a quarter of the total heat dissipation.

Bogg's research results showed that ordinary Portland cements emit about half of the total heat in 1-3 days. The heat release depends on the chemical composition of the cement and represents the sum of the heat of hydration of all cement constituents. From this, it follows that, if the composition of cement is known, its heat release can be determined with a high degree of accuracy (Shevchenko, 2004; Neville, 1972).

Since at an early age, the hydration of the individual components proceeds at different speeds, the rate of heat release, as well as the total amount of heat, depends on the composition of the cement. From this, it follows that by reducing the percentage of the most rapidly hydrating components $\left(\mathrm{C}_{3} \mathrm{~A}\right.$ and $\left.\mathrm{C}_{3} \mathrm{~S}\right)$, the rate of heat generation of concrete at an early age can be reduced.

On the other hand, heat release during cement hydration can prevent the freezing of water in the capillaries of freshly laid concrete in cold weather. Therefore, high heat release, in this case, is a positive factor. It is clear that it is desirable to know the heat release value of various cements in order to choose the most suitable type of cement for each specific case. 
For many applications of concrete, moderate heat generation is a positive factor (Neville, 1972).

The initial framework of the cement stone that arose during the setting significantly affects the further structure of the hydration products, in particular, the crack resistance and strength growth rate. Therefore, it is not surprising that there is a definite relationship between the degree of hydration and strength.

Temperature changes do not occur instantly, and it depends on the temperature difference, the properties of concrete, the massiveness of the structure, the heat generation of cement, and other factors. Therefore, a jumplike change in temperature can be arbitrarily adopted, especially since the strength of concrete hardening at different temperatures is affected by the mineralogical composition of cement, watercement ratios, and others. The normal temperature of the concrete hardening medium is conventionally considered $15 \ldots 20^{\circ} \mathrm{C}$.

It is known that heating accelerates chemical reactions. An increase in concrete temperature activates the interaction of water and cement and accelerates the hardening of concrete. Moreover, the phase composition of cement hydration products hardening at different temperatures remains almost the same.

The resulting neoplasms fix the expanded volume of concrete, however, concrete exhibits residual deformations, that is, its volume after heating is greater than the original.

\section{CONCLUSIONS:}

1. In concrete, the maximum hydration temperature $-79.0^{\circ} \mathrm{C}$ was reached 26 hours 30 minutes after pouring structures No.2 and maintaining a high temperature in the range of 78.0-79.0 ${ }^{\circ} \mathrm{C}$ continues for 9 hours.

2. The preservation of the reached maximum temperature of concrete in thermometers can be observed from 4 to 9 hours, depending on the place of their installation. This fact confirms that the third stage of the hydration process, occurring after 5 hours 30 minutes, lasts up to 27 hours after pouring concrete.

3. It should be borne in mind that the rate of increase in the strength of concrete is gradually slowing down, and its final strength will depend on in which growth certain temperature fluctuations occur.

4. In fact, temperature changes do not occur instantly. The intensity of heating and cooling depends on the temperature difference, the properties of concrete, the massiveness of the structure, heat dissipation of cement, and other factors.

\section{ACKNOWLEDGMENTS:}

The authors are grateful to the leadership of the Satbayev University for creating the conditions for carrying out this work.

\section{REFERENCES:}

1. Volzhensky A.V. Mineral binders. Textbook for high schools / A.V. Volzhensky. - Ed. $4^{\text {th }}$, rev. and add. - M .: Stroyizdat, 1986 .- 464 p.

2. Bazhenov Yu.M. Concrete technology. Textbook. - M .: DIA Publishing House, 2002. $500 \mathrm{p}$.

3. Building materials (Materials science and technology). Textbook. Under the general Editor. V.G. Mikulsky. - M.: DIA Publishing House, 2002.- 536 p.

4. Dvorkin L.I. Cement concretes with microfillers. Under the editorship of L.I. Dvorkin. - Kiev: Budivelnik, 1991. - $136 \mathrm{p}$.

5. Solomatov V.I. Intensive technology of concrete. - M .: Stroyizdat, 1989.- 253 p.

6. Krivenko P.V., Pushkareva E.K., Malyarenko V.V. Hydration and dehydration of slag-alkaline materials based on manganese-containing slag. Cement. - 1989. No.10. 8-14pp.

7. Neville A. M. Concrete Properties. - Moscow: Publishing house of building literature, 1972. $344 \mathrm{p}$.

8. Reichel V., Conrad D. Concrete: The $2^{\text {nd }}$ part of Part 1. Properties. Design. Test. - Moscow: Stroyizdat, 1979. $111 \mathrm{p}$.

9. Construction: Encyclopedic Dictionary / Compiled by D.V. Artyukhovich. - Stavropol: Stavropol publishing house "Paragraph", 2011. $766 \mathrm{p}$.

10. Shevchenko A.A. Chemical resistance of nonmetallic materials and corrosion protection: Textbook. - Moscow: Chemistry, Colossus, 2004.- 248 p.

11. Puliaev I.S., Puliaev S.M. To the question of the maximum base temperature at which concrete mix is allowed during the construction of transport structures. Scientific and Technical Journal Bulletin of MGSU. No.2. 2011. P. 295- 
304.

12. Solovyanchik A.R., Pulyaev I.S. Influence of heat exchange characteristics of hardening concrete of structures with the environment on its crack resistance. Bulletin of the Tyumen State University of Architecture and Civil Engineering. Number 4. 2015. P. 60-64.

13. Solovyanchik A.R., Pulyaev I.S. The construction of the cable-stayed bridge across the river Oku on the bypass of Murom. Scientific works of TsNIIS OJSC "Research on the interaction of technosphere and natural components of transport natural-technical systems", No. 251. M .: TsNIIS, 2008. P. 20-31.

14. Sokolov S.B. The effect of fluctuations in air temperature in greenhouses on the temperature of hardening concrete during the construction of monolithic plate-ribbed spans in the cold season. Scientific works of TsNIIS OJSC "From the hydraulic integrator to modern computers", No. 213. M .: TsNIIS, 2002. P. 167-172.

15. Smirnov N.V., Antonov E.A. The role of concrete creep in the formation of the thermal stress state of monolithic reinforced concrete structures in the process of its construction. Scientific works of TsNIIS OJSC "From the hydraulic integrator to modern computers", No. 213. M: TsNIIS, 2005. P. 89-117.

16. Solovyanchik A.R., Korotin V.N., Weitsman S.G., Pulyaev I.S. The construction of reinforced concrete pylons of the cable-stayed bridge across the river Oku bypass the city of Murom. Bulletin of bridge building. No. 2. M .: 2008. P.11-16.

17. Evlanov S.F. Technological cracks on the surface of monolithic spans. Scientific works of the Central Scientific and Research Institute of Information Technologies "Problems of rationing and research of consumer properties of bridges", No. 208. M .: Central Scientific Research Institute of Information Technologies, 2002. P. 27-36.

18. Krasnovsky B.M. Engineering and physical foundations of winter concreting methods. M.: GASIS, 2004 - 470 p.

19. Shifrin S.A., Tkachev A.V. Thermal interaction of hardening concrete and concrete base in conditions of solar radiation. Proceedings of VNIIPITeploproject. M.: VNIIPITeploproject, 1985. P. 19-27.

20. Sychev M.M. Hardening of binders. Stroyizdat, 1974. 80 p.

21. Lukyanov V.S., Solovyanchik A.R. The physical basis for predicting our own thermal stress state of concrete and reinforced concrete structures. Proceeding of TsNIIS, No. 73. M: TsNIIS, 1972. P 36-42.

22. Lukyanov V.S., Solovyanchik A.R. Investigation of the heat release of cement in the thermos calorimeter TsNIIS. Proceeding of "Methods for the experimental determination and calculation of heat in concrete" - M.: VNIIIPI Teploproject, 1971. P.45-58.

23. Velichko V.P., Tsimerinov A.I. Forecasting technique thermally stressed state of cylindrical concrete arrays. Proceeding of TsNIIS, No. 73. M.: TsNIIS, 1972. P. 117-129.

24. Solovyanchik A.R. Energy-saving fundamentals of manufacturing technology for bridge and other reinforced concrete structures. M.: NIIZHB, 1985. 403 p.

25. Shifrin S.A. Thermal-physical basis for the formation of consumer properties of structural elements of transport structures from monolithic and precast monolithic reinforced concrete. $\mathrm{M}$.: TsNIIS, 2007. 297 p. 
Table 1. Classification of cements by hardening rate

\begin{tabular}{|c|c|c|c|}
\hline $\begin{array}{l}\text { Type of } \\
\text { cement }\end{array}$ & The mineralogical characteristics & $\begin{array}{c}K_{28 . \ldots 90}= \\
R_{90} \\
R_{28}\end{array}$ & $\begin{array}{c}\mathrm{K}_{28 \ldots 180}= \\
\mathbf{R}_{180} \\
\mathbf{R}_{28}\end{array}$ \\
\hline $\mathrm{I}$ & Aluminate cement $\left(\mathrm{C}_{3} \mathrm{~A}\right)>12 \%$ & $\frac{\text { K28 }}{1 \ldots 1,05}$ & $\frac{\mathbf{M}_{28}}{1 \ldots 1,05}$ \\
\hline II & Alite cement $\left(\mathrm{C}_{3} \mathrm{~S}>50 \%, \mathrm{C}_{3} \mathrm{~A}<8 \%\right)$ & $1,05 \ldots 1,2$ & $1,1 \ldots 1,3$ \\
\hline III & $\begin{array}{c}\text { Cement with complex mineralogical } \\
\text { characteristics (pozzolanic, Portland cement } \\
\text { with content } \mathrm{C}_{4} \mathrm{AF}>14 \% \text {, Portland cement slag } \\
\text { with slag content } 30 \ldots 40 \% \text { ) }\end{array}$ & $1,2 \ldots 1,5$ & $1,3 \ldots 1,8$ \\
\hline \multirow[t]{2}{*}{ IV } & $\begin{array}{l}\text { Belite Portland cement and slag Portland } \\
\text { cement with a slag content of more than } 50 \%\end{array}$ & $1,6 \ldots 1,7$ & 1,85 \\
\hline & $\begin{array}{c}\text { For comparison } \\
\mathrm{Lg} n \\
\mathrm{R}_{\mathrm{n}}=\mathrm{R}_{28}-\mathrm{g} \\
\mathrm{Lg} 28\end{array}$ & 1,35 & 1,55 \\
\hline
\end{tabular}

Table 2. The change in temperature of concrete over time

\begin{tabular}{|c|c|c|c|c|c|c|c|c|}
\hline \multirow[t]{2}{*}{ Time } & \multicolumn{8}{|c|}{ Thermometer number } \\
\hline & 1 & 2 & 3 & 4 & 5 & 6 & 7 & 8 \\
\hline \multicolumn{9}{|c|}{$2019 / 08 / 23$} \\
\hline $10: 00$ & 29 & 30 & 30 & 25 & 31 & 30 & 30 & 29 \\
\hline $10: 30$ & 30 & 31 & 30 & 26 & 31 & 29 & 31 & 28 \\
\hline 11:00 & 30 & 31 & 31 & 27 & 31 & 31 & 31 & 29 \\
\hline $11: 30$ & 30 & 31 & 31 & 27 & 31 & 31 & 31 & 29 \\
\hline $12: 00$ & 31 & 31 & 31 & 28 & 31 & 31 & 31 & 30 \\
\hline $12: 30$ & 32 & 32 & 32 & 29 & 31 & 31 & 32 & 31 \\
\hline 13:00 & 33 & 33 & 33 & 30 & 32 & 32 & 33 & 31 \\
\hline $13: 30$ & 33 & 33 & 33 & 30 & 33 & 33 & 33 & 31 \\
\hline $14: 00$ & 34 & 34 & 34 & 31 & 34 & 34 & 34 & 31 \\
\hline $14: 30$ & 36 & 35 & 36 & 31 & 35 & 35 & 36 & 32 \\
\hline $15: 00$ & 38 & 37 & 38 & 32 & 37 & 38 & 38 & 32 \\
\hline $15: 30$ & 40 & 39 & 41 & 33 & 39 & 40 & 40 & 31 \\
\hline $16: 00$ & 43 & 42 & 43 & 34 & 42 & 43 & 43 & 32 \\
\hline $16: 30$ & 45 & 44 & 46 & 34 & 43 & 46 & 45 & 32 \\
\hline $17: 00$ & 48 & 46 & 49 & 34 & 46 & 49 & 48 & 32 \\
\hline $17: 30$ & 52 & 49 & 53 & 34 & 48 & 52 & 51 & 32 \\
\hline \multicolumn{9}{|c|}{$2017 / 08 / 12$} \\
\hline $08: 30$ & 76 & 47 & 69 & 27 & 60 & 78 & 69 & 29 \\
\hline 09:00 & 76 & 47 & 69 & 27 & 60 & 78 & 69 & 30 \\
\hline 09:30 & 76 & 47 & 69 & 29 & 61 & 78 & 69 & 32 \\
\hline $10: 00$ & 76 & 48 & 69 & 31 & 61 & 78 & 69 & 34 \\
\hline $10: 30$ & 76 & 48 & 68 & 32 & 61 & 78 & 69 & 35 \\
\hline $11: 00$ & 76 & 48 & 68 & 31 & 61 & 78 & 69 & 34 \\
\hline $11: 30$ & 76 & 48 & 68 & 33 & 61 & 79 & 69 & 36 \\
\hline $12: 00$ & 76 & 48 & 68 & 33 & 61 & 79 & 69 & 36 \\
\hline $12: 30$ & 75 & 49 & 68 & 37 & 60 & 79 & 69 & 35 \\
\hline $13: 00$ & 75 & 49 & 68 & 37 & 60 & 79 & 68 & 35 \\
\hline $13: 30$ & 75 & 49 & 68 & 37 & 60 & 79 & 68 & 35 \\
\hline $14: 00$ & 75 & 49 & 67 & 38 & 60 & 79 & 68 & 35 \\
\hline $14: 30$ & 75 & 49 & 67 & 38 & 60 & 79 & 68 & 36 \\
\hline $15: 00$ & 75 & 50 & 67 & 38 & 60 & 79 & 68 & 36 \\
\hline $15: 30$ & 75 & 50 & 67 & 36 & 59 & 78 & 68 & 35 \\
\hline $16: 00$ & 74 & 49 & 67 & 36 & 59 & 78 & 68 & 34 \\
\hline $16: 30$ & 74 & 49 & 67 & 35 & 59 & 78 & 68 & 34 \\
\hline $17: 00$ & 74 & 49 & 66 & 35 & 59 & 78 & 68 & 33 \\
\hline $17: 30$ & 74 & 49 & 66 & 34 & 59 & 78 & 68 & 33 \\
\hline $18: 00$ & 74 & 48 & 66 & 34 & 58 & 77 & 68 & 33 \\
\hline $18: 30$ & 73 & 48 & 66 & 32 & 58 & 76 & 68 & 31 \\
\hline $19: 00$ & 73 & 47 & 65 & 30 & 57 & 76 & 67 & 30 \\
\hline
\end{tabular}




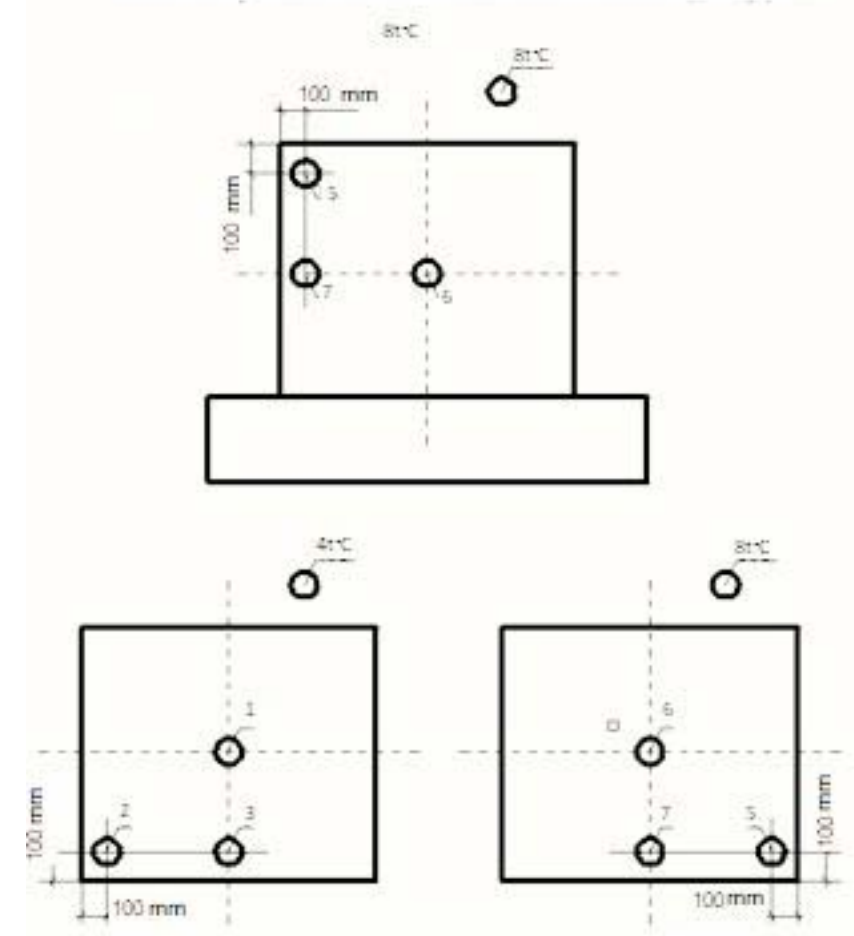

Figure 1. The scheme of the installation of hte temperature sensor

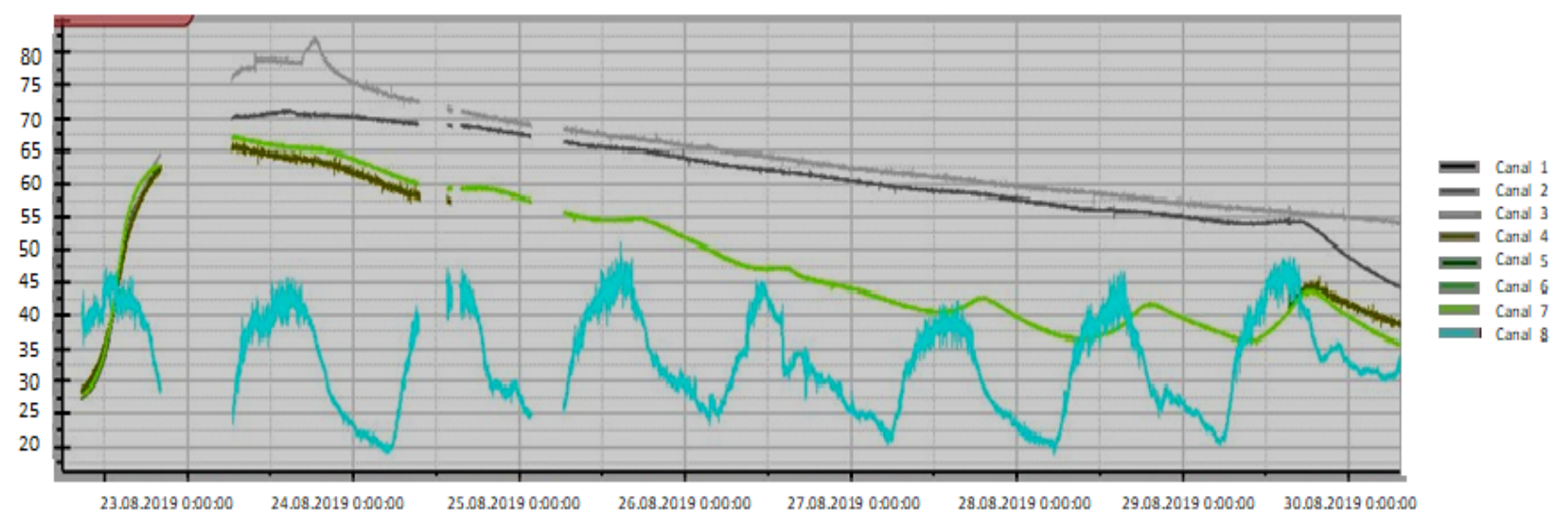

Figure 2. Concrete temperature change over time 


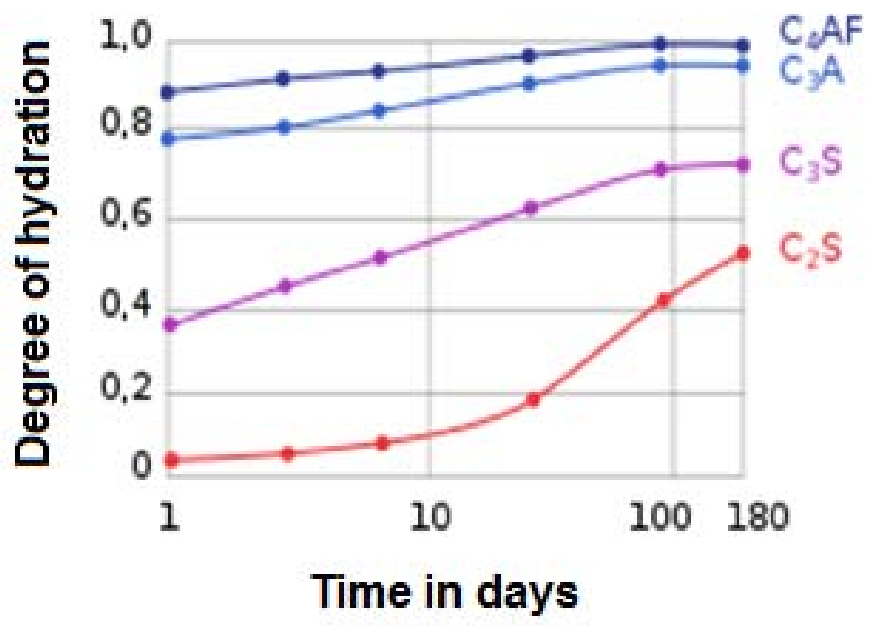

Figure 3. The degree of hydration of minerals

The SOUTHERN BRAZILIAN JOURNAL OF CHEMISTRY (ISSN: 2674-6891; 0104-5431) is an open-access journal since 1993. Journal DOI: 10.48141/SBJCHEM. http://www.sbjchem.com. This text was introduced in this file in 2021 for compliance reasons.

(C) The Author(s)

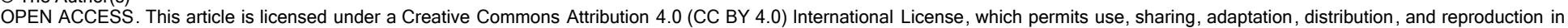

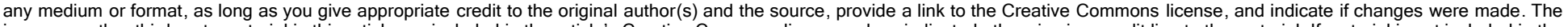

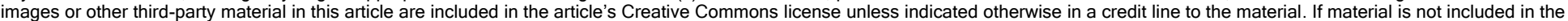

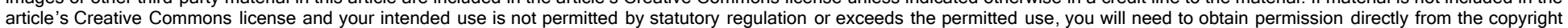
holder. To view a copy of this license, visit http://creativecommons.org/ licenses/by/4.0/. 


\title{
SOUTHERN BRAZILIAN JOURNAL OF CHEMISTRY QUINOLINE DERIVATIVES AS GROWTH REGULATORS FOR ORNAMENTAL PLANTS
}

\author{
VOSTRIKOVA, Tatiana V. ${ }^{1 *}$; KALAEV, Vladislav N. ${ }^{2}$; MEDVEDEVA, Svetlana M. ${ }^{3}$; \\ LEDENEVA, Irina $V^{4}{ }^{4}$, SHIKHALIEV, Khidmet S. ${ }^{5}$; \\ 1,2 Voronezh State University, Botanical Garden, Russian Federation \\ 3,4,5 Voronezh State University, Department of Organic Chemistry, Russian Federation \\ * Correspondence author \\ e-mail: tanyavostric@rambler.ru
}

Received 01 May 2020; received in revised form 02 June 2020; accepted 23 June 2020

\begin{abstract}
It is investigated the effect of synthesized organic compounds of 6-hydroxy-2,2,4-trimethyl-1,2dihydroquinoline, its derivatives, and hydrogenated analogs. These compounds affected the height of seedlings when they were used for pre-sowing seed treatment of the following ornamental plants: annual ornamental grass - scarlet sage (Salvia splendens) and woody plant - yellow rhododendron (Rhododendron luteum). Prior to the sprouting process, the seeds of $R h$. luteum and $\mathrm{S}$. splendens were soaked in water solutions of compounds with concentrations of $0.01 \%, 0.05 \%$, and $0.1 \%$ for 18 hours. Dihydro- and tetrahydroquinolines with a concentration of $0.05 \%$ proved to be the most effective for both plants. For Rhododendron luteum, the compounds of 6-hydroxy-2,2,4-trimethyl-1,2-dihydroquinoline, its derivatives, and hydrogenated analogs with a concentration of $0.1 \%$ proved to be the most effective. Dihydroquinolines at concentrations of 0.05 and $0.1 \%$ proved to have the strongest effect when applied to the studied perennial woody plant (Rhododendron luteum). Dihydroquinoline at the concentration of $0.05 \%$ also proved to be effective when applied to the annual grass (Salvia splendens). For annual S. splendens, tetrahydroquinoline at concentrations of 0.01 and $0.05 \%$ appeared to be the most effective. The pre-sowing seed treatment of grass Salvia splendens and woody plant Rhododendron luteum with the studied compounds demonstrated that their effect on the height of the seedlings is species-specific. The pre-sowing seed treatment of Rh. luteum and S. splendens allows increasing the height of the seedlings by 3-61\% and 17-25\%, respectively. It is suggested using the compounds of 6-hydroxy-2,2,4trimethyl-1,2-dihydroquinoline, its derivatives, and hydrogenated analogs as effective growth stimulators for ornamental grasses and woody plants.
\end{abstract}

Keywords: quinolinic compounds, growth regulators, grasses, woody plants.

\section{INTRODUCTION}

Several heterocycles have shown biological activity: a potent antibacterial (Brown et al., 2004), anti-inflammatory (Gavrilov et al., 1988), antitrypanosomal (Fotie et al., 2010) and other effects. The same quinolinic compounds at different concentrations may either stimulate or inhibit the biological processes (Gavrilov et al., 1988; Litvinov, 1998; Dorey et al., 2000; Brown et al., 2004; Le et al., 2007; Fotie et al., 2010).

Some papers also study the biological effect of quinolinic compounds, such as dihydroand tetrahydroquinoline, on seed germination and the root growth of the stem cuttings of woody plants (Shmyreva, 2000; Butorina et al., 2002; Baranova, 2013 a). Over the last years, attempts have been made to synthesize new quinolinic compounds that can be used as growth regulators (Dorey et al., 2000; Croisy-Delcey et al., 2000; Pravin et al., 2000ab, 2003; Abadi, Brun, 2003; Denmark, Venkatraman, 2006). The effect of certain quinolines on seed germination and the size of the seedlings of Rhododendron ledebourii was also investigated (Moiseeva et al., 2012 a; Kalaev et al., 2013). However, the effect of 6-hydroxy-2,2,4-trimethyl-1,2-dihydroquinoline, its derivatives, and hydrogenated analogs on the growth of other plants has not been studied yet.

Therefore, the aim of our research was to study the effect of synthesized organic compounds of 6-hydroxy-2,2,4-trimethyl-1,2dihydroquinoline, its derivatives and hydrogenated analogs on the height of seedlings, when used for pre-sowing seed treatment of the 
following ornamental plants: annual ornamental grass - scarlet sage (Salvia splendens) and woody plant - yellow rhododendron (Rhododendron luteum).

The annual ornamental grass, scarlet sage (Salvia splendens Ker Gawl.), was selected as the study material because it is often planted in urban gardens and grows slowly in the early stages of its development (Nikolaenko 1971, Gladky 1977). Highly decorative deciduous shrub yellow rhododendron (Rhododendron luteum Sweet.) is quite winter-hardy and droughtresistant (Alexandrova 2003; Vostrikova 2011; Moiseeva et al., 2012 b; Baranova, 2013 b). It is planted in urban and residential areas, and its propagation requires additional stimulators of growth and seed germination.

\section{MATERIALS AND METHODS}

The research was conducted at the $\mathrm{B}$. M. Kozo-Polyansky Botanical Garden of Voronezh State University in 2017. The study focused on the following organic compounds synthesized at the Department of Organic Chemistry of Voronezh State University:

6-hydroxy-2,2,4-trimethyl-1,2,3,4-tetrahy_ droquinoline (compound 1),

6-hydroxy-2,2,4-trimethyl-1,2-dihydroquino_ line (compound 2),

7-[(dimethylamino)methyl]-6-hydroxy-2,2,4-trime_ thyl-1,2,3,4-tetrahydroquinoline (compound 3),

7-[(dimethylamino)methyl]-6-hydroxy-2,2,4-trime thyl-1,2-dihydroquinoline (compound 4), and

1-ben_zoyl-6-hydroxy-2,2,4-trimethyl-1,2-dihy_ droquinoline (compound 5), and the way they influence the height of seedlings of $R h$. luteum.

The effect of 6-hydroxy-2,2,4-trimethyl1,2,3,4-tetrahydroquinoline and 6-hydroxy-2,2,4trimethyl-1,2-dihydroquinoline on the height of the "Hot fire" variety of scarlet sage (Salvia splendens Ker Gawl.) was also studied.

Prior to the sprouting process, the seeds of $R h$. luteum and Salvia splendens were soaked in water solutions of the above-listed compounds with concentrations of $0.01 \%, 0.05 \%$, and $0.1 \%$ for 18 hours. The control group consisted of the same type of seeds soaked in a tap water solution of a commonly used growth stimulator, Epibrassinolide (commercial fraction Epin Extra produced by NNPP NEST $M$, Russia), with the concentration of $0.05 \%$ (following the instruction of commercial fraction). In the case of each of the studied concentrations of the acids, as well as the control group, the experiment was conducted three times using a set of 100 seeds. After soaking, the rhododendron seeds were placed in Petri dishes containing blotting paper and germinated in the laboratory conditions at a constant temperature of $22{ }^{\circ} \mathrm{C}$. On the 21st day, the sprouts were planted in containers filled with high-moor peat and then kept in a greenhouse. The height of the seedlings of Rhododendron luteum was measured with a ruler, 7 months after the start of the experiment. After the first true leaves appear, young plants are considered seedlings (Korovkin 2007).

The seeds of $S$. splendens were sown in containers filled with a mixture of soil and sand (3 parts soil/1 part sand) and kept in a greenhouse at $20^{\circ} \mathrm{C}$, as recommended in (Nikolaenko 1971, Gladky 1977). Seed germination was evaluated on the 20th day of the experiment. On the 42nd day of the experiment, the seedlings, having been preliminarily hardened for 12 days, were removed from the greenhouse and planted on the field. The field experiment was designed according to B. A. Dospekhov (1985). The height of the seedlings was measured on the 42nd day using a ruler. The results were statistically processed using the STADIA software package. The procedures of data grouping and processing were described by A. P. Kulaichev (2006). The mean values were compared using Student's ttest. The variances were compared using the Ftest. The coefficient of variation (Cv) was counted, according to G. F. Lakin (1990). If CV was below $10 \%$, it meant that the degree of variation was low, with $\mathrm{Cv}$ between 10 and $25 \%$. The degree of variation was medium, and when Cv was over $25 \%$, the degree of variation was high (Lakin 1990). To estimate the influence of various concentrations of the chemical compounds on the height of the plants, a oneway analysis of variance was used. The power of influence was estimated, according to Snedecor (in \%).

\section{RESULTS AND DISCUSSION:}

The height of the seedlings of Rhododendron luteum 7 months after the seeds were treated with the studied organic compounds are given in Table 1 and Figure 1. The seedlings in all the experimental groups were higher than the ones in the control group, with 6-hydroxy- 
2,2,4-trimethyl-1,2-dihydroquinoline (compound 2) demonstrating the stronger stimulating effect than 6-hydroxy-2,2,4-trimethyl-1,2,3,4-tetrahy_ droquinoline (compound 1).

It is demonstrated that 6-hydroxy-2,2,4trimethyl-1,2,3,4-tetrahydroquinoline (compound 1), 6-hydroxy-2,2,4-trimethyl-1,2-dihydroquinoline (compound 2) and 1-benzoyl-6-hydroxy-2,2,4trimethyl-1,2-dihydroquinoline (compound 5) appear to have strong stimulating effect with any of the studied concentrations: $0.01,0.05$, and $0.1 \%$ (differences with the control group are reliable, $\quad P<0.001)$. 1-Benzoyl-6-hydroxy-2,2,4trimethyl-1,2-dihydroquinoline shows the strongest stimulating effect and 7-[(dime thylamino)methyl]-6-hydroxy-2,2,4-trime_ thyl1,2,3,4-tetrahydroquinoline (compound 3) appears to be less active. But 7-[(dime thylamino)methyl]-6-hydroxy-2,2,4-trimethyl-

1,2,3,4-tetrahydroquinoline (compound 3 ) and 7[(dimethylamino)methyl]-6-hydroxy-2,2,4-trime thyl-1,2-dihydroquinoline (compound 4) at concentrations of 0.05 and $0.1 \%$ (Tables 1,2 ) also demonstrated a stimulating effect. However, 7-[(dimethylamino)methyl]-6-hydroxy-2,2,4-trime thyl-1,2-dihydroquinoline (compound 4 ) is more effective. 7 months after the start of the experiment, the height of $R h$. luteum seedlings increased by $3.0-61.2 \%$ (Table 2). For $R h$. luteum the strongest stimulating effect was demonstrated by all the studied compounds with the concentration of $0.1 \%$.

The study also determined the effect of the chemical compounds on the height of Salvia splendens and the variation coefficient for this parameter (Table 3). Variance analysis demonstrated that the studied quinolinic compounds influence the height of plants. The power of influence is given in Table 4.

Quinolinic compounds 6-hydroxy-2,2,4trimethyl-1,2,3,4-tetrahydroquinoline with concentrations of $0.01 \%$ and $0.05 \%$ and 6hydroxy-2,2,4-trimethyl-1,2-dihydroquinoline with the concentration of $0.05 \%$ can be used as growth stimulators for scarlet sage plants, increasing their height by $17-25 \%$.

\section{CONCLUSIONS:}

The conducted experiments demonstrated that the stimulators have both similar and species-specific effects on annual grasses and perennial woody plants. 6-Hydroxy-2,2,4trimethyl-1,2,3,4-tetrahydroquinoline and 6- hydroxy-2,2,4-trimethyl-1,2-dihydroquinoline with the concentration of $0.05 \%$ have the most substantial growth stimulating effect on the seedlings of all the studied plant species. However, the effect of the compounds on annual grass is different from the one they have on woody plants. For the annual grass tetrahydroquinoline with concentrations of $0.01 \%$ and $0.05 \%$ proved to be the most effective. For Rhododendron luteum compounds of 6-hydroxy2,2,4-trimethyl-1,2-dihydroquinoline, its derivati ves, and hydrogenated analogs with the concentration of $0.1 \%$ proved to be the most effective. Dihydroquinoline at the concentration of $0.05 \%$ also proved to be effective when applied to the annual grass (Salvia splendens), while the other studied concentrations did not influence the height of the seedlings. The effect of synthesized chemical compounds of 6-hydroxy-2,2,4-trime thyl-1,2-dihydroquinoline and its hydrogenated analog on grasses and woody plants is speciesspecific. Tetrahydroquinolines are more effective than dihydroquinolines for the annual grass (Salvia splendens). Dihydroquinolines are stronger than tetrahydroquinolines for the woody plant (Rhododendron luteum). The pre-sowing seed treatment of $R h$. luteum and $S$. splendens allows increasing the height of the seedlings by $3-61 \%$ and $17-25 \%$, respectively. It is suggested using the compounds of 6-hydroxy-2,2,4trimethyl-1,2-dihydroquinoline, its derivatives, and hydrogenated analogs as effective growth stimulators for grasses and woody plants.

\section{ACKNOWLEDGMENTS:}

The study received financial support from the Ministry of Science and Higher Education of the Russian Federation within the framework of State Contract with universities regarding scientific research in 2020-2022, project No. FZGU-2020-0044.

\section{REFERENCES:}

1. Abadi, A. H., Brun, R. Synthesis and evaluation of novel 7-trifluoromethyl-4-(4substituted anilino) quinolines as antiparasitic and antineoplastic agents Arzneimforsch. Drug. Res., 2003, 53, 655-663.

2. Alexandrova, M. S. Rhododendrons. Moscow: ZAO Fiton+, 2003.

3. Baranova, T. V. Accelerated production of plants resistant to urban conditions. 
Ecology and Industry of Russia, 2013a, 4, 65-67.

4. Baranova, T. V. Phenological characteristics of species of the genus Rhododendron $\mathrm{L}$. in the Central Black Soil. Bulletin of Krasnoyarsk State Agrarian University, 2013b, 4, 74-79.

5. Brown, C. W., Liu, S., Klucik, J., Berlin, K. D., Brennan, P. J., Kaur, D., Benbrook, D. M. Novel heteroarotinoids as potential antagonists of Mycobacterium bovis BCG. Journal of Medicinal Chemistry, 2004, 47 (4), 1008-1017.

6. Butorina, A. K. Vostrikova, T. V., Shmyreva, J. V., Belchinskaya, L. I., Kondaurova, V. A. The effect of chemical stimulants on germination and cytogenetic indicators of seedlings of birch seeds hanging. Forestry, 2002, 5, 33-35.

7. Croisy-Delcey, M., Coroisy, A., Carrez, D., Huel, C., Chiaroni, A., Ducrot, P., Bisagni, E., Jin, L., Leclercq, G. Bioorg, Diphenyl quinolines and isoquinolines: synthesis and primary biological evaluation. Med. Chem., 2000, 8(ii), 2629-2641.

8. Denmark, S., Venkatraman, S. On the mechanism of the Skraup-Doebner-Von Miller quinoline synthesis. J. Org. Chem., 2006, 71, 1668-1676.

9. Dorey, G., Lockhart, B., Lestage, P., Casara, P. New quinolinic derivatives as centrally active antioxidants. Bioorg. Med. Chem. Lett., 2000, 10, 935-939.

10. Dospekhov, B. A. The methodology of field experience (with the basics of statistical processing of research results). 5th ed. add. and reslave. Textbook: benefits for high school. Moscow: Agropromizdat, 1985.

11. Fotie, J., Kaiser, M., Delfı'n, D. A., Manley, J., Reid, C. S., Paris, J.-M., Wenzler, T., Maes, L., Mahasenan, K. V., Li, C., Werbovetz, K. A. Antitrypanosomal Activity of 1,2-Dihydroquinolin-6-ols and Their Ester Derivatives. Journal of Medicinal Chemistry, 2010, 53, 966-982. doi: 10.1021/jm900723w

12. Gavrilov, M.Y., Mardanova, L.G., Kolla, V.E., Konshin, M.E. Synthesis, antiinflammatory and analgesic activities of 2-arylamino-5,6,7,8tetrahydroquinoline-3-carboxamides. Pharmaceut. Chem. J., 1988, 22, 554556.

13. Gladkiy, N. P. Decorative floriculture in the garden. Reference book. Leningrad: Kolos (Leningrad branch), 1977.
14. Kalaev, V. N., Moiseeva, E. V., Baranova, T. V., Medvedeva, S. M., Shikhaliev, H. S., Voronin, A. A. Growth stimulants for species of the genus Rhododendron L.: Patent 2490892 Russian Federation. 2012112006/13, declared 29. 03.12, published 27. 08.13, 24.

15. Korovkin, O. A. Anatomy and morphology of higher plants: a dictionary of terms. Moscow: Drofa, 2007.

16. Kulaichev, A. P. Methods and tools for integrated data analysis. Moscow: FORUM: INFA-M, 2006.

17. Le, T. C., Berlin, K. D., Benson, S. D., Eastman, M. A., Bell-Eunice, G., Nelson, A. C., Benbrook, D. M. Heteroarotinoids with Anti-Cancer Activity Against Ovarian Cancer Cells. The Open Medicinal Chemistry Journal, 2007, 1, 11-23.

18. Moiseeva, E. V., Baranova, T. V., Kalaev, V. N., Kuznetsov, B. I., Shcherbakov, G. S., Voronin, A. A., Potapov, A. Yu., Shikhaliev, H. S. The effect of compounds of the quinoline series on the germination and growth processes of Ledebour's rhododendron (Rhododendron Ledebourii Pojark.). Basic Research, 2012a, 5 (1), 172-176.

19. Moiseeva, E. V., Baranova, T. V., Voronin, A. A., Kuznetsov, B. I. A collection of representatives of the genus rhododendron (Rhododendron L.) in the botanical garden B.M. Kozo-Polyansky Voronezh State University. Ecosystems, their optimization and protection, 2012b, 7, 39-44.

20. Nikolaenko, N. P. Handbook of the florist. Moscow: Kolos, 1971.

21. Pravin, M. P., Rajini, T. P., Rajini, M. P. Study on the copolymerization kinetics of 8-quinolinyl methacrylate, n-butyl methacrylate and styrene. Int. J. Polym. Mater., 2000a, 46, 471-476.

22. Pravin, M. P., Rajini, T. P., Rajini, M. P. Synthesis and characterization of 8quinolinyl methacrylate with methyl acrylate and vinyl acetate copolymers. Int. J. Polym. Mater., 2000b, 46, 141-150.

23. Pravin, M. P., Rajini, T. P., Rajini, M. P. Acrylic homo- and copolymers based on 2,4-dichlorophenyl Methacrylate and 8- 
Quinolinyl Methacrylate. J. Polym. Res., 2003, 11, 65-73.

24. Shmyreva, J. V. 2, 2, 4-Trimethylhydroquinolins. Voronezh: VSU, 2000.

25. Vostrikova, T. V. Ecological and biological features of rhododendrons during introduction in the conditions of the Central Chernozem region. Bulletin of Krasnoyarsk State Agrarian University, 2011, 4, 27-30.
26. Williamson, N., Ward, D. The preparation and some chemistry of 2,2-dimethyl-1,2dihydroquinolines. Tetrahedron, 2005, 61, 155-165.

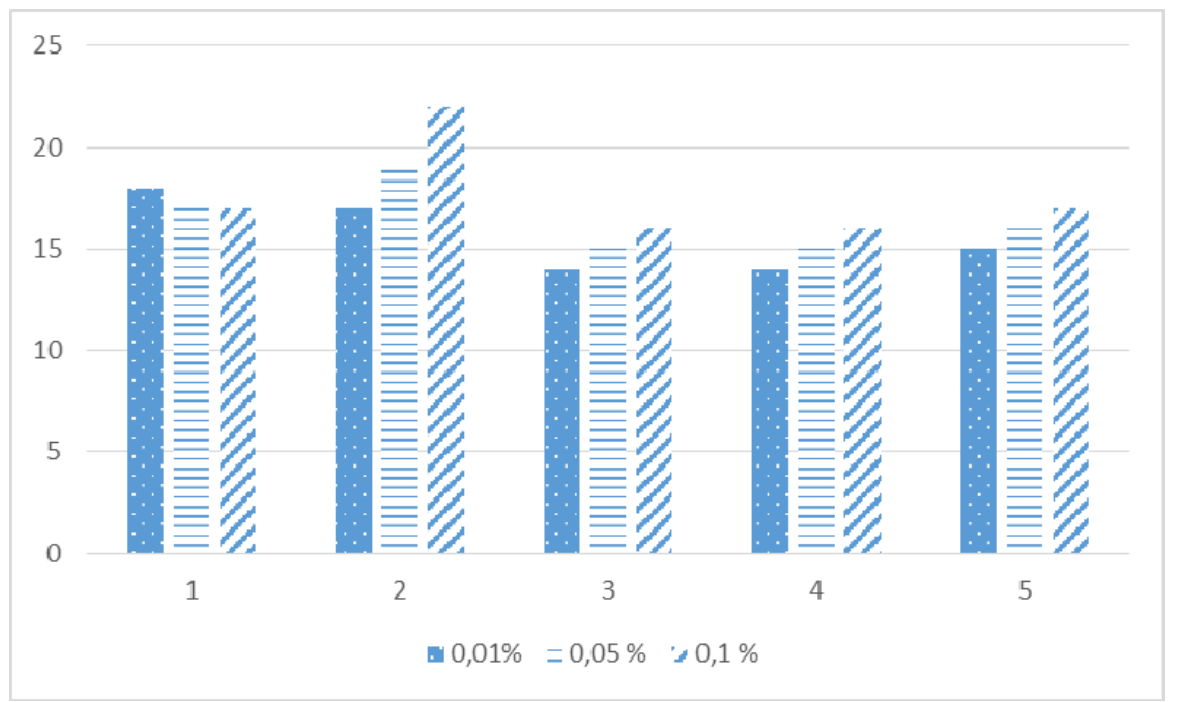

Figure 1. Comparative height (in $\mathrm{mm}$ ) of Rh. luteum seedlings 7 months after the start of the experiment for the compounds 1-5 
Table 1. The height (in $\mathrm{cm}$ ) of Rh. luteum seedlings 7 months after the start of the experiment

\begin{tabular}{|c|c|c|c|c|c|c|c|}
\hline $\begin{array}{l}\text { Con } \\
\text { centr } \\
\text { ation }\end{array}$ & $\begin{array}{l}\text { Control } \\
\text { group, \% }\end{array}$ & $\begin{array}{l}\text { Epin Extra } \\
\text { group, \% }\end{array}$ & $\begin{array}{c}\text { compound } \\
1\end{array}$ & $\begin{array}{c}\text { compound } \\
2\end{array}$ & $\begin{array}{c}\text { compound } \\
3\end{array}$ & $\begin{array}{c}\text { compound } \\
4\end{array}$ & $\begin{array}{c}\text { compound } \\
5\end{array}$ \\
\hline $\begin{array}{l}0.01 \\
\%\end{array}$ & \multirow{3}{*}{$6.7 \pm 0,2$} & \multirow{3}{*}{$6.9 \pm 0,2^{*}$} & $6.9 \pm 0,2^{*}$ & $7.6 \pm 0,1^{* * 2}$ & $6.8 \pm 0,2$ & $6.8 \pm 0.2$ & $7.7 \pm 0.2^{* * 2}$ \\
\hline $\begin{array}{l}0.05 \\
\%\end{array}$ & & & $7.8 \pm 0,2^{\star * 2}$ & $7.9 \pm 0,2^{* * 2}$ & $7.0 \pm 0,2^{*}$ & $7.1 \pm 0.2 * 1$ & $\begin{array}{l}8.9 \pm 0.3^{* * *} \\
3\end{array}$ \\
\hline $\begin{array}{l}0.1 \\
\%\end{array}$ & & & $\begin{array}{l}8.4 \pm 0,2^{* * *} \\
3\end{array}$ & $\begin{array}{l}9.4 \pm 0,2^{* * *} \\
3\end{array}$ & $\begin{array}{l}8.3 \pm 0.2^{* * *} \\
3\end{array}$ & $\begin{array}{l}9.5 \pm 0.2^{\star * \star} \\
3\end{array}$ & ${ }_{* 3}^{10.8 \pm 0.3^{* *}}$ \\
\hline
\end{tabular}

Reference for Table 1-2:

* - differences with the control group are reliable $(p<0.05)$

* - differences with the control group are reliable $(p<0.01)$

* - differences with the control group are reliable $(p<0.001)$

1 - differences with the Epin Extra group are reliable $(p<0.05)$;

2 - differences with the Epin Extra group are reliable $(p<0.01)$;

3 - differences with the Epin Extra group are reliable $(p<0.01)$;

6-hydroxy-2,2,4-trimethyl-1,2,3,4-tetrahydroquinoline (compound 1),

6-hydroxy-2,2,4-trimethyl-1,2-dihydroquinoline (compound 2),

7-[(dimethylamino)methyl]-6-hydroxy-2,2,4-trimethyl-1,2,3,4-tetrahydroquinoline (compound 3),

7-[(dimethylamino)methyl]-6-hydroxy-2,2,4-trimethyl-1,2-dihydroquinoline (compound 4),

1-benzoyl-6-hydroxy-2,2,4-trimethyl-1,2-dihydroquinoline (compound 5).

Table 2. The increase (in \%) in the height of Rh. luteum seedlings 7 months after the start of the experiment

\begin{tabular}{|c|c|c|c|c|c|c|}
\hline $\begin{array}{c}\text { Concen } \\
\text { tration }\end{array}$ & Epin, \% & $\begin{array}{c}\text { compound } \\
1\end{array}$ & $\begin{array}{c}\text { compound } \\
2\end{array}$ & $\begin{array}{c}\text { compound } \\
3\end{array}$ & $\begin{array}{c}\text { compound } \\
4\end{array}$ & $\begin{array}{c}\text { compound } \\
5\end{array}$ \\
\hline $0,01 \%$ & & 3.0 & 13.4 & - & - & 14.9 \\
\hline $0,05 \%$ & - & 16.4 & 17.9 & 4.5 & 6.0 & 32.8 \\
\hline $0,1 \%$ & & 25.3 & 40.3 & 23.9 & 41.8 & 61.2 \\
\hline
\end{tabular}


Table 3. The height of Salvia splendens seedlings after the pre-sowing seed treatment with quinolinic compounds

\begin{tabular}{|c|c|c|c|c|}
\hline $\begin{array}{c}\text { concentration, } \\
\%\end{array}$ & $\begin{array}{c}\text { Average height } \\
\text { of the plants, } \\
\text { cm }\end{array}$ & $\begin{array}{c}\text { Max - } \\
\min , \mathrm{cm}\end{array}$ & $\begin{array}{c}\text { Variation / } \\
\text { Cv, \% }\end{array}$ & $\begin{array}{l}\text { Increase in } \\
\text { the height of } \\
\text { the plants, } \%\end{array}$ \\
\hline Control group & $15.8 \pm 0.6$ & $14-20$ & $4.0 / 12.7$ & - \\
\hline $\begin{array}{c}\text { Epin Extra } \\
\text { group }\end{array}$ & $13.9 \pm 0.7^{*}$ & $12-18$ & $4.3 / 15.1$ & - \\
\hline \multicolumn{5}{|c|}{ 6-hydroxy-2,2,4-trimethyl-1,2,3,4-tetrahydroquinoline (stimulator 1) } \\
\hline $0,01 \%$ & $18.5 \pm 0.3^{* * 2}$ & $17-20$ & $1.2^{\mathrm{a}} / 5.9$ & 17,1 \\
\hline $0,05 \%$ & $19.8 \pm 0.5^{* * * 2}$ & $18-22$ & $2.2 / 7.6$ & 25,3 \\
\hline $0,1 \%$ & $15.3 \pm 0.4$ & $14-17$ & $1.3 / 7.8$ & - \\
\hline \multicolumn{5}{|c|}{ 6-hydroxy-2,2,4-trimethyl-1,2-dihydroquinoline (stimulator 2) } \\
\hline $0,01 \%$ & $15.8 \pm 0.3^{1}$ & $14-17$ & $1.1^{a} / 6.3$ & - \\
\hline $0,05 \%$ & $18.8 \pm 0.2^{* * * 2}$ & $18-20$ & $6.2^{\sigma} / 4.3$ & 19,0 \\
\hline $0,1 \%$ & $14.7 \pm 0.2$ & $14-16$ & $4.6^{6} / 4.8$ & - \\
\hline
\end{tabular}

Reference: Cv - variation coefficient; * - differences with the control group are reliable $(p<0.05) ;{ }^{* *}$ differences with the control group are reliable $(p<0.01) ;{ }^{* * *}$ - differences with the control group are reliable $(p<0.001) ;{ }^{1}$ - differences with the Epin Extra group are reliable $(p<0.05) ;{ }^{2}$ - differences with the Epin Extra group are reliable $(p<0.001) ;{ }^{a}$ - differences with the Epin Extra group are reliable $(p<0.05) ;{ }^{\sigma}$ - differences in variation within the experimental group and control group are reliable $(p<0.01)$.

Table 4. The power of influence (in \%) of the stimulator on the height of Salvia splendens on the 42nd day of the experiment

\begin{tabular}{cccc}
\hline compound & $\begin{array}{c}\text { as compared to } \\
\text { the control } \\
\text { group }\end{array}$ & $\begin{array}{c}\text { as compared } \\
\text { to the Epin } \\
\text { Extra group }\end{array}$ & as is \\
\hline compound 1 & $5.2^{* *}$ & $7.7^{* * *}$ & $7.3^{* * *}$ \\
\hline compound 2 & $4.8^{* * *}$ & $7.0^{* * *}$ & $9.1^{* * *}$
\end{tabular}
$(p<0.001)$.

\footnotetext{
The SOUTHERN BRAZILIAN JOURNAL OF CHEMISTRY (ISSN: 2674-6891; 0104-5431) is an open-access journal since 1993. Journal DOI: 10.48141/SBJCHEM. http://www.sbjchem.com. This text was introduced in this file in 2021 for compliance reasons.

(C) The Author(s)

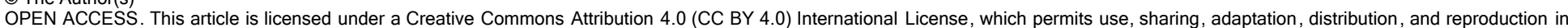

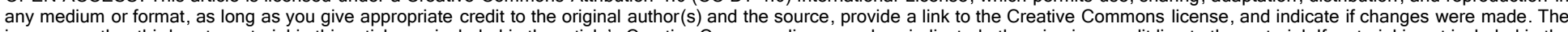

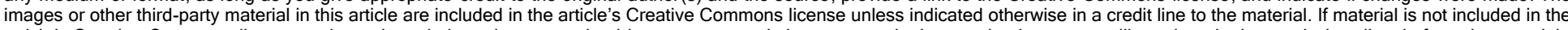

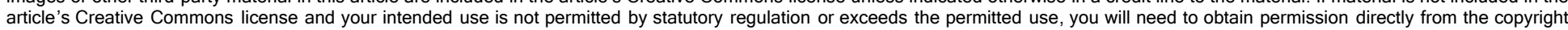
holder. To view a copy of this license, visit http://creativecommons.org/ licenses/by/4.0/.
} 


\title{
SOUTHERN BRAZILIAN JOURNAL OF CHEMISTRY
}

\section{COMPARATIVE STUDY ON ANTIOXIDANT ACTIVITY OF SALVIA NEMOROSA L. FROM TWO DIFFERENT LOCATIONS}

\author{
GHAFIYEHSANJ, Elham; DILMAGHANI, Kamaladdin*2; CHAPARZADE, Nader; \\ SAADATMAND, Sara ${ }^{4}$;
}

1,4 Islamic Azad University, Science and Research Branch, Faculty of Science, Biology Department

2 Islamic Azad University, Marand Branch, Faculty of Science, Biology Department

${ }^{3}$ Azerbaijan Tarbiat-e-Moallem University, Faculty of Science, Department of Biology

* Correspondence author

e-mail: dilmaghanikamal@gmail.com

Received 11 March 2020; received in revised form 30 May 2020; accepted 23 June 2020

\begin{abstract}
In order to investigate the antioxidant activity of Salvia nemorosa L. collected from Ahar and Urmia regions in Iran at different growth stages, aerial parts of sage after collecting were dried, and for measurement, the ability of scavenge DPPH (2,2-diphenyl-1-picryl-hydrazyl-hydrate) radical in different concentrations $(0.025,0.05,0.07$, $0.1,0.2,0.04$ and 0.6 ) of methanolic extracts were prepared. The result showed that the ability to scavenge DPPH radical and amount of inhibition percent of vegetative stage leaves, flowering stage leaves, and flowers increased with increasing concentrations of methanolic extracts from 0.25 to $0.6 \mathrm{mg} / \mathrm{ml}$. In the region of Urmia, the highest amount of DPPH inhibition there was in vegetative stage leaves, and the lowest amount of DPPH inhibition was seen in flowers. In Ahar regions, unlike the Urmia region, the highest amount of DPPH inhibition there was in flowers, but the lowest of DPPH inhibition was seen in flowering stage leaves. Also, the content of inhibition of DPPH in Ahar and Urmia regions similarly increased between two phenological stages (vegetative stage leaves, flowering stage leaves, and flowers) in $0.4 \mathrm{mg} / \mathrm{ml}$ and $0.6 \mathrm{mg} / \mathrm{ml}$ concentrations.
\end{abstract}

Keywords: Lamiaceae, Salvia nemorosa, Antioxidant activity, Methanolic extracts, 2,2-diphenyl-1-picrylhydrazyl $(D P P H)$

\section{INTRODUCTION}

The enlarged lamiaceae contains about 236 genera and 6,900 to 7,200 species, and the most abundant genera are Salvia. The most common purpose of medical and aromatic herbs is Salvia spp (Mirjalili et al., 2006). The genus Salvia is represented in Iran by 58 species, 17 of which are endemic. Salvia nemorosa L., commonly known as wood sage, is growing in central Europe and Western Asia (Skala and Wysokinska, 2004). The members of the genus display a remarkable diversity in growth form, floral morphology, pollination biology, and secondary compounds. They are distributed all around the world (Walker et al., 2004). Many species of Salvia are used in traditional medicine throughout the world. In Iranian folk medicine, several Salvia species have been used as antiseptic for wounds, as a diuretic, stomach tonic, anti flatulent, and reconstitute, and for the treatment of eye disorders, diarrhea, dyspepsia, fever, rheumatism, excessive menstruation, common cold, coughing, pertussis, and sinusitis (Naghibi et al., 2005). There is a growing interest in medicinal plants as therapeutic agents against many illnesses such as Alzheimer's disease, diabetes mellitus, and oxidative damages (Zengin et al., 2014).

Antioxidants such as flavonoids, tannins, coumarins, xanthons, phenolics, lignans, and terpenoids are found in various plant products (such as fruits, leaves, seeds, and oils) (Jeong et al., 2004). DPPH is one of the most popular sensitive and frequently used methods for the determination of the antioxidant activity of plant extracts, which was usually explained with the presence of phenolic acids and flavonoids in them. (Fazal et al., 2011). The effect of antioxidants on DPPH radical scavenging is due to their hydrogen donating ability, which is accepted as an electron or hydrogen radical to become a stable diamagnetic molecule (Hadbaoui et al., 2010). Studies have showed that $S$. nemorosa is a rich source of bioactive metabolites (flavonoids). 
Also, S. nemorosa exhibited considerable antioxidant, antibacterial, and inhibitory enzyme activities. In conclusion, S. nemorosa is a valuable source of natural products and could be used for preparing novel functional foods, cosmetics, and pharmaceutical ingredients. It was reported, phenolic compounds of Salvia nemorosa are gallic acid, protocatechuic acid, catechin, p-hydroxybenzoic acid, caffeic acid, epicatechin, vanillin, p-coumaric acid, ferulic acid, sinapic acid, benzoic acid, o-coumaric acid, rutin, hesperidin, rosmarinic acid, trans-cinnamic acid, quercetin, luteolin, kaempferol, apigenin (Bahadori et al., 2017).

Herein, we aim to evaluate the influence of the region on the antioxidant activity of $S$. nemorosa in the northwest of Iran.

\section{MATERIALS AND METHODS}

\subsection{Plant material}

Sage plants (Salvia nemorosa L.) were collected at two vegetative and flowering stages from two regions in the northwest of Iran including Ahar (75 km from Tabriz to Ahar) (longitude: $38.26^{\circ} \mathrm{E}^{\prime}$, latitude: $47.04 \circ \mathrm{N}$ and altitude: $1391 \mathrm{~m}$ ) and in East Azarbaijan and Urmia, Qasemlu village (longitude: $37.65^{\circ} \mathrm{E}^{\prime}$, latitude: $47.05^{\circ} \mathrm{N}$ and altitude:1328m) in western Azarbaijan. Plant collection times at the vegetative stage were May 12th to May 26th, 2017, and collection times at the flowering stage were May 19th to June 5th, 2017. After collecting the plants, they were dried at room temperature.

\subsection{Extraction}

After collecting plants at two growth stages (vegetative and flowering) from two regions (Ahar and Urmia) and after drying flowers and leaves in shade conditions, each was powdered, and they were soaked using $50 \mathrm{ml}$ absolute methanol and were extracted for three days by a shaker. Extracts, then, were centrifuged for 20 minutes in 1000 rpm (Sarrou et al., 2016).

\subsection{DPPH radical scavenging}

The antioxidant activity of sage plants extracts in this study was evaluated using DPPH (2,2-diphenylpicrylhydrazyl) scavenging assay. The hydrogen atom or electron donation abilities of the corresponding extracts were measured from the bleaching of the purple-colored methanol solution of DPPH. Various concentrations $(0.025$, $0.05,0.07,0.1,0.2,0.4,0.6 \mathrm{mg} / \mathrm{ml}$ ) of the extracts in methanol were added to $2 \mathrm{ml}$ of methanol solution of DPPH. The absorbance was read against a blank at $517 \mathrm{~nm}$. Inhibition of free radical DPPH in percent (I\%) was calculated with the following equation:

$1 \%=\left(A_{\text {blank }}-A_{\text {sample }} / A_{\text {blank }}\right) \times 100$ (Sarrou et al. 2016).

\subsection{Statistical analysis}

Data on DPPH radical activity in this study were performed with SPSS statistical software. Multi-Way-ANOVA analysis of variance was used to compare variables in regions, stages, different concentrations, and their interactions. Duncan's test was used to show the least significant difference in the probability level of $5 \%$ (P-value $\leq 0.05)$.

\section{RESULTS AND DISCUSSION:}

The capability of sage plants in quenching the oxidant radicals have previously been reported (Et-Touys et al., 2016). According to table 1, there was no considerable difference in the content of inhibition of DPPH by regions (Ahar and Urmia) between flowers, vegetative stage leaves, and flowering stage leaves (Table1). In the region of Urmia, the highest amount of DPPH inhibition there was in vegetative stage leaves, and the lowest amount of inhibition was seen in flowers. In Ahar, unlike the Urmia region, the highest amount of DPPH inhibition there was in flowers, but the lowest of DPPH inhibition was seen in flowering stage leaves (Figure 1).

In the Ahar region, the most the content of inhibition was observed in flowers in $0.025,0.05$, 0.07 , and $0.2 \mathrm{mg} / \mathrm{ml}$ concentrations, but there was no considerable difference between vegetative stage leaves and flowering stage leaves. Also, in the Ahar region in $0.1 \mathrm{mg} / \mathrm{ml}$ concentration, the most and the lowest content of inhibition of DPPH were in vegetative stage leaves, and flowering stage leaves. In the Urmia region, the most and the lowest the content of inhibition of DPPH by increasing the concentration of $0.025 \mathrm{mg} / \mathrm{ml}$ to 0.2 $\mathrm{mg} / \mathrm{ml}$ was seen in vegetative stage leaves and flowers, respectively. So that, in this region from the vegetative stage to an insignificant flowering decrease was observed (Figure 1). Similar to our results, in the study of Et-Touys et al. (2016) on antioxidant activity of Salvia officinalis was seen that DPPH inhibition in methanolic, ethanolic and en-hexane extracts were dose-dependent and by increasing the concentration from 0 to $500 \mu \mathrm{g} / \mathrm{ml}$ increased, and the most of inhibition percentage in methanolic extracts was observed. While inhibition percentage by increasing the concentration from 500 to $1000 \mu \mathrm{g} / \mathrm{ml}$ didn't show the significant change (Et-Touys et al. 2016). 
Moreover, in this study was observed that the methanolic extracts of vegetative stage leaves of plants collected from Urmia region had higher antioxidant properties in comparison with methanolic extracts of flowers and flowering stage leaves of sage plants while the methanolic extracts of flowers in Ahar region plants showed the highest antioxidant activities (Figure 1). About the amount of phenolic compound in the growth of different stages of plants, several studies were done that the effect of plant growth stages shows on the amount of this compound. According to the results of previous studies, the total phenolic content of extracts from fenugreek (Omezzine and Haouala 2013) and Asparagus racemosus decreased from vegetative to fructification stages (Verma and Kasera 2007).

In the study of the effect of DPPH $(2,2-$ diphenyl-1-picrylhydrazyl) radical trapping in different concentrations of methanolic extracts of $S$. nemorosa was observed that from each of the collected region, methanolic extracts prepared from plants samples in scavenger of DPPH radical dosedependent acted very effective and useful and the best antioxidant activity was in the high concentration of extracts. So that, by increasing concentration from 0.025 to $0.6 \mathrm{mg} / \mathrm{ml}$, the content of inhibition percentage showed an increase in each growth stage (flowers, vegetative stage leaves, flowering stage leaves). The content of the inhibition percentage showed the same increase in the highest concentrations $(0.4$ and $0.6 \mathrm{mg} / \mathrm{ml})$ in different phonologic stages (Figure 1).

Also, it has been shown that total polyphenolic content increased at the flowering stage in Boerhavia diffusa, Sida cordifolia (Verma and Kasera 2007) and Crithmum maritimum (Males et al., 2003), during floral budding in Hypericum hyssopifolium, $H$. scabrum and at full flowering in $H$. pruinatum (Ayan et al., 2007). In addition, in spinach leaves, higher levels of total phenolics and antioxidant capacity were reported at the mid-maturity stage in comparison with the immature stage (Pandjaitan et al., 2005). Furthermore, leaf methanolic extracts of Aegle marmelos (Siddique et al., 2010), Myrtus communis var. italica (Wannes et al., 2010), Artemisia absinthium (Riahi et al., 2013) and Malva sylvestris (Barros et al., 2011) showed the highest antioxidant capacity compared to other plant parts (Alimpić et al., 2014). It seems that a decrease in phenolic content with age is probably due to their dilution with growth or that may be because of great cellular division at the early growth stages and formation transport phenomenon toward the young organs (Wang and Lin 2000; Del Bano et al., 2003). Also, it was reported that the existence of by-products, especially during the flowering stage, maybe considered a significant source of natural antioxidants in sage plants. Antioxidant activity is related to phenolic compounds that play a crucial role in neutralizing free radicals as a result of the fact that phenolics have a hydroxyl group (ViudaMartos et al., 2010).

According to previous studies, the major phenolic compounds identified in the extracts of sage plants are rosmarinicacid, carnosic acid, salvianolic acid, and its derivatives carnosol, rosmanol, epirosmanol and rosmadial (Lu and Foo 2001). Among these, rosmanol is a major constituent of many salvia species and possesses strong antioxidant capacity because these groups cause phenols to more easily donate hydrogen atoms to activate free radicals to interrupt the chain reaction of antioxidants (Weng and Wang 2000). Furthermore, natural antioxidant compounds have various mechanisms such as prevention of chain initiation and breaking by donating hydrogen atoms or electrons, decomposition of peroxides, and prevention of continued hydrogen abstraction (Fazal et al. 2011). In addition, the reductive potential measures the ability of a sample to act as an electron donor and, therefore, reacts with free radicals converting them to more stable products and thereby terminates radical chain reactions (Sarikurkcu et al., 2010).

Observed differences in antioxidant activities of sage plants in Ahar and Urmia regions in this study can be caused by the effect of the difference in environmental factors such as longitude, latitude, altitude, harvest season, plants age, growth stages, soil and climate conditions in these regions. For example, it has been reported that the concentration of phenolic compounds can be affected by age and seasonal variation (Uddin et al., 2012). Also, variation in the amounts of phenolic compounds can be attributed to several reasons. Many of intrinsic factors such as plant species (genetic), parts of the plants and extrinsic factors such as environmental conditions (e.g., climate, soil, irrigation, temperature range, exposure to diseases and pests), cultural practices, harvest season, drying methods, handling and storage factors can influence the phenolic content of plants during the plant growth cycles (Tavassoli and Djomeh 2011). 


\section{CONCLUSIONS:}

On the basis of all the analyses, it could be concluded that the methanolic extracts of vegetative stage leaves in the Urmia region showed the highest amount of antioxidant activity, but in the Ahar region, the highest amount antioxidant activity in the methanolic extracts of flowers was observed. So, different stages of growth of Salvia nemorosa plants, harvest times, different in climatic condition, major habitat and direct relation between ecological and genetic factors have led to differences in the antioxidant activity of sage plants in Ahar and Urmia regions which, can be investigated as a source of plant antioxidants, with potential use in food, cosmetics, and pharmaceutical fields.

\section{REFERENCES:}

1. Alimpić, A., Oaldje, M., Matevski, V., Marin, P., Duletić-Laušević, S. Arch Biol Sci. 2014, 66, 307-316.

2. Alkhatib, A., Tsang, C., Tiss, A., Bahorun, T., Arefanian, H., Barake, R., Khadir, A., Tuomilehto, J. Nutrients. 2017, 9.

3. Ayan, A. K., Yanar, P., Cirak, C., Bilgener, M. Bangl J Bot. 2007, 36, 39-46.

4. Bahadori, M. B., Asghari, B., Dinparast, L., Zengin, G., Sarikurkcu, C., AbbasMohammadi, M., Bahadori, S. LWT. 2017, 75, 42-50.

5. Barros, L., Carvalho, A. M., Ferreira, I. C. Phytochem Anal. 2011, 22, 181-188.

6. Del Bano, M. J., Lorente, J., Castillo, J., Benavente-García, O., Del Rio, J. A., Ortuño, A., Quirin, K.-W., Gerard, D. J Agric Food Chem. 2003, 51, 4247-4253.

7. Et-Touys, A., Fellah, H., Mniouil, M., Bouyahya, A., Dakka, N., Sadak, A., Bakri, Y. Microbiol Res J Int. 2016, 1-10.

8. Fazal, H., Ahmad, N., Khan, M. A. Pak J Bot. 2011, 43, 63-67.

9. Hadbaoui, Z., Djeridane, A., Yousfi, M., Saidi, M., Nadjemi, B. Medit J Nutri Metabol. 2010, 3, 215-220.

10. Lu, Y., Foo, L. Y. Tetrahedron Lett. 2001, 42, 8223-8225.

11. Males, Z., Zuntar, I., Nigović, B., Plazibat, M.,
Vundać, V. B. Acta Pharm. 2003, 53, 139-144.

12. Mirjalili, M. H., Salehi, P., Sonboli, A., Vala, M. M. Chem Nat Comp. 2006, 42, 19-23.

13. Naghibi, F., Mosadegh, M., Mohammadi, M. S., Ghorbani, A., 2005.

14. Omezzine, F., Haouala, R. Scien Horti. 2013, 160, 335-344.

15. Pandjaitan, N., Howard, L., Morelock, T., Gil, M. J Agric Food Chem. 2005, 53, 8618-8623.

16. Riahi, L., Chograni, H., Elferchichi, M., Zaouali, Y., Zoghlami, N., Mliki, A. Indus Crop Prod. 2013, 46, 290-296.

17. Sarikurkcu, C., Ozer, M. S., Eskici, M., Tepe, B., Can, Ş., Mete, E. Food Chem Toxicol. 2010, 48, 1801-1805.

18. Sarrou, E., Martens, S., Chatzopoulou, P. Indus Crop Prod. 2016, 94, 240-250.

19. Siddique, N. A., Mujeeb, M., Najmi, A. K., Akram, M. Afr J Plant Sci. 2010, 4, 1-5.

20. Tavassoli, S., Djomeh, Z. E. Global Veterinaria. 2011, 7, 337-341.

21. Uddin, M., Juraimi, A. S., Ali, M., Ismail, M. R. International journal of molecular sciences. 2012, 13, 10257-10267.

22. Verma, V., Kasera, P. K. Ind J Plant Physiol. 2007, 12, 203.

23. Viuda-Martos, M., El Gendy, A. E.-N. G., Sendra, E., Fernandez-Lopez, J., Abd El Razik, K., Omer, E. A., Perez-Alvarez, J. A. J Agric Food Chem. 2010, 58, 9063-9070.

24. Walker, J. B., Sytsma, K. J., Treutlein, J., Wink, M. Am J Bot. 2004, 91, 1115-1125.

25. Wang, S. Y., Lin, H.-S. J Agric Food Chem. 2000, 48, 140-146.

26. Wannes, W. A., Mhamdi, B., Sriti, J., Jemia, M. B., Ouchikh, O., Hamdaoui, G., Kchouk, M. E., Marzouk, B. Food Chem Toxicol. 2010, 48, 1362-1370.

27. Weng, X., Wang, W. Food Chem. 2000, 71, 489-493.

28. Zengin, G., Sarikurkcu, C., Aktumsek, A., Ceylan, R. J Func Food. 2014, 11, 538-547. 
Table 1. Variance Analysis to compare DPPH inhibition in different concentrations in Ahar and Urmia regions

\begin{tabular}{c|l|c}
\hline Regions & \multicolumn{1}{|c|}{ Stages } & Mean squer \\
\hline \multirow{4}{*}{ Ahar } & Vegetative leaves & $57.732^{\mathrm{ns}}$ \\
\cline { 2 - 3 } & Flowering leaves & $53.847^{\mathrm{ns}}$ \\
\cline { 2 - 3 } & Flowers & $65.444^{\mathrm{ns}}$ \\
\hline \multirow{3}{*}{ Urmia } & & $71.448^{\mathrm{ns}}$ \\
\cline { 2 - 3 } & Vegetative leaves & $68.702^{\mathrm{ns}}$ \\
\cline { 2 - 3 } & Flowering leaves & $50.854^{\mathrm{ns}}$ \\
\cline { 2 - 3 } & Flowers & \\
\hline
\end{tabular}

Note: 'ns' indicate non-significant diffrence at $\% 5$.

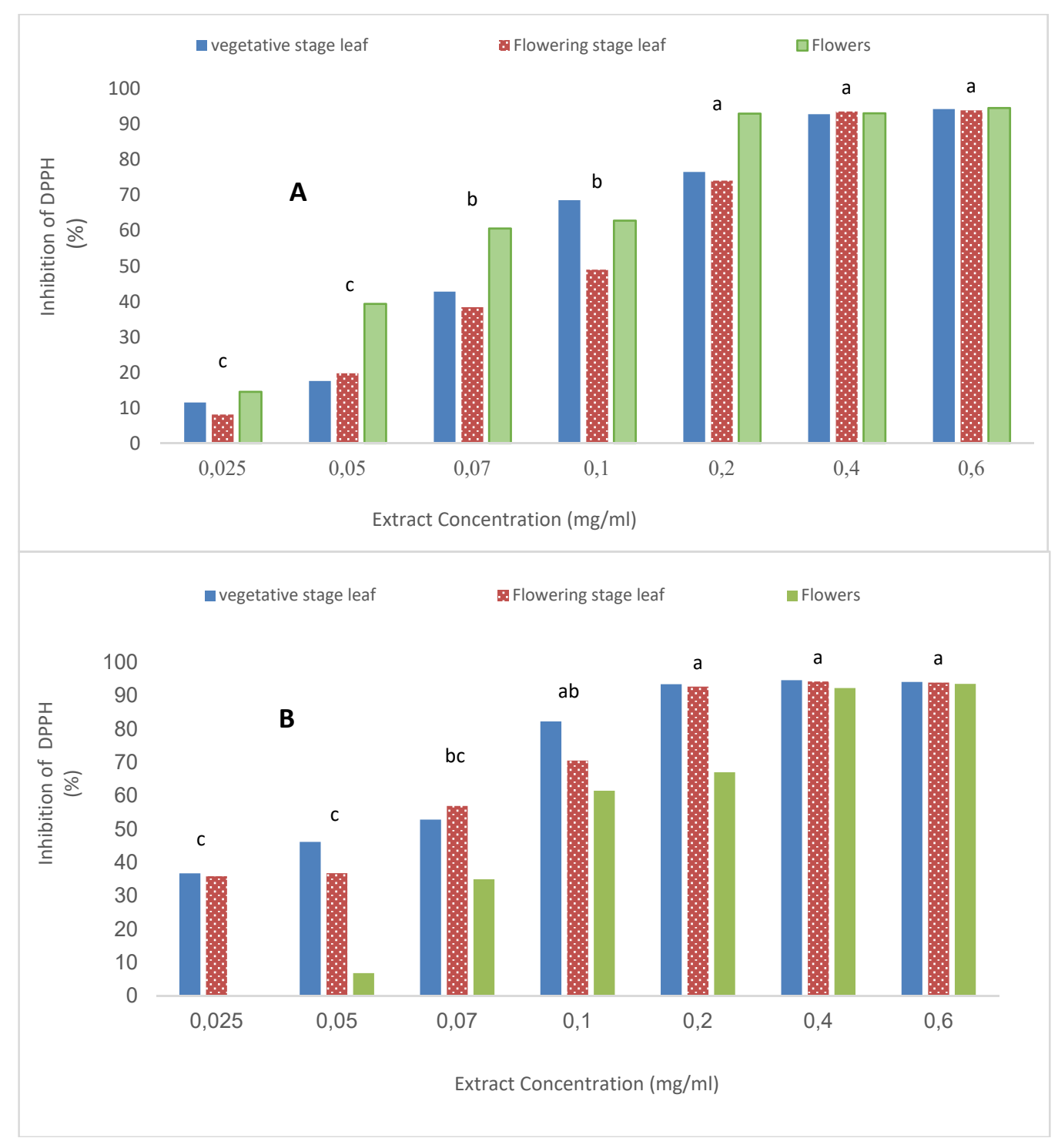

Figure 1. The percentage of DPPH inhibition in different concentrations of Ahar (A) and Urmia $(B)$ regions separately in different stages of growth

The SOUTHERN BRAZILIAN JOURNAL OF CHEMISTRY (ISSN: 2674-6891; 0104-5431) is an open-access journal since 1993. Journal DOI: 10.48141/SBJCHEM. http://www.sbjchem.com. This text was introduced in this file in 2021 for compliance reasons.

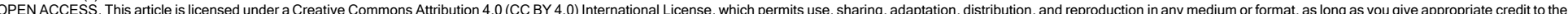

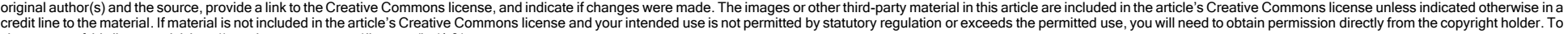
view a copy of this license, visithttp://creativecommons.org/licenses/by/4.0\%. 


\title{
SOUTHERN BRAZILIAN JOURNAL OF CHEMISTRY
}

\section{ANTIBIOTIC SUSCEPTIBILITY OF ESCHERICHIA COLI ISOLATE FROM URINARY TRACT INFECTION OF THALASSEMIC PATIENTS IN THI-QAR PROVINCE}

\author{
OKAB, Alaa Abood Yasir ${ }^{1 *}$; SALIH, Manal B. ${ }^{2}$ \\ ${ }^{1}$ Ministry of Health-Thi-Qar health office. \\ ${ }^{2}$ Department of biology-College of science-Thi-Qar University. \\ * Corresponding author \\ e-mail: alaaabood425@gmail.com
}

Received 30 April 2020; received in revised form 14 May 2020; accepted 05 June 2020

\begin{abstract}
Escherichia coli (E. coli) is the most common type of pathogen that causes Urinary tract infection disease. It can be presented as pathogenic or non-pathogenic strain and found not only in the animal but also in the human intestine. This bacterium can cause opportunistic infection when the human host comprised of thalassemia patients or changes the healthy hemostatic flora. This study aimed to analyze the presence of bacteria in thalassemia patients with urinary tract infection. A total of 303 samples were collected during the period from August 2019 to January 2020 from thalassemia patients who suffered from urinary tract infection. The results showed that there were $6.9 \%$ of patients infected with E. coli, $2.6 \%$ of patients were infected with $S$. aureus, $0.7 \%$ with both Proteus and Klebsiella, while $89.1 \%$ of patients had a negative sample for bacteria. Also, the incidence of urinary tract infections in females is higher than in males. Besides, its occurrence in rural areas is higher than in city residents. Moreover, among 16 antibiotics tested to sensitize bacteria to antibiotics, Imipenem showed $100 \%$ efficacy on all isolated bacteria. In contrast, Netilmicin showed $80.1 \%$ efficacy, Gentamycin $80.1 \%$, and Amikacin 76.2\%. Ampicillin, Aztreonam, Amoxicillin-Clavulanic Acid, Tetracycline, and Ticarcillin-Clavulanic Acid, did not show any effectiveness toward the bacteria while other antibiotics showed different activities. Furthermore, the isolated microbes from thalassemia patients were the highest resistance to antibiotics in comparison with other studies, and this antibiotic-resistant may be due to the weakening of the patient's immune status and frequent blood taking and the antibodies it contains.
\end{abstract}

Keywords: thalassemia, urinary tract infection, bactéria, Escherichia coli, antibiotics.

\section{INTRODUCTION:}

The term thalassemia (derived from the Greek -thalassall, which means - the seallreferring to the Mediterranean-and -emiall, meaning -related to bloodll) indicates a heterogeneous group of genetic disorders of hemoglobin synthesis characterized by a disturbance of the production of globin chains, leading to anemia, ineffective erythropoiesis, and destruction of erythroblasts in the bone marrow and of erythrocytes in the peripheral blood (Faust et al., 2011) In individuals that produce normal hemoglobin, two types of polypeptide chains (a and non- $\alpha$ ) pair with each other at a ratio close to $1 / 1$ to form normal hemoglobin molecules. In thalassaemic patients, an excess of the customarily produced type accumulates in the cell as an unstable product, leading to the destruction of the cell (Javad et al., 2011). This imbalance is the hallmark of all forms of thalassemia. Types of thalassemia are usually named after the underproduced chain or chains, in patients with $\beta$ thalassemia major, the most important cause of mortality and morbidity is organ failure due to deposits of iron (Ricerca et al., 2009) Urinary tract infection (UTIs) is one of the most common diseases caused by different types of pathogens. In thalassemia patients, infection of urinary tract infection occurs as a result of organ failure, including the urinary system, as a result of the accumulation of iron resulting from the breakdown of red blood cells (Vento et al., 2006). Women are often more likely to be infected than men for physiological and anatomical reasons for the urinary system (Aldudak et al., 2000). The infection at urinary tract infection called by a local infection in top of the urinary system is called pyelonephritis, and the lower part of the body called cystitis, in the two cases can be detected through clinical manifestations and laboratory diagnosis (NoorBahr et al., 2016).

\section{$E$.coli is the most common type of}


pathogen that causes UTI disease. These bacteria are usually considered non-pathogenic when they are present in the intestines, and they reach the urinary system and become pathogenic (Marrs et al., 2015). E. coli has many virulence factors that are gained by the ability to invade the host, which is related to adhesion, toxin, and some works to protect the bacteria from attacking the immune system (Nielsen et al., 2014). Several studies demonstrated E. coli's capability to cause opportunistic infections when the changing habitat or immune system compromised in the host and also by change hemostat through using antibiotics. Commensal $E$. coli strains efficiently exchange genetic material with pathogenic $E$. coli strain or other pathogens such as Salmonella, Shigella, Yersinia, and Vibrio (Hussein et al., 2018)(Shahdoust et al., 2016).

This study aimed to analyze the presence of bacteria in thalassemia patients with urinary tract infection.

\section{MATERIALS AND METHODS:}

\subsection{Sample Collection}

After taking approval from Thi-Qar University ethical committee, The research was performed in Nasiriya Center for Hereditary blood disorder, where three hundred and seven patients with thalassemia agreed to perform and publish this research. Their ages ranged from 4 to 30 years. Their choice is based on having a urinary tract infection, as evidenced by symptoms, doctor diagnosis, and urine microscopy examination. Urine samples were collected and tested for antimicrobial susceptibility of E. Coli. Samples of urine were taken from patients whose normal texture consistency was without any signs of disease. E. coli commensal, isolated from a healthy person, does not take any antibiotic for an extended period of about three months. Approximately $5 \mathrm{ml}$ of urine from the middle of the urethra was collected from each patient and healthy individuals in sterile containers and transported directly to the laboratory.

\subsection{Microscopic Examination}

All specimens were pre-examined by microscopy to identify the presence of pus cell, epithelial cell, red blood cell, throat mucus, bacterial cells, and other substances (Lloyd et al., 2009).

\subsection{Culture of samples}

SOUTHERN BRAZILIAN JOURNAL OF CHEMISTRY.

ISSN 0104-5431. vol.28, $n^{\circ} 28$. 2020. Downloaded from www.sbjchem.com

Established in 1993.
Selected samples were labeled and cultivated on blood agar and MacConkey agar for urine sample grown on MacConkey agar only incubated overnight at $37^{\circ} \mathrm{C}$ in an incubator under aerobic conditions. Any E. coli suspected from urine sample was submitted to subculture on blood agar and MacConkey agar. All specimens lactose fermenter colonies on MacConkey, because they are fermented lactose sugar, which leads to the formation of lactic acid, and with the presence of a neutral red pigment as an indicator appears the pink color. Depending on morphological features of the colonies and microscopically examination with Gram's stain, the pure cultures were prepared for biochemical tests to distinguish E. coli from other Enterobacteriaceae (Yamamoto, 2007).

\section{RESULTS AND DISCUSSION:}

\subsection{Distribution of E. coli among Urinary Tract Infection}

A total of 303 urine samples were collected during the period from September 2019 to March 2020 from thalassemia patients who suffered from urinary tract infection. The results showed that there were $6.9 \%$ of patients infected with $E$. coli, $2.6 \%$ of patients were infected with $S$. aureus, $0.7 \%$ with both Proteus and Klebsiella, while $89.1 \%$ of patients had a negative sample for bacteria (Figure 1).

\subsection{The Percentage of Infection with E. coli Compared to other Isolated Bacteria}

A total of 33 infectious bacteria were isolated from thalassemia patients by urine. There were $64 \%$ of patients infected with E. coli, $36 \%$ with other infectious bacteria as $S$. aureus, and $0.7 \%$ of patients infected with both Proteus and Klebsiella (Figure 2).

\subsection{Distribution of the Thalassemia patients Infected with E. coli According to Age Group}

The results showed that the higher infection was in second age groups (38.1\%), followed by the third age group (33.3\%). The lowest infection was in the first age (28.6\%) (Figure 3 and Table 1)

\subsection{Distribution of the Thalassemia patients Infected with E. Coli According to Gender}

The results showed that the higher infection was in females was $61.9 \%$, while the lowest infection was in the males (38.1\%) (Figure 4 and Table 2). 
3.5. Distribution of the Thalassemia patients Infected with E. coli According to Habitation

The results showed that the higher infection was in rural was $61.9 \%$, while the lowest infection was in the urban (38.1\%) (Figure 5 and Table 3).

\subsection{Identification of $E$. coli Bacterium}

\subsubsection{Morphological Properties}

E. coli colonies appear smooth colonies with distinct edges and pink colonies on the MacConkey agar during incubation at $37^{\circ} \mathrm{C}$ overnight. E. coli usually lactose ferments. E. coli colonies on the blood agar Milky to white color with or without zone of hemolysis, or most UPEC appearance $\beta$ - hemolytic. While the commensal non-hemolytic (Figure 6).

\subsubsection{E. coli Bacterium on CLED agar}

CLED agar (cysteine-lactose-electrolytedeficient agar or medium) is a valuable noninhibitory growth medium used to isolate and differentiate urinary infectious microbes. It contains cysteine and lactose, and it is electrolyte deficient; the latter trait prevents the swarming of Proteus species. Cysteine promotes the formation of cysteine-dependent dwarf colonies (Figure 7). Bromothymol blue is the indicator used in the agar, and it changes to yellow in case of acid production during fermentation of lactose or changes to deep blue in case of alkalization. Lactose-positive bacteria build yellow colonies. Bacteria which decarboxylate L-Cysteine cause an alkaline reaction and build deep blue colonies. E. coli appear on medium opaque yellow colonies with a slightly deeper yellow center.

\subsection{Antibiotic Susceptibility}

The antimicrobial susceptibility test for 31 isolates of $E$. coli was performed on Muller Hinton agar by the modified Kirby Bauer disc diffusion method. All E. coli isolates that included 31 UPEC, 46 , and 20 controls healthy, were screened against 16 antimicrobial agents (Figure 8).

\subsubsection{Antibiotics Susceptibility Pattern}

The results of the current study showed that there were among 16 antibiotics used only Imipenem had activity against all isolated $E$. coli. While the Ampicillin, AT, Streptomycin, Ciprofloxacin, Ticarcillin-clavulanic acid, Amoxicillin- clavulanic acid, and TI had no activity against isolated $E$. coli. Other antibiotics like Amikacin, Piperacillin, Tetracycline, and Netilmicin recorded only one intermediate activity in addition to the other activities (Table 4).

\subsection{Discussion}

\subsubsection{Distribution of Thalassemia} according to Age, Gender and Habitation

Patients

The current study showed a significant increase in thalassemia among the second age group. The high rate of prevalence of thalassemia occurred in the second age group because the syndrome begins in the people who carry it, according to the inherited, it may be within two years or more and the patients who are up to 20 years or more is exposed to many complications, the most important of which is the increase iron overload and this effects on the heart muscle and kidneys and endocrine, in addition to the viral infections, which lead to many deaths status. The results agree with the study of (Al-attar et al., 2014), in Irbil, their results designate that major thalassemia phenotype can be diagnosed perfectly within the early months or early days of age because the exhibitions of the disease may perform after a complete switch from fetal to adult $\mathrm{Hb}$ synthesis occurs. Typically, this switch is completed by the sixth month after birth. Frequently, milder forms are discovered by chance and at different ages, and many patients whose conditions to be homozygous may show no significant symptoms or anemia for several years (Pourgheysari et al., 2016).

According to gender, the results showed that there was a non-significant difference between gender because thalassemia is a genetic disease that is transmitted from parents to offspring and for both sexes equally. The results agree with the study of (Ayyash et al., 2018) that evaluated biochemical and hematological parameters in $\beta$-thalassemia in Gaza and recorded non-significant differences between thalassemia syndrome according to gender.

According to habitation, the result showed that there was a significant increase in thalassemia syndrome in rural habitats. This is due to some common tribal traditions among the rural population and their mating and lack of openness to other families, especially those who marry cousins. The current results agree with the study of (Kremastinos et al., 2010), in North America, they showed that the distribution of thalassemia increases significantly in rural habitat than urban habitat. Although the study disagrees with the (Alattar et al., 2014) study, Irbil showed that there 
was no relationship between the distribution of the syndrome and the habitat, the compatibility between the two studies may be due to random sampling of models or all ages without discrimination. The disagreement between the two studies may be due to the number of reasons, such as a large number of rural-urban migrations, especially after the 1990s, the scarcity of rural resources and employment in the city, or the study was limited to the study of family genetic diseases.

\subsubsection{Isolation and Identification E. coli Bacterium}

E. coli bacterium is composed of pathogenic and non-pathogenic strains, Nonpathogenic strains that may evolve into pathogenic variables, and vice versa. Most extraintestinal infections associated with $E$. coli are caused by commensal strains that become pathogenic by adaptation stratagems or the acquisition of virulence determinants (Sáez-López et al., 2016).

The commensal E. coli and Uropathogenic $E$. coli can colonize the gastrointestinal tract and be well adapted to conditions in the large intestine (Bailey et al., 2010). Some physiological studies about $E$. coli had demonstrated the ability of these organisms to adapt themselves to their different habitats (Polage et al., 2012).

The isolates of $E$. coli from thalassemia patient who suffer from urinary tract infection assigned for the current study and based on patients with UTI were $216.9 \%$, out of a total of 303 patients with UTI, and $82.6 \% \mathrm{~S}$. aureus, 2 $0.7 \%$ for both Klebsiella and Proteus. They were diagnosed by a physic and microscopic examination of urine. By culture, both isolated commensal and uropathogenic $E$. coli have the same morphological form on MacConkey agar. Still, most uropathogenic $E$. coli $\beta$ - hemolytic and commensal $E$. coli were non-hemolytic on blood agar.

In the current study, the UPEC isolates were diagnosed as $28.6 \%$ isolates in group I from 6 samples, $38.1 \%$ isolates in group II from 8 samples, and $33.3 \%$ isolates group III from 7 samples. This result corresponds with many studies that focused on the predominant of UPEC among categories patients. The current study agreed with the study of (Abd ALameer et al., 2015), where they study 318 different samples from a burn, vaginal swab, urine, and environment and recorded $25: 28 \%$ of $E$. coli from a urine sample. Also, a local study performed by (Al Badry, A. et al., 2016), in Thi-Qar province, they studied the identification of pathogenic bacteria from thalassemia patient and recorded among 40 patients the $E$. coli recorded $6.6 \%$ among other bacteria. The study also agreed with the study of (Shah et al., 2019), in Waist province they study virulence factors of uropathogenic Escherichia coli (UPEC) and correlation with antimicrobial resistance and recorded 22: 20\% from 105 urine sample infected with $E$. coli bacterium. The study also agreed with the study of (Hosseini et al., 2009), in Tehran, they studied the distribution of $E$. coli among patients with urinary tract infection and showed 243: $16.2 \%$ from total sample infected with pathogenic E. coli. While the current study disagreed with the study of (Melo et al., 2015), in Brazil, they study the diversity of Escherichia coli isolated from humans and foods and recorded among 84 urine samples $48: 57.1 \%$ infected with E. coli. The reason behind the current and previous studies may be due to the different location of the study, as well as the immune status of the patient, in addition to the development of this bacterium as well as novel strains of $E$. Coli, a potential human pathogen, has been attributed to advances in diagnostic capabilities and not to the emergence of a new pathogenic strain (Sullivan et al., 2011).

E. coli which generally produces from fecal or the per urethral flora and the vaginal serve as a reservoir for it, are responsible most UTIs tapping expands in (2000) (Kawamori et al., 2008), the commensal $E$. coli contain specific surface structures that can able induce signal cascades if the organism encountering the appropriate receptor and the ability to acquire and propagate plasmid types can vary between E. coli commensal and pathogenic subgroups $E$. coli (Cohen, 2017). However, commensal E. coli that evolved into a pathogen depends not only on the gaining of virulence factor genetic information enabling successful colonization of the host but as well on the presence of functional genes directly contributing to pathogenesis. That is what they explained (Marrs et al., 2015); these strains cause disease if the host is compromised immunologically.

The isolation of $E$. coli from thalassemia patients considering them immunocompromised patients in the present study was consistent with most local and international studies, as for the differences in the results, it may be due to: the study was more specialization for a particular category, living conditions and nature of the population, the progress of society or hygiene, ratio of males to females allocated in the study, isolated from the patient without symptomatic urinary tract infection, social status and methods 
of insulation and techniques used.

\subsubsection{Antibiotic Susceptibility Pattern}

Antibiotic susceptibility patterns will help choose the right antibiotic and reduce antibiotics problem, from misuse, antibiotics. This information will be useful to reduce the problem of antibiotic resistance, and it is a global problem, resistance may be natural resistance or acquired resistance. Natural resistance is especially specific to bacteria with certain antibiotic resistance, such as having a cellular wall that prevents the passage of the antibiotic, the acquired resistance is caused by genes inherited by plasmids, transposons, and integrin's or conjunction. Also, increased resistance is usually due to the widespread and incorrect use of antibiotics. When talking in general about $E$. coli through sensitivity and resistance to the direction of antibiotics.

The results of the current study showed that there were among 16 antibiotics used only Imipenem had activity against all isolated $E$. coli with $100 \%$ sensitivity. While the Ampicillin, Aztreronam, Streptomycin, Ciprofloxacin, Ticarcillin-clavulanic acid, Amoxicillin- clavulanic acid, and Tetracycline had no activity against all isolated $E$. coli with $100 \%$ sensitivity. Other antibiotics as Amikacin, Piperacillin, Tetracycline, and Netilmicin recorded only one intermediate activity in addition to the other activities. The E. coli showed in the present study resistance for most $\beta$ lactamase antibiotics, while the anti- $\beta$-lactamase antibiotics act by binding to certain proteins in the cytoplasmic membrane called Binding Proteins Penicillin. These proteins are responsible for some interactions in the peptidoglycan synthesis process. Therefore, the association of anti- $\beta$ lactam with these enzymes leads to the disruption of its work and thus stops the process of manufacturing the cell wall to produce a cell wall deficient incoherent, which makes the bacteria sensitive to the pressure of osmosis and then the death of bacteria. The previous study done by (Abd ALameer et al., 2015), in Thi-Qar province showed among 46 isolate

E. coli from a patient with urinary tract infection $100 \%$ resistant for Penicillin, 96\% resistant for Amoxicillin Clavulanic acid, 74\% resistant for Ceftriaxone, $87 \%$ resistant for Tetracycline and $96 \%$ resistant for both Ticarcillin Clavulanic acid and Trimethoprim. While all isolate sensitive for Amikacin and $96 \%$ sensitive for Netilmicin. Also, a study performed by (Igbeneghu et al., 2014), in Nigeria, they showed that the strains were highly resistant to Cefalothin $100 \%$, Streptomycin $94.0 \%$, Tetracycline $92.0 \%$, and
Trimethoprim $89.3 \%$ while resistance to the Quinolones was low 3.3 - $14.0 \%$. A study of (Patricia et al., 2011), in Brazil, they studied antimicrobial susceptibility for $E$. coli isolate from diarrheagenic patients and showed the most effective drug were Ceftazidime, Ceftriaxone, Imipenem and Piperacillin-tazobactam, for which no resistance observed. Most recent studies suggested the increase and spread of antibiotics resistance related to horizontal transfer of resistance genes such as integrons among bacterial populations or through conjunction. Transport resistance genes from commensal $E$. coli to pathogenic bacteria represent a potential risk to public health as well as the common and wrong use of antibiotics in addition to taking large doses of antibiotics at an early age, which leads to curbing and weakening the immune system.

\section{CONCLUSIONS:}

E. coli has the highest incidence among other bacterial in thalassemia patients infected with urinary tract infection, the incidence of urinary tract infection in females is higher than in males, as well as in rural population is higher than in the urban population. The antibiotics have proven to be very effective in treating bacteria are Imipenem, Gentamycin, Amikacin, while the Ampicillin, Aztreonam, Tetracycline, Amoxicillin-Clavulanic acid and Piperacillin are not effective against isolated bacteria, the culture medium CLED and IPE 20E have proved effective in diagnosing isolated bacteria.

\section{REFERENCES:}

1. D. M. Faust and J. M. Markiewicz. (2011). "Human liver sinusoidal endothelial cells respond to interaction with Entamoeba histolytica by changes in morphology, integrin signalling and cell death," Cell. Microbiol., vol. 13, no. 7, pp. 1091-1106, DOI: 10.1111/j.1462-5822.2011.01604.x.

2. G. Javad, A. Saeid, and N. (2011). Mohammadmehdi, "Thalassemia and immune system dysfunction-review article," Int J Curr Res, vol. 3, no. June, pp. 105-8.

3. B. M. Ricerca and A. Girolamo. (2009). "Infections in Thalassemia and Hemoglobinopathies," Mediterr. J. Hematol. Infect. Dis., vol. 5, no. 11r, pp. 16, DOI: 10.4084/mjhid.2009.028.

4. S. Vento and F. Cainelli. (2006). "Infections 
and thalassaemia," Lancet Infect. Dis., vol. 6 , no. 4, pp. 226-233, doi: 10.1016/S14733099(06)70437-6.

5. B. Aldudak et al. (2000). "Renal function in pediatric patients with $\beta$-thalassemia major," Pediatr. Nephrol., vol. 15, no. 1-2, pp. 109-112, doi: $10.1007 / \mathrm{s} 004670000434$.

6. A. A. NoorBahr and M. T. S. Al-ouqaili. (2016). "Microbial and Molecular Detection of Shigella dysenteriac and Entamoeba History Causing Diarrhea in Children Under Five Years Age in Ramadi ProvinceIraq Submitted by Noor Al-Huda Abd-Allah Bahr Supervised by Mushtak T. S. AlOuqaili," 2016.

7. C. F. Marrs and L. Zhang, "Escherichia coli mediated urinary tract infections: Are there distinct uropathogenic E. coli (UPEC) pathotypes?," FEMS Microbiol. Lett., vol. 252, no. 2, pp. 183-190, 2015, doi: 10.1016/j.femsle.2005.08.028.

8. K. L. Nielsen, P. Dynesen, P. Larsen, and N. Frimodt-Møller, "Faecal Escherichia coli from patients with $E$. coli urinary tract infection and healthy controls who have never had a urinary tract infection," J. Med. Microbiol., vol. 63, no. 4, pp. 582-589, 2014, DOI: 10.1099/jmm.0.068783-0.

9. R. A. Hussein and B. M. Salih, "Molecular Typing of Uropathogenic and Normal Flora Escherichia coli Isolated from Immunosuppression Patients.," Thi-Qar, 2018.

10. S. Shahdoust, M. Niyyati, A. Haghighi, E. Azargashb, and M. R. Khataminejad, "Prevalence of intestinal parasites in referred individuals to the medical centers of Tonekabon city, Mazandaran province," Gastroenterol. Hepatol. from Bed to Bench, vol. 9, pp. S75-S79, 2016, doi: 10.22037/ghfbb.v0i0.978.

11. A. L. Lloyd, T. A. Henderson, P. D. Vigil, and H. L. T. Mobley, "Genomic islands of uropathogenic Escherichia coli contribute to virulence," J. Bacteriol., vol. 191, no. 11, pp. 3469-3481, 2009, doi: 10.1128/JB.01717-08.

12. S. Yamamoto, "Molecular epidemiology of uropathogenic Escherichia coli," J. Infect. Chemother., vol. 13, no. 2, pp. 68-73, 2007, doi: 10.1007/s10156-007-0506-y.

13. M. S. Al-attar and M. S. Shekha, "The
Prevalence of Thalassemia in Erbil Province," J. Pure Appl. Sci. Salahaddin Univ. -, vol. 18, no. 3, pp. 46-51, 2014.

14. B. Pourgheysari and L. Karimi, "Alteration of $T$ cell subtypes in beta-thalassaemia major: Impact of ferritin level," J. Clin. Diagnostic Res., vol. 10, no. 2, pp. DC14DC18, 2016, doi: 10.7860/JCDR/2016/16094.7272.

15. H. Ayyash and M. Sirdah, "Hematological and biochemical evaluation of $\beta$ thalassemia major ( $\beta$ TM) patients in Gaza Strip: A cross-sectional study.," Int. J. Health Sci. (Qassim)., vol. 12, no. 6, pp. 18-24, 2018.

16. D. T. Kremastinos et al., " $\beta$-thalassemia cardiomyopathy: History, present considerations, and future perspectives," Circ. Hear. Fail., vol. 3, no. 3, pp. 451-458, 2010,

DOI: 10.1161/CIRCHEARTFAILURE.109.9138 63.

17. E. Sáez-López et al., "Characterization of vaginal Escherichia coli isolated from pregnant women in two different African sites," PLoS Comput. Biol., vol. 11, no. 7, pp. 1-10, 2016, doi: 10.1371/journal.pone.0158695.

18. C. R. Polage, J. V. Solnick, and S. H. Cohen, "Nosocomial diarrhea: Evaluation and treatment of causes other than clostridium difficile," Clin. Infect. Dis., vol. 55, no. 7, pp. 982-989, 2012, DOI: 10.1093/cid/cis551.

19. R. Abd ALameer, Y. Abbas A, and B. Khudaier Y, "Genotyping of Escherichia Coli Isolated From Clinical and Hospitals Environment," Univ. Thi-Qar J. Sci., vol. 5, no. 3, pp. 3-13, 2015.

20. B. J. Al Badry, A. A. Hussin, I. N. Abid, A. Sh Jabber, and A. M. Thmen, "Bacterial Infections in Thalassemia Patients at ThiQar Province/ South Iraq," Technol. Sci. Am. Sci. Res. J. Eng., vol. 19, no. 1, pp. 199-205, 2016.

21. C. Shah, R. Baral, B. Bartaula, and L. B. Shrestha, "Virulence factors of uropathogenic Escherichia coli (UPEC) and correlation with antimicrobial resistance," BMC Microbiol., vol. 19, no. 1, pp. 1-6, 2019, DOI: 10.1186/s12866-0191587-3.

22. S. H. Hosseini, J. Simiari, and B. 
Farhadpour, "The Prevalence and Antimicrobial Susceptibility of Bacterial Uropathogens Isolated from Pediatric Patients," Iran. J Publ Heal., vol. 18, no. 1, pp. 3-13, 2009, doi: 10.1017/CBO9781107415324.004.

23. D. B. Melo, A. P. de O. Menezes, J. N. Reis, and A. G. Guimarães, "Antimicrobial resistance and genetic diversity of escherichia coli isolated from humans and foods," Brazilian J. Microbiol., vol. 46, no. 4, pp. 1165-1170, 2015, doi: 10.1590/S1517-838246420130874.

24. T. Sullivan et al., "Microbiological identification and analysis of swine tonsils collected from carcasses at slaughter," Can. J. Vet. Res., vol. 75, no. 2, pp. 106111, 2011.

25. F. Kawamori et al., "Molecular typing of Japanese Escherichia coli O157:H7 isolates from clinical specimens by multilocus variable-number tandem repeat analysis and PFGE," J. Med. Microbiol., vol. 57, no. 1 , pp. 58-63, 2008, DOI: 10.1099/jmm.0.47213-0.

26. T. C. P. S. Cohen, "Commensal and Pathogenic Escherichia coli Metabolism in the Gut," Physiol. Behav., vol. 176, no. 1, pp. 139-148, 2017, DOI: 10.1016/j.physbeh.2017.03.040.

27. O. A. Igbeneghu and A. Lamikanra, "Multiple-resistant commensal Escherichia coli from Nigerian children: Potential opportunistic pathogens," Trop. J. Pharm. Res., vol. 13, no. 3, pp. 423-428, 2014, DOI: 10.4314/tjpr.v13i3.17.

28. G. G. Patricia, S. L. Vania, and D. G. Claudio, "Occurrence and Antimicrobial Drug Susceptibility Patterns of Commensal and Diarrheagenic Escherichia coli in Fecal Microbiota from Children with and without Acute Diarrhea," J. Microbiol., vol. 49, no. 1, pp. 46-52, 2011, DOI: 10.1007/s12275-011-0172-8.

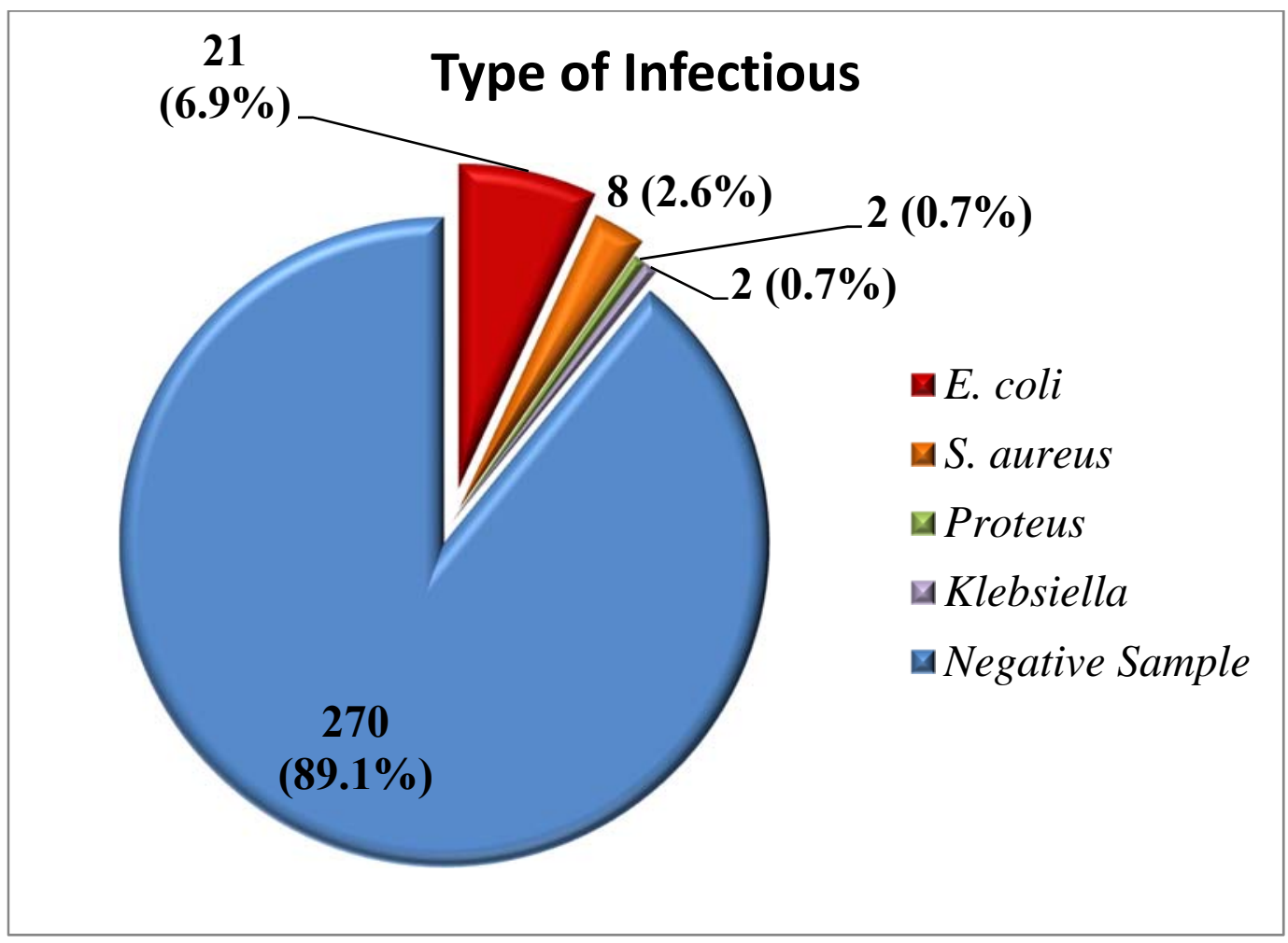

Figure 1. The percent of Escherichia coli isolated from urine samples of thalassemia patients with UTI 


\section{Infectious Bacteria}

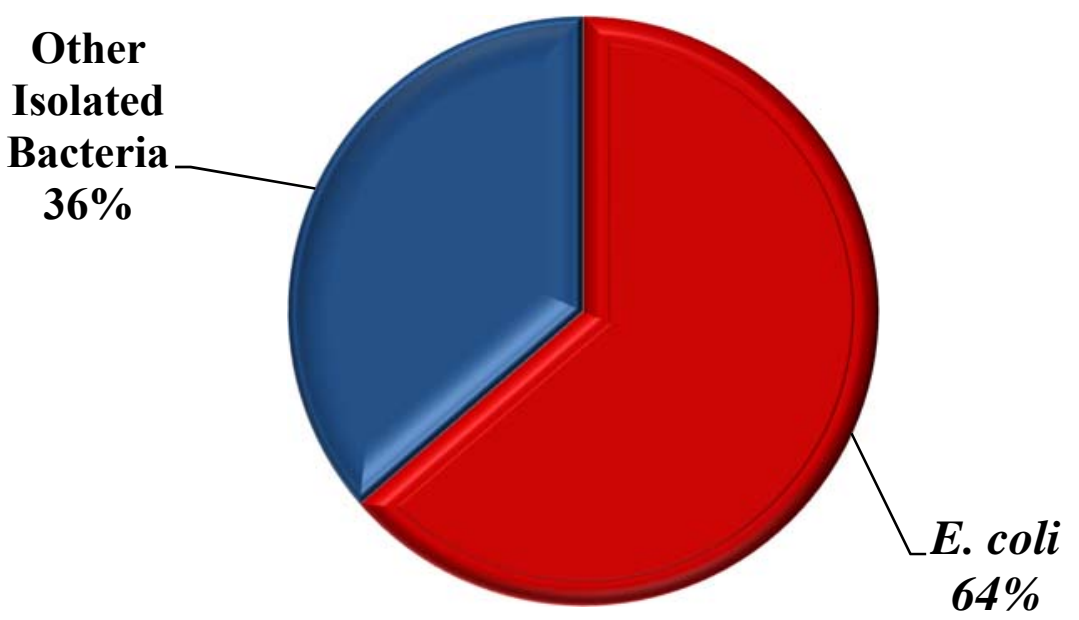

Figure 2. Percentage of Infection with E. coli Compared to other Isolated Bacteria

\section{Number of infection}

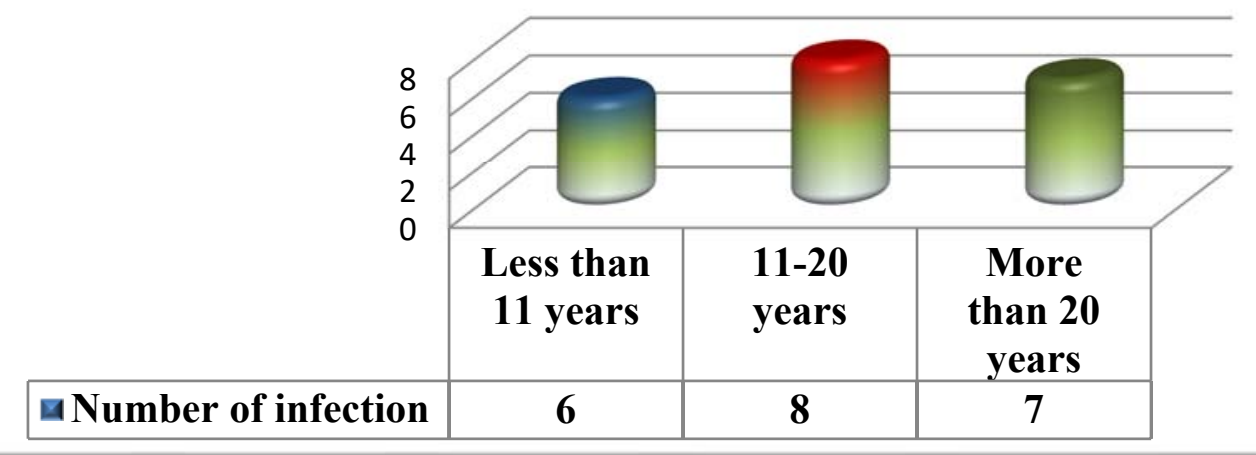

Figure 3. Distribution of E. coli According to Age Group.

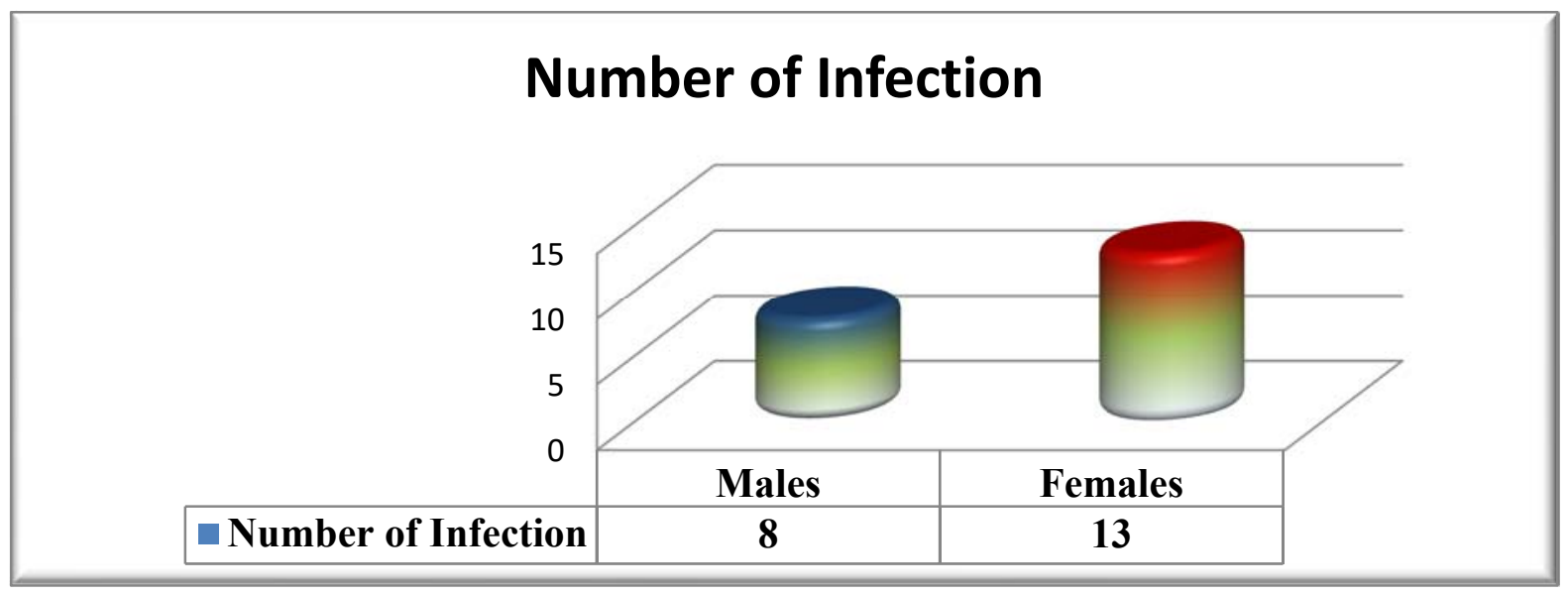

Figure 4. Distribution of E. coli According to Gender. 


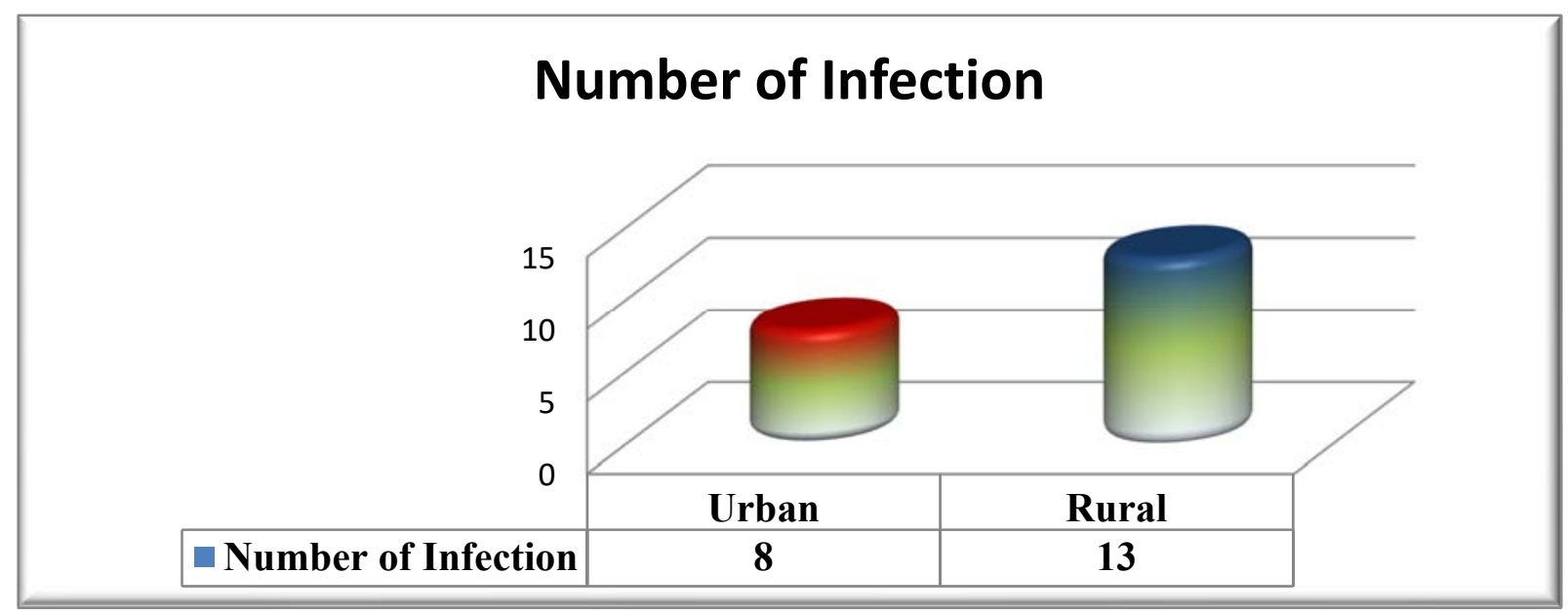

Figure 5. Distribution of E. coli According to Habitation.

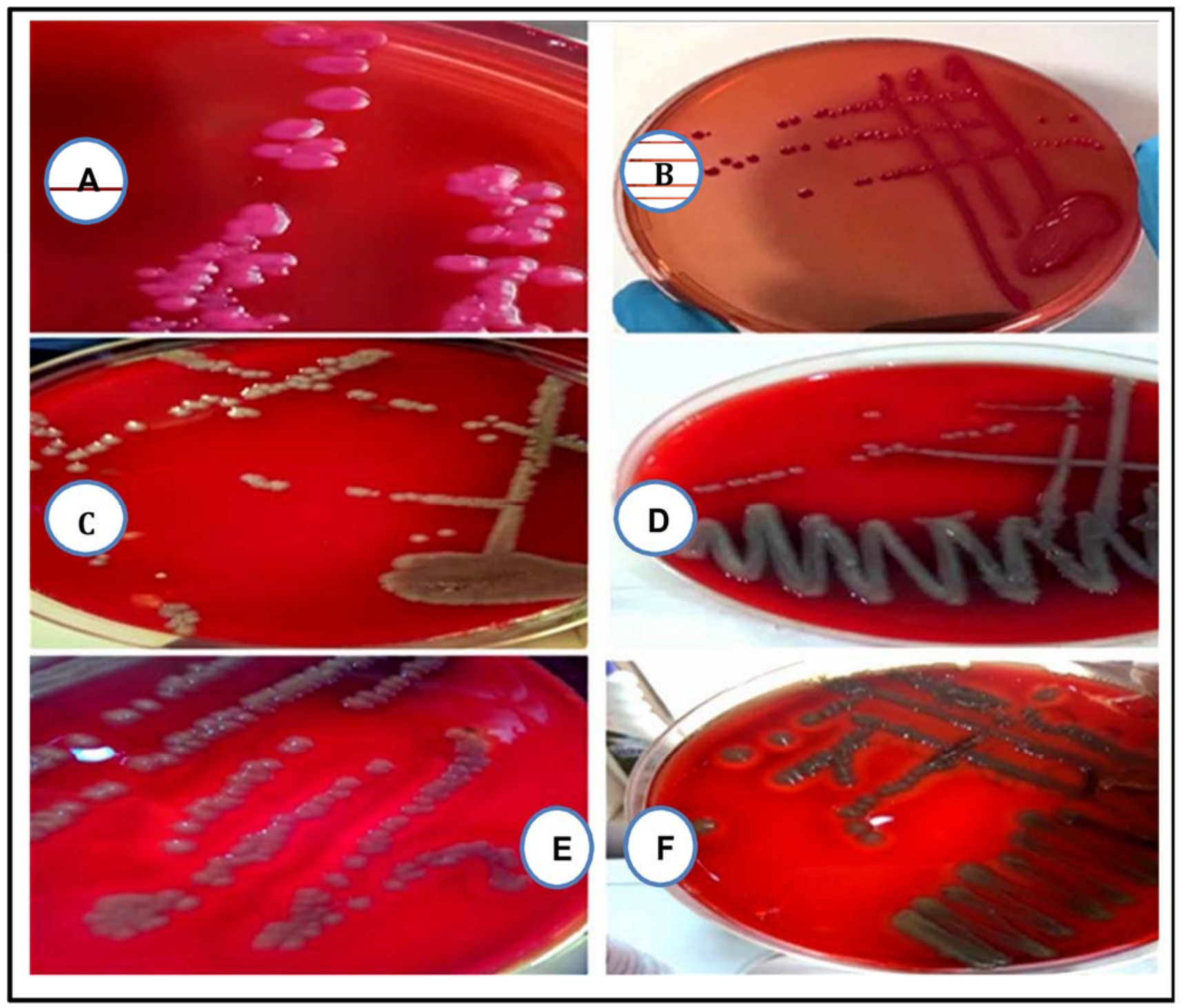

Figure 6. Morphological of E. coli colony A and B: E. coli colony on MacConkey agar lactos ferment, C: commensal E. coli colony on blood agar non-hemolytic, D: UPEC colony $\alpha$ hemolytic, $E$ and F: UPEC $\beta$-hemolytic E. coli. 


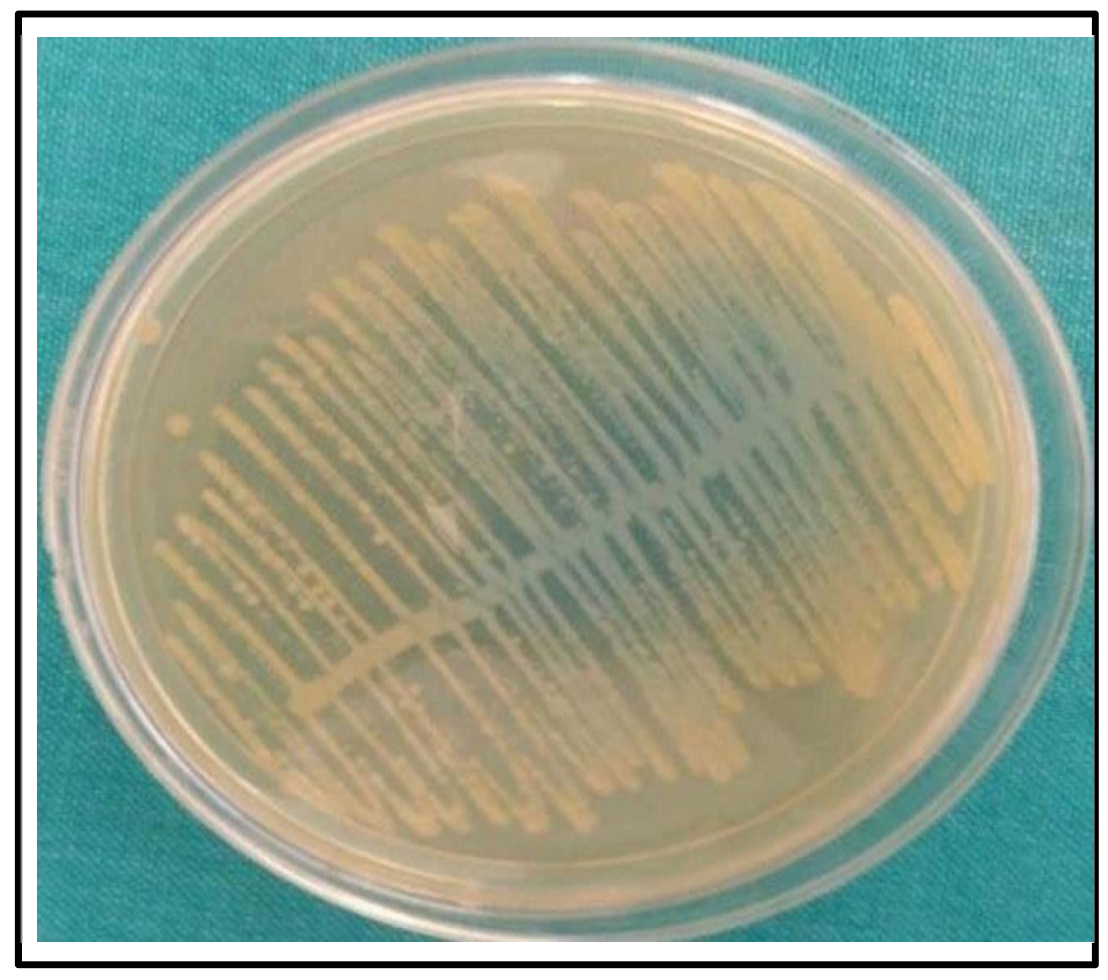

Figure 7. E. coli grow on CLED agar

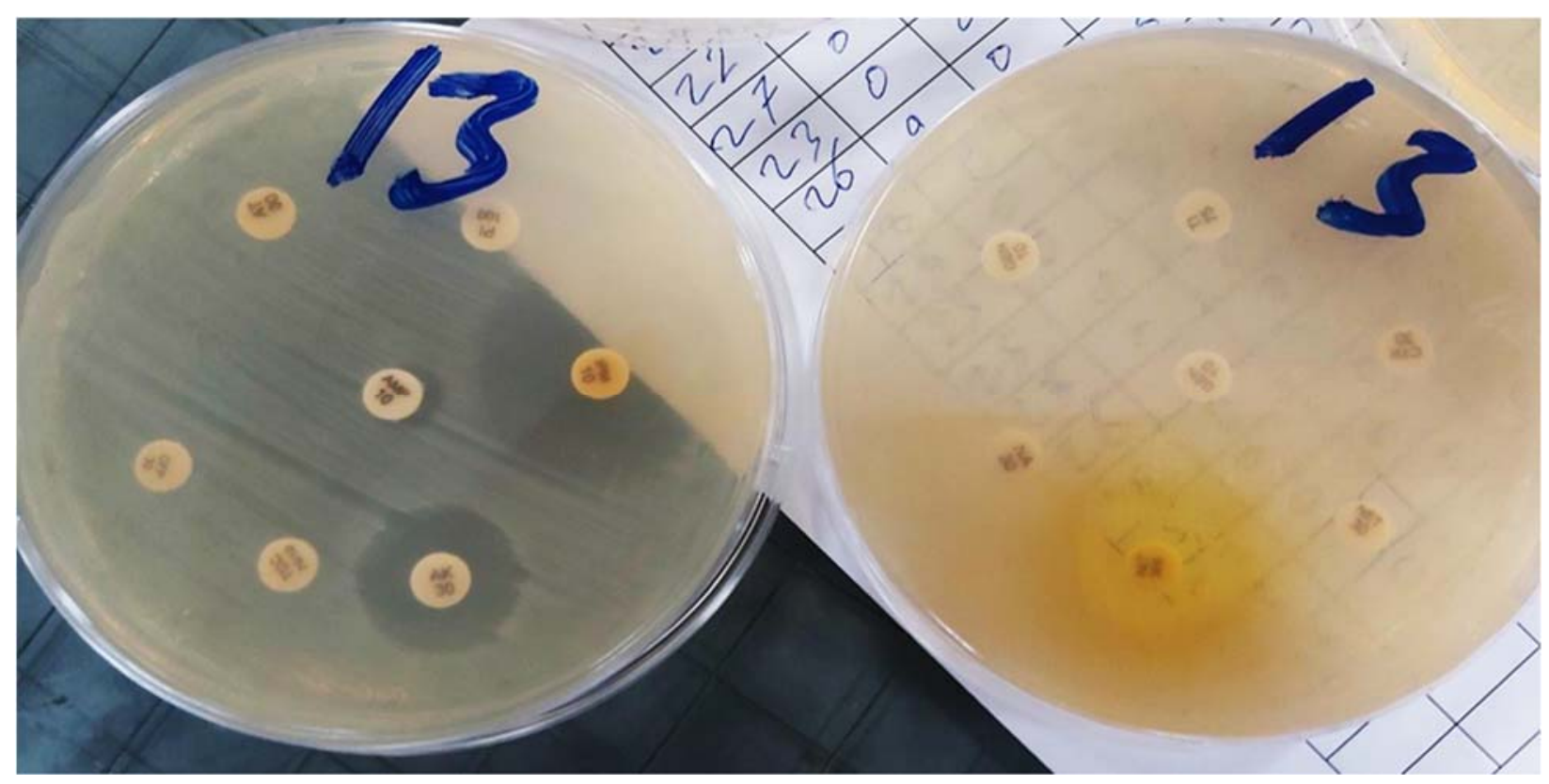

Figure 8. Antimicrobial susceptibility test; for E. coli isolated. 
Table 1. Distribution of E. coli According to Age Group

\begin{tabular}{c|c|c|c|c}
\hline \multirow{2}{*}{ Pathogen } & \multicolumn{2}{|c|}{ E. coli } & \multicolumn{2}{c}{ Total } \\
\cline { 2 - 5 } & No. & $\%$ & No. & $\%$ \\
\hline Less than 11 years & 6 & 28.6 & 6 & 28.6 \\
\hline 11-20 years & 8 & 38.1 & 8 & 38.1 \\
\hline More than 20 years & 7 & 33.3 & 7 & 33.3 \\
\hline Total & 21 & 100 & 21 & 100 \\
\hline
\end{tabular}

Table 2. Distribution of E. coli According to Gender

\begin{tabular}{c|c|c|c|c}
\hline \multirow{2}{*}{ Gender Pathogen } & \multicolumn{2}{|c|}{ E. coli } & \multicolumn{2}{c}{ Total } \\
\cline { 2 - 5 } & No. & $\%$ & No. & $\%$ \\
\hline Male & 8 & 38.1 & 8 & 38.1 \\
\hline Female & 13 & 61.9 & 13 & 61.9 \\
\hline Total & 21 & 100 & 21 & 100 \\
\hline
\end{tabular}

Table 3. Distribution of E. coli According to Habitation

\begin{tabular}{c|c|c|c|c}
\hline \multirow{2}{*}{ Pathogen } & \multicolumn{2}{|c|}{ E. coli } & \multicolumn{2}{c}{ Total } \\
\cline { 2 - 5 } & No. & $\%$ & No. & $\%$ \\
\hline Urban & 8 & 38.1 & 8 & 38.1 \\
\hline Rural & 13 & 61.9 & 13 & 61.9 \\
\hline Total & 21 & 100 & 21 & 100 \\
\hline
\end{tabular}


Table 4. Antibiotic susceptibility of E. coli against isolates 16 types of antibiotics.

\begin{tabular}{|c|c|c|c|c|c|c|c|c|}
\hline \multirow{3}{*}{ Type of Response } & \multicolumn{8}{|c|}{ Antibiotic Susceptibility } \\
\hline & \multicolumn{2}{|c|}{ Resistance } & \multicolumn{2}{|c|}{ Intermediate } & \multicolumn{2}{|c|}{ Sensitive } & \multicolumn{2}{|c|}{ Total } \\
\hline & No. & $\%$ & No. & $\%$ & No. & $\%$ & No. & $\%$ \\
\hline IPM & 0 & 0.00 & 0 & 0.00 & 21 & 100 & 21 & 100 \\
\hline AMP & 21 & 100 & 0 & 0.00 & 0 & 0.00 & 21 & 100 \\
\hline AT & 21 & 100 & 0 & 0.00 & 0 & 0.00 & 21 & 100 \\
\hline CTR & 21 & 100 & 0 & 0.00 & 0 & 0.00 & 21 & 100 \\
\hline CEP & 21 & 100 & 0 & 0.00 & 0 & 0.00 & 21 & 100 \\
\hline NET & 3 & 14.3 & 0 & 0.00 & 18 & 85.7 & 21 & 100 \\
\hline AK & 5 & 23.8 & 1 & 4.8 & 15 & 71.4 & 21 & 100 \\
\hline TTC & 21 & 100 & 0 & 0.00 & 0 & 0.00 & 21 & 100 \\
\hline $\mathrm{PI}$ & 20 & 95.2 & 1 & 4.8 & 0 & 0.00 & 21 & 100 \\
\hline TE & 20 & 95.2 & 1 & 4.8 & 0 & 0.00 & 21 & 100 \\
\hline AMC & 21 & 100 & 0 & 0.00 & 0 & 0.00 & 21 & 100 \\
\hline GEN & 4 & 19.0 & 0 & 0.00 & 17 & 81.0 & 21 & 100 \\
\hline $\mathrm{TI}$ & 21 & 100 & 0 & 0.00 & 0 & 0.00 & 21 & 100 \\
\hline NIT & 7 & 33.3 & 1 & 4.8 & 13 & 61.9 & 21 & 100 \\
\hline NA & 18 & 85.7 & 2 & 9.5 & 1 & 4.8 & 21 & 100 \\
\hline CIP & 19 & 90.5 & 0 & 0.00 & 2 & 9.5 & 21 & 100 \\
\hline CalX $^{2}=260.107$ & \multicolumn{3}{|c|}{$\mathrm{TabX}^{2}=43.77$} & \multicolumn{2}{|c|}{$\mathrm{DF}=30$} & \multicolumn{3}{|c|}{ P. Value $=0.0001$} \\
\hline
\end{tabular}

The SOUTHERN BRAZILIAN JOURNAL OF CHEMISTRY (ISSN: 2674-6891; 0104-5431) is an open-access journal since 1993. Journal DOI: 10.48141/SBJCHEM. http://www.sbjchem.com. This text was introduced in this file in 2021 for compliance reasons.

(C) The Author(s)

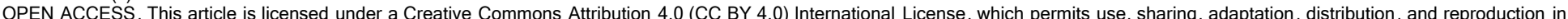

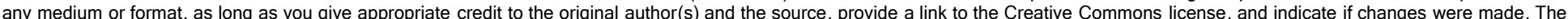

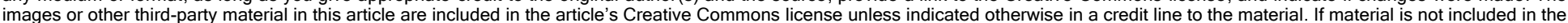

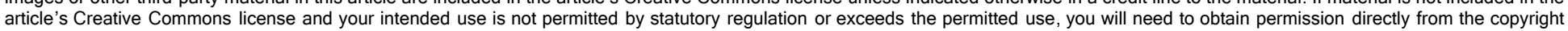
holder. To view a copy of this license, visit http://creativecommons.org/licenses/by/4.0/. 


\title{
SOUTHERN BRAZILIAN JOURNAL OF CHEMISTRY
}

\section{STUDY ON THE DPPH FREE RADICAL-SCAVENGING ACTIVITY OF SALVIA NEMOROSA L. AT TWO GROWTH STAGES}

\author{
GHAFIYEHSANJ, Elham¹; DILMAGHANI, Kamaladdin*2; CHAPARZADE, Nader; \\ SAADATMAND, Sara ${ }^{4}$; \\ 1,4 Islamic Azad University, Science and Research Branch, Faculty of Science, Biology Department \\ 2 Islamic Azad University, Marand Branch, Faculty of Science, Biology Department \\ ${ }^{3}$ Azerbaijan Tarbiat-e-Moallem University, Faculty of Science, Department of Biology \\ * Correspondence author \\ e-mail: dilmaghanikamal@gmail.com
}

Received 12 April 2020; received in revised form 22 May 2020; accepted 22 June 2020

\begin{abstract}
This study was designed to examine the DPPH free radical-scavenging activity, in different concentrations $(0.025,0.05,0.07,0.1,0.2,0.04$ and 0.6$)$ of methanolic extracts of Salvia nemorosa L. collected from the northwest of Iran (Zonouz and Ardabil regions) at two-stage of growth (vegetative stage leaves, flowering stage leaves, and flowers). The result showed that the mean of inhibition percentage in the Zonouz region increased in various concentrations and between flowers, vegetative stage leaves, and flowering stage leaves, compared with the plants of the Ardabil region. In each of the regions of Zonouz and Ardabil, the highest amount of DPPH inhibition was observed in the vegetative stage leaves in comparison with flowering stage leaves and flowers. In addition, in the effect of DPPH radical trapping in different concentrations of methanolic extracts of Salvia nemorosa L. was observed that from each of the collected region, methanolic extracts from sage plants were dose-dependent and acted very effective and useful and the best antioxidant activity was in the high concentration of extracts, So in Zonouz and Ardabil regions, the content of inhibition of DPPH increased significantly, by increasing the concentration of $0.025 \mathrm{mg} / \mathrm{ml}$ to $0.6 \mathrm{mg} / \mathrm{ml}$ and in Zonouz region the content of inhibition of DPPH similarly increased in $0.2,0.4$ and $0.6 \mathrm{mg} / \mathrm{ml}$ concentrations. In the Ardabil region, the most content of inhibition of DPPH was seen in $0.4 \mathrm{mg} / \mathrm{ml}$ and $0.6 \mathrm{mg} / \mathrm{ml}$ concentrations, but in this region, the content of inhibition of DPPH in $0.2 \mathrm{mg} / \mathrm{ml}$ concentration there was only in vegetative stage leaves and flowering stage leaves.
\end{abstract}

Keywords: Salvia nemorosa, Lamiaceae, Growth stage, Antioxidant activity, 2,2-diphenyl-1-picrylhydrazyl $(D P P H)$.

\section{INTRODUCTION}

It is known that $50,000-75,000$ plant species are used in traditional and modern medicine worldwide (Schippmann et al., 2002). Medical and aromatic herbs have had essential components of healthcare throughout human history (Schippmann et al. 2002). From the past until now, by use of plants for the cure of different disease types in worldwide was usual because they contain components of therapeutic value. This was the basic formation of medicinal plants (Raja et al., 2010). Recently, there has been a general opinion that synthetic materials that are commonly used in the food and drug industry cause many diseases, such as cancer. This has led to an increasing global demand for natural and organic forms of medication. As a result of this demand, healing herbs and medicines of herbal origins are commonly used worldwide as a part of traditional culture worldwide, and prefer alternative medicine methods at least once a year, and consume herbal drugs and healing herbs (Schipmann 2006).

Medical and aromatic herbs are used in such domains as cosmetics, medicine, dye, herbal tea, nutritional supplements, liquor, pesticide and fungicide, essential oil products, perfumes, flavoring liquids, and cleaning products. Previously, local usage of these herbs was common as part of the traditional culture, but today, these herbs have become an important source of national and international trade (Schipmann 2006).

The genus Salvia L. one of the largest genera in the Lamiaceae family (subfamily Nepetoideae), comprises over 900 species throughout the Old and New World (Hedge 1992). 
The Lamiaceae (Labiate) is one of the most diverse and widespread plant families in terms of ethnomedicine, and its medicinal value is based on the concentration of the volatile oil (Sarac and Ugur 2007). Also, the Lamiaceae plant family is one of the largest families among the dicotyledons, many species belonging to the family being highly aromatic, due to the presence of external glandular structures that produce volatile oil (Giuliani and Bini 2008). Salvia nemorosa L., commonly known as wood sage, is growing in central Europe and Western Asia (Skała and Wysokińska 2004). In addition, S. nemorosa exhibits a considerable antioxidant, antibacterial, and enzyme inhibitory activities. Studies have showed that $S$. nemorosa is a rich source of bioactive metabolites (flavonoids and phenolic compounds) and could be used for preparing novel functional foods, cosmetics, and pharmaceutical ingredients (Bahadori et al., 2017).

Observing the considerable amount of phytochemicals of $S$. nemorosa with attempted to design a study to reveal the quantity of its antioxidant activity as well as the effect two different regions in northwest of Iran.

\section{MATERIALS AND METHODS}

\subsection{Plant material}

Salvia nemorosa L. plants were harvested at different growth stages (vegetative and flowering stages) from the northwest of Iran including Zonouz gardens in East Azarbaijan (longitude: $38.26^{\circ} \mathrm{E}$, latitude: $45.46^{\circ} \mathrm{N}$ and altitude: $1550 \mathrm{~m}$ ) and $85 \mathrm{~km}$ from Khalkhal to Ardabil (Abbasabad village) in Ardabil province (longitude: $38.13^{\circ} \mathrm{E}$ ', latitude: $48.19^{\circ} \mathrm{N}$ and altitude: $1335 \mathrm{~m}$ ). Plants were harvested during the vegetative stage from May 12th to May 26th, 2017, and were harvested during the flowering stage from May 19th to June 5th, 2017.

\subsection{Extraction}

The flowers and leaves of sage plants were dried at room temperature, and in shade conditions, then each was powdered, and they to extract were soaked in absolute methanol $(50 \mathrm{ml})$, and extraction was carried out by shaking at room temperature for $72 \mathrm{~h}$. They were centrifuged for 20 minutes in 1000 rpm (Sarrou et al., 2016).

\section{3. $D P P H$ radical scavenging}

The ability of plant extracts to scavenge DPPH free radicals was determined according to the method described by Bondet et al., (1997). The sage extracts at different concentrations $(0.025$, $0.05,0.07,0.1,0.2,0.4,0.6 \mathrm{mg} / \mathrm{ml}$ ) were mixed with $2 \mathrm{ml}$ of methanol solution of DPPH. The disappearance of DPPH was read against a blank at $517 \mathrm{~nm}$. Free radical scavenging capacity was calculated by Equation 1:

$\%$ scavenging $=\left(100-\frac{(\text { Abc sample })}{(\text { Abc DPPH })}\right) \times 100 \% \quad$ (Eq. 1)

Abs sample $=$ Abs measured - Abs control (i.e., the absorbance of the sample tested without DPPH) (Barros et al., 2011).

\subsection{Statistical analysis}

Duncan's test was used to show the least significant difference in the probability level of $5 \%$ $(P$-value $\leq 0.05)$. Data on DPPH radical activity in this study were performed with SPSS statistical software. Multi-Way-ANOVA analysis of variance was performed to compare variables, regions, stages, and different concentrations.

\section{RESULTS AND DISCUSSION:}

According to Table 1, there was no considerable difference in the content of inhibition of DPPH by regions (Zonouz and Ardabil) between flowers, vegetative stage leaves, and flowering stage leaves (Table1). But significant difference $(p<0.01)$ was observed in each separate region between various concentrations $(0.025,0.05$, $0.07,0.1,0.2,0.4$ and $0.6 \mathrm{mg} / \mathrm{ml})$. In each of the regions of Zonouz and Ardabil, the highest amount of DPPH inhibition was observed in the vegetative stage leaves in comparison with flowering stage leaves and flowers. So, in two regions, from vegetative stage leaves to flowers, an insignificant decrease was observed (Figure 1).

The mean inhibition percentage in the Zonouz region showed an increase in various concentrations and in flowers, vegetative stage leaves, and flowering stage leaves, in comparison with the plants of the Ardabil region (Table 1). In this two regions, the content of inhibition of DPPH increased significantly, by increasing the concentration of $0.025 \mathrm{mg} / \mathrm{ml}$ to $0.6 \mathrm{mg} / \mathrm{ml}$ and in Zonouz region the content of inhibition of DPPH similarly increased in $0.2,0.4$ and $0.6 \mathrm{mg} / \mathrm{ml}$ concentrations (Figure 1)

Similar to our results, in the study of antioxidant activities of Salvia officinalis L. extracts was observed that DPPH inhibition in methanolic, ethanolic and n-hexane extracts was dosedependent and by increasing the concentration 
from 0 to $500 \mu \mathrm{g} / \mathrm{ml}$ increased while, inhibition percentage in the highest concentrations (500 to $1000 \mu \mathrm{g} / \mathrm{ml}$ ) didn't show the significant change (EtTouys et al., 2016).

The more ever-present research showed that in each of regions of Zonouz and Ardabil, the highest amount of DPPH inhibition was observed in the vegetative stage leaves in comparison with flowering stage leaves and flowers. Similarly, in the study of Moghaddam et al., (2018) on total phenolic content and antioxidant activity of Fumaria vaillantii $\mathrm{L}$. extract at different growth stages was seen that highest accumulation amount of phenolic compounds was at the early growth stages, but the lowest was in the flowering stage.

In the Ardabil region, the most content of inhibition of DPPH was seen in $0.4 \mathrm{mg} / \mathrm{ml}$ and 0.6 $\mathrm{mg} / \mathrm{ml}$ concentrations, but in this region, the content of inhibition of DPPH in $0.2 \mathrm{mg} / \mathrm{ml}$ concentration there was only in vegetative stage leaves and flowering stage leaves. Also, the content of inhibition of DPPH in flowers of the Zonouz region increased in comparison with flowers of the Ardabil region. In Zonouz and Ardabil regions, the content of inhibition of DPPH in higher concentrations $(0.2,0.4$ and $0.6 \mathrm{mg} / \mathrm{ml})$ significantly increased in compared with 0.25 , $0.05,0.07$ and $0.1 \mathrm{mg} / \mathrm{ml}$ concentrations. In this regions, content of inhibition of DPPH in 0.07 and $0.1 \mathrm{mmg} / \mathrm{ml}$ concentrations significantly decreased in compared with 0.4 and $0.6 \mathrm{mg} / \mathrm{ml}$ but significantly increased in compared with 0.025 and $0.05 \mathrm{mg} / \mathrm{ml}$ concentrations (Figure 1).

The influence of age and seasonal variation in the concentration of phenolic compounds are reported in previous researches by Munné-Bosch et al. (2000); Sellami et al. (2009) and Uddin et al., (2012). A decrease in phenolic content with age is probably due to their dilution with growth, or that may be because of great cellular division at the early growth stages. (Wang and Lin 2000; Del Bano et al., 2003). Also, it seems that the existence of phenolic compounds during the earlier stages suggests a transport phenomenon toward the young organs. It was reported that some phenolic compounds disappeared from the vascular system by growing the plants. Also, endogenous biosynthesis and transportation in plants are two phenomena that can influence the distribution of phenolic compounds. It appears that a close relationship among different processes of biosynthesis, degradation, and transport are involved in the distribution of polyphenols in the plants (Del Bano et al. 2003). Furthermore, the type of solvent, the degree of polymerization of phenolics, the interaction of phenolics with other food constituents, and the formation of the insoluble complex are also important (Gálvez et al., 2005; Česonienè et al., 2012).

Recently, phenolic compounds have received considerable attention because of their physiological functions, including antioxidant and free radical-scavenging abilities that are affected by the quality and nutritional value (Govindarajan et al., 2007). Therefore, antioxidant activity in plants is related to phenolic compounds that play a crucial role in neutralizing free radicals as a result of the fact that phenolics have a hydroxyl group. Due to the previous reports, the phenolic compounds are associated with redox properties, which allow them to act as reducing agents, hydrogen donators, and singlet oxygen quenchers as well as their metal-chelating abilities (ViudaMartos et al., 2010). It is well-established that sage phenolic compounds (rosmarinic acid, carnosic acid, salvianolic acid, and its derivatives carnosol, rosmanol, epirosmanol, rosmadial) are highly effective free radical scavengers and antioxidants. It is showed that good antioxidant properties of $S$. officinalis by-products are a result of the high content of polyphenolics. Significance and role of phenolic compounds showing significant correlations with antioxidant tests are undoubted. Nevertheless, it should be taken into consideration that the total antioxidant capacity of sage extracts is the result of the potential cumulative or synergistic effects of the diversity of major and minor phenolic components (Lu and Foo 2001; Johnson and Jorge 2005).

Observed differences in this study such as the content of DPPH inhibition in higher concentrations, the mean of DPPH inhibition and differences at different growth stages between Zonouz and Ardabil regions probably due to variation in the amounts of phenolic compounds and environmental factors such as longitude, latitude, altitude, harvest season, plants age, growth stages, soil, temperature changes and annual humidity and rainfall in these regions. Similarly, Tavassoli and Djomeh (2011) stated that variation in the amounts of phenolic compounds could be attributed to several reasons such as plant species (genetic), parts of the plants and extrinsic factors such as environmental conditions (e.g., climate, height, soil characteristic, temperature, humidity irrigation, temperature range, exposure to diseases and pests, cultural practices, harvest season, drying methods, handling and storage factors) can influence the phenolic content of plants during the plant growth 
cycles.

\section{CONCLUSIONS:}

According to the present study, it can be concluded that observed differences in the content of antioxidant activities in higher concentrations, the increase of mean of DPPH inhibition in Zonouz region and the decrease of radical inhibition in flowers of Ardabil region probably due to differences in climatic conditions, the type of solvent, the degree of polymerization of phenolics, in two regions Zonouz and Ardabil that are affected antioxidant activities and phenolic contents in sage plants. Moreover, an increase in the number of antioxidant activities at the vegetative growth stage in these two regions shows that this stage is the best stage of the harvest to obtain the highest amount of natural antioxidants of salvia nemorosa for using in various industries, including food industries.

\section{REFERENCES:}

1. Bahadori, M. B., Asghari, B., Dinparast, L., Zengin, G., Sarikurkcu, C., AbbasMohammadi, M., Bahadori, S. LWT. 2017, 75, 42-50.

2. Barros, L., Carvalho, A. M., Ferreira, I. C. Phytochem Anal. 2011, 22, 181-188.

3. Bondet, V., Brand-Williams, W., Berset, c. Food Sci Technol-Zurich-. 1997, 30, 609615.

4. Česonienè, L., Daubaras, R., Viškelis, P., Šarkinas, A. Plant Food Human nutrition. 2012, 67, 256-261.

5. Del Bano, M. J., Lorente, J., Castillo, J., Benavente-García, O., Del Rio, J. A., Ortuño, A., Quirin, K.-W., Gerard, D. J Agric Food Chem. 2003, 51, 4247-4253.

6. Et-Touys, A., Fellah, H., Mniouil, M., Bouyahya, A., Dakka, N., Sadak, A., Bakri, Y. Microbiol Res J Int.. 2016, 1-10.
7. Gálvez, M., Martín-Cordero, C., Houghton, P. J., Ayuso, M. J. J Agric Food Chem. 2005, 53, 1927-1933.

8. Giuliani, C., Bini, L. M. Plant Syst Evol. 2008, 276, 199.

9. Govindarajan, R., Singh, D., Rawat, A. J Pharm Biomed Anal. 2007, 43, 527-532.

10. Hedge, I. C. Advan Labiat Sci. 1992, 7-17.

11. Johnson, C., Jorge, J. C. L. Spanish J Agri Res. 2005, 106-112.

12. Lu, Y., Foo, L. Y. Tetrahedron Lett. 2001, 42, 8223-8225.

13. Moghaddam, M., Khaleghi Miran, S. N., Mehdizadeh, L. Int J Horti Sci Technol. 2018, 5, 93-102.

14. Munné-Bosch, S., Alegre, L., Schwarz, K. Eur Food Res Technol. 2000, 210, 263267.

15. Raja, R., Prakash, J., Jeeva, S. Ethnic tribes, and medicinal plans. Jaipur: Pointer Publishers. 2010, 28-45.

16. Sarac, N., Ugur, A. EurAsian J BioSci. 2007, 4, 28-37.

17. Sarrou, E., Martens, S., Chatzopoulou, P. Indus Crop Product. 2016, 94, 240-250.

18. Schipmann, W. Beltz Juventa. 89ff. 2006.

19. Schippmann, U., Leaman, D. J., Cunningham, A. Biodiv Ecosy Appro Agri Fores Fish. 2002.

20. Sellami, I. H., Maamouri, E., Chahed, T., Wannes, W. A., Kchouk, M. E., Marzouk, B. Indus Crop Product. 2009, 30, 395-402.

21. Skała, E., Wysokińska, H. In Vitro Cellular \& Devel Biol Plant. 2004, 40, 596-602.

22. Tavassoli, S., Djomeh, Z. E. Glob Veteri. 2011, 7, 337-341.

23. Uddin, M., Juraimi, A. S., Ali, M., Ismail, M. R. Int J Mol Sci. 2012, 13, 10257-10267.

24. Viuda-Martos, M., El Gendy, A. E.-N. G., Sendra, E., Fernandez-Lopez, J., Abd El Razik, K., Omer, E. A., Perez-Alvarez, J. A. J Agric Food Chem. 2010, 58, 9063-9070.

25. Wang, S. Y., Lin, H.-S. J Agric Food Chem. 2000, 48, 140-146. 
Table 1. Variance Analysis to compare DPPH inhibition in different concentrations in Zonouz and Ardabil regions

\begin{tabular}{c|l|c}
\hline Regions & \multicolumn{1}{|c|}{ Stages } & Mean squer \\
\hline \multirow{3}{*}{ Ardebil } & Vegetative leaves & $63.871^{\mathrm{ns}}$ \\
\cline { 2 - 3 } & Flowering leaves & $57.109^{\mathrm{ns}}$ \\
\cline { 2 - 3 } & Flowers & $37.799^{\mathrm{ns}}$ \\
\hline \multirow{3}{*}{ Zenouz } & Vegetative leaves & $72.997^{\mathrm{ns}}$ \\
\cline { 2 - 3 } & Flowering leaves & $65.541^{\mathrm{ns}}$ \\
\cline { 2 - 3 } & Flowers & $59.049^{\mathrm{ns}}$ \\
\hline
\end{tabular}

Note: 'ns' indicate non-significant difference at \% 5.

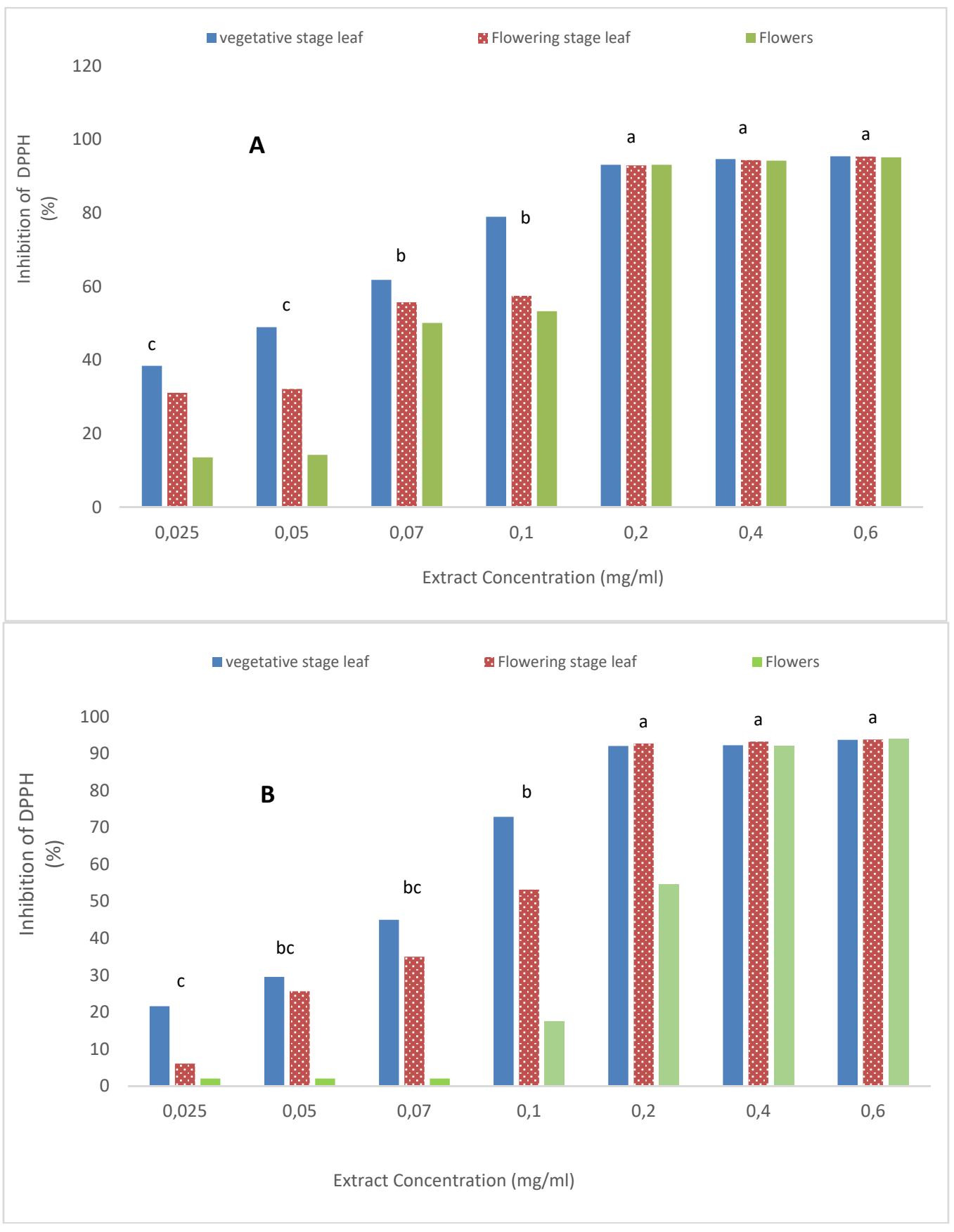

Figure 1. The percentage of DPPH inhibition in different concentrations of Zonouz $(A)$ and Ardabil $(B)$ regions separately in different stages of growth. 


\title{
SOUTHERN BRAZILIAN JOURNAL OF CHEMISTRY
}

\section{USING SYNTHESISED ORGANIC COMPOUNDS AS ENVIRONMENTALLY FRIENDLY RETARDANTS FOR ORNAMENTAL PLANTS}

\author{
VOSTRIKOVA, Tatiana V.. ${ }^{1 *}$; KALAEV, Vladislav N².; POTAPOV, Andrey Yu. ${ }^{3}$; VANDYSHEV, \\ Dmitry Y.4; SHIKHALIEV, Khidmet S. ${ }^{5}$; \\ 1,2 Voronezh State University, Botanical Garden, Russian Federation \\ ${ }^{3,4,5}$ Voronezh State University, Department of Organic Chemistry, Russian Federation \\ * Correspondence author \\ e-mail: tanyavostric@rambler.ru
}

Received 06 April 2020; received in revised form 20 May 2020; accepted 23 June 2020

\begin{abstract}
The pre-sowing treatment of scarlet sage (Salvia splendens Ker Gawl.) seeds with 4-methyl-2-piperidin1-yl-pyrimidine-5-carboxylic acid at concentrations of $0.01,0.05$, and $0.1 \%$ proved to have an obvious inhibiting effect. Prior to sowing, the seeds of Salvia splendens were soaked in a water suspension of 4-methyl-2piperidin-1-yl-pyrimidine-5-carboxylic acid and 4-methyl-2-morpholin-4-pyrimidine-5-carboxylic acid with concentrations of $0.01 \%, 0.05 \%$, and $0.1 \%$ for 18 hours. On the 42 nd day of the experiment, the seedlings, having been preliminarily hardened for 12 days, were removed from the greenhouse and planted on the field. The pre-sowing treatment of Salvia splendens seeds with 4-methyl-2-morpholin-4-pyrimidine-5-carboxylic acid proved to have the inhibiting effect at concentrations of 0.01 and $0.05 \%$. The height of the seedlings decreased by $13.3-43.7 \%$. It was revealed that 4-methyl-2-piperidin-1-yl-pyrimidine-5-carboxylic acid at concentrations of $0.01,0.05$, and $0.1 \%$ decreased the growth of the seedlings by $30.4-43.7 \%$, and 4 -methyl-2-morpholin-4pyrimidine-5-carboxylic acid at concentrations of 0.01 and $0.05 \%$ decreased the growth of the seedlings by 13.3-22.2\%. By contrast, the effect of pyrimidinecarboxylic acids on seed germination and plant height of another annual flower - spreading marigold (Tagetes patula L.) was stimulating. It was investigated some different concentrations from 0.01 to $0.05 \%$. The same concentrations of identical compounds were tested, but effects from them were opposite for Tagetes patula, and Salvia splendens seedlings. Consequently, the species-specific effect of pyrimidinecarboxylic acids on seed germination and plant height for ornamental grasses takes place. Therefore,4-methyl-2-piperidin-1-yl-pyrimidine-5-carboxylic acid and 4-methyl-2-morpholin4-pyrimidine-5-carboxylic acid are recommended as growth retardants for Salvia splendens.
\end{abstract}

Keywords: synthesized organic compounds, pyrimidinecarboxylic acids, grasses, retardants.

\section{INTRODUCTION}

To cultivate scrubby and compact plants, special growth regulators - retardants, are used, which inhibit the plant growth. The most commonly used retardants are: chlorcholine chloride ((2-chloroethyl)-trimethylammonium chloride), alar (succinic mono-(N,Ndimethylhydrazide)), and ethephon ((2chloroethyl)phosphonic acid) (http:// www.valleyflora.ru/53-1.html). Chlorcholine chloride is the basis for a plant growth regulator "Toor", which used to be very popular in Russia and its neighboring countries (today the regulator is manufactured under the name Atlet $^{\circledR}$ by PCC Rokita SA (Poland). (2-chloroethyl)phosphonic acid is used all over the world to synthesize various preparative forms of growth retardants, such as Ethephon (commercial formulation Ethrel $^{\circledR}$ produced by Bayer CropScience AG (Germany)). Ethephon is used to synthesize growth retardants which efficiently induce the production of ethylene. These regulators contain disodium salts of ethephon together with hydrazine (hydrel) and dimethylhydrazine (dihydrel). 2,2-Dimethylhydrazide of succinic acid is also commonly used (Sherer, Gadiev, 1991).

Over the last years, attempts have been made to synthesize new organic compounds that can be used as growth regulators (Dlugosz, Dus, 1996; Abdel-Gawad et al., 2005; Shujiang et al., 2005; Marjani et al., 2011; Ostroshenko, Ostroshenko, 2011). Such compounds should be more effective than the existing commercial formulations (Vasin et al., 2008; 2009). Several 
heterocycles have shown a potent antibacterial effect (El-Sayed et al., 2002a,b, 2004; Brown et al., 2004). The genotoxicity of some heterocyclic compounds has been verified using cytogenetic indicators, and they were recognized as environmentally friendly (Butorina et al., 2002). The effect of pyrimidinecarboxylic acids on seed germination and plant height was studied using another annual flower - spreading marigold (Tagetes patula L.) (Vostrikova et al., 2012). However, the effect of pyrimidinecarboxylic acids on the growth of other plants has not been studied yet. They may appear to have an inhibiting effect and thus can function as retardants used to reduce the height of plants and cultivate low growing ornamental grasses.

It is studied the effect of synthesized organic compounds of pyrimidinecarboxylic acids when used for pre-sowing seed treatment of the ornamental grass plant scarlet sage (Salvia splendens Ker Gawl.).

\section{MATERIALS AND METHODS}

The research was conducted at the B.M. Kozo-Polyansky Botanical Garden of Voronezh State University (geographic coordinates: $39^{\circ} 22^{\prime} \mathrm{N}, 5^{\circ} 40^{\prime} \mathrm{E}$; 168.2 meters above sea level).

In the study, it was used the annual ornamental plant the "Hot fire" variety of scarlet sage (Salvia splendens Ker Gawl.), which is often planted in urban gardens.

In the research, it was focused on the effect of synthesized organic (heterocyclic) compounds of pyrimidinecarboxylic acids on the height of seedlings of $S$. splendens. The following heterocyclic compounds were used: 4-methyl-2piperidin-1-yl-pyrimidine-5-carboxylic acid, 2benzylamino-4-methyl-pyrimidine-5-carboxylic

acid, and 4-methyl-2-morpholin-4-pyrimidine-5carboxylic acid synthesized at the Department of Organic Chemistry of Voronezh State University.

\section{2-Substituted}

4-methylpyrimidine-5carboxylic acids [4-methylpyrimidine-5-carboxylic acids] are synthesized by condensation of the corresponding caboximidamides (1piperidinecarboxamide, benzylguanidine, and 4morpholinecarboximidamide) with ethyl ethoxymethyleneacetoacetate in boiling ethanol. Acid hydrolysis of ethyl esters 2-R-4-methyl-5pyrimidinecarboxylic acids obtained by this model to the desired 2-R-4-methylpyrimidine-5- carboxylic acids with a yield of $60-69 \%$ counting on the starting caboximidamides.

Prior to sowing, the seeds of Salvia splendens were soaked in a water suspension of 4-methyl-2-piperidin-1-yl-pyrimidine-5-carboxylic acid and 4-methyl-2-morpholin-4-pyrimidine-5carboxylic acid with concentrations of $0.01 \%$, $0.05 \%$, and $0.1 \%$ for 18 hours. The control group included the same type of seeds soaked in tap water. In the case of each of the studied concentrations of the acids, as well as the control group, the experiment was conducted three times using a set of 100 seeds. The seeds of Salvia splendens were sown in containers filled with a mixture of soil and sand (3 parts soil/ 1 part sand) and kept in a greenhouse at $20{ }^{\circ} \mathrm{C}$, as recommended in (Nikolaenko, 1971). On the 42nd day of the experiment, the seedlings, having been preliminarily hardened for 12 days, were removed from the greenhouse and planted on the field. The field experiment was designed according to B. A. Dospekhov (1985). The height of the seedlings was measured on the 42 nd day using a ruler. The results were statistically processed using the STADIA software package. The procedures of data grouping and processing were described by A. P. Kulaichev (2006). The mean values were compared using Student's ttest. The coefficient of variation (Cv) was counted, according to G. F. Lakin (1990). If CV was below $10 \%$, it meant that the degree of variation was low, with $\mathrm{Cv}$ between 10 and $25 \%$ it was medium, and when Cv was over $25 \%$ - the degree of variation was high (Lakin, 1990). To estimate the influence of various concentrations of the chemical compounds on the height of the plants, a one-way analysis of variance was used. The power of influence was calculated according to Snedecor (in \%).

\section{RESULTS AND DISCUSSION:}

When applied to Salvia splendens seeds, 4-methyl-2-piperidin-1-yl-pyrimidine-5-carboxylic acid at concentrations of $0.01,0.05$, and $0.1 \%$ demonstrated the inhibiting effect on the growth of plants. The same effect was observed for 4methyl-2-morpholin-4-pyrimidine-5-carboxylic acid at concentrations of 0.01 and $0.05 \%$. The height of the seedlings decreased by $30.4-43.7 \%$ in the former case and by 13.3-22.2 \% in the latter, as compared to the seedlings in the control group (Table 1).

\section{4-methyl-2-piperidin-1-yl-pyrimidine-5-car_}


boxylic acid inhibits the growth of the seedlings at all the studied concentrations $(0.01,0.05$, and $0.1 \%$ ), with the effect being more obvious when the concentration was $0.1 \%$. The height of the plants was $8.9 \pm 0.4 \mathrm{~cm}$ (at the concentration of $0.1 \%, \quad P<0.001$ ) and $11 \pm 0.5 \mathrm{~cm}$ (at the concentration of $0.01 \%, \mathrm{P}<0.001)$. The height of the plants in the control group was $15.8 \pm 0.6 \mathrm{~cm}$.

Earlier research studied the stimulating effect of $0.01-0.05 \%$ 4-methyl-2-piperidin-1-ylpyrimidine-5-carboxylic acid on the germination and growth of the seedlings of spreading marigold: with the concentration of $0.03-0.05 \%$, the height of the plants increased (differences with the control group are reliable, $P<0.001)$. However, other compounds of pyrimidine-5carboxylic acids at the studied concentrations demonstrated stronger stimulating effects (Vostrikova et al., 2012).

4-methyl-2-morpholin-4-pyrimidine-5carboxylic acid at concentrations of 0.01 and $0.05 \%$ inhibits the growth significantly. The mean height of the plants was $12.3 \pm 0.3$ and $13.7 \pm 0.4$ $\mathrm{cm}$, respectively (differences with the control group are reliable, $\mathrm{P}<0.001, \mathrm{P}<0.01)$. The height of the plants in the control group was $15.8 \pm 0.6$ $\mathrm{cm}$. $\quad 4$-methyl-2-morpholin-4-pyrimidine-5carboxylic acid at the concentration of $0.01 \%$ did not affect the growth of the plants. The parameter "height of the seedlings" in the control group and in the experimental group (treated with 4-methyl2-piperidin-1-yl-pyrimidine-5-carboxylic acid, excluding the $0.5 \%$ concentration) was characterized by the medium coefficient of variation (12.7-15.1\%), which indicates the high level of intravarietal variability. When the seeds of Salvia splendens were treated with 4-methyl-2morpholin-4-pyrimidine-5-carboxylic acid, the variability level was low, which is proved by low Cv (6.6-8.9 \%). This indicates that individual seedlings show similar reactions to the compounds used.

The effect of the treatment of seeds with the synthesized organic compounds on the height of the seedlings was evaluated using the one-way analysis of variance (Table 2). The rate of the decrease in the height of Salvia splendens seedlings (in \%) is shown in Table 1.

It was demonstrated that 4-methyl-2piperidin-1-yl-pyrimidine-5-carboxylic acid at concentrations of $0.01,0.05$, and $0.1 \%$ decreased the growth of the seedlings by $30.4-$ 43.7\%, and 4-methyl-2-morpholin-4-pyrimidine-5carboxylic acid at concentrations of 0.01 and $0.05 \%$ decreased the growth of the seedlings by
$13.3-22.2 \%$.

\section{CONCLUSIONS:}

The pre-sowing treatment of Salvia splendens seeds with 4-methyl-2-piperidin-1-ylpyrimidine-5-carboxylic acid at concentrations of $0.01,0.05$, and $0.1 \%$ proved to have an obvious inhibiting effect. The pre-sowing treatment of seeds with 4-methyl-2-morpholin-4-pyrimidine-5carboxylic acid proved to have the inhibiting effect at concentrations of 0.01 and $0.05 \%$. Thus, synthesized organic compounds of pyrimidinecarboxylic acids can lower the height of Salvia splendens seedlings by $13.3-43.7 \%$. It was revealed that 4-methyl-2-piperidin-1-ylpyrimidine-5-carboxylic acid at concentrations of $0.01,0.05$, and $0.1 \%$ decreased the growth of the seedlings by $30.4-43.7 \%$, and 4-methyl-2morpholin-4-pyrimidine-5-carboxylic acid at concentrations of 0.01 and $0.05 \%$ decreased the growth of the seedlings by $13.3-22.2 \%$. By the contrast, the effect of pyrimidinecarboxylic acids on seed germination and plant height of another annual flower - spreading marigold (Tagetes patula L.) was stimulating (Vostrikova et al., 2012). It was investigated some different concentrations from 0.01 to $0.05 \%$. The same concentrations of identical compounds were tested, but effects from them were opposite for Tagetes patula, and Salvia splendens seedlings. Consequently, the species-specific effect of pyrimidinecarboxylic acids on seed germination and plant height for ornamental grasses takes place. The genotoxicity of heterocyclic compounds has been tested previously, and they have been recognized as environmentally friendly. Therefore, the studied compounds at the said concentrations can be used for pre-sowing seed treatment as retardants which yield lowheight and compact ornamental forms of Salvia splendens plants.

The data discussed in the Results and Discussion showing the relevance of the work and how different it is from other researches. Also, point out the benefits and improvements that can be observed in order to develop new scientific standards that can change something in the related field.

\section{ACKNOWLEDGMENTS:}

The study received financial support from the Ministry of Science and Higher 
Education of the Russian Federation within the framework of State Contract With universities regarding scientific research in 2020-2022, project

No.

FZGU-2020-0044.

\section{REFERENCES:}

1. Abdel-Gawad, S. M., El-Gagy, M. S. A., Heiba, H. I., Aly, H. M., Ghorab, M. M. Synthesis and radiation stability of some new biologically active hydroquinoline and pyrimido[4,5-b]quinoline derivatives. $J$. Chin. Chem. Soc., 2005, 52, 1227-1236.

2. Brown, C. W., Liu, S., Klucik, J., Berlin, K. D., Brennan, P. J., Kaur, D., Benbrook, D. M. Novel heteroarotinoids as potential antagonists of Mycobacterium bovis BCG. Journal of Medicinal Chemistry, 2004, 47 (4), 1008-1017.

3. Butorina, A. K. Vostrikova, T. V., Shmyreva, J. V., Belchinskaya, L. I., Kondaurova, V. A. The effect of chemical stimulants on germination and cytogenetic indicators of seedlings of birch seeds hanging. Forestry, 2002, 5, 33-35.

4. Dlugosz, A., Dus, D. F. Synthesis and anticancer properties of pyrimido(4,5b)quinolines. Chem Inf Abstr., 1996, 51, 367-374.

5. Dospekhov, B. A. The methodology of field experience (with the basics of statistical processing of research results). 5th ed. add. and reslave. Textbook: benefits for high school. Moscow: Agropromizdat, 1985.

6. El-Sayed, O. A., Al-Bassam, B. A., Hussein, M. E. Synthesis of some novel quinoline-3-carboxylic acids and pyrimidoquinoline derivatives as potential antimicrobial agents. Archiv Pharmazie, 2002a, 335, 403-410.

7. El-Sayed, O. A., El-Bieh, F. M., El-Aqeel, S. I., Al-Bassam, B. A., Hussein, M. E. Novel 4-aminopyrimido[4,5-b]quinoline derivatives as potential antimicrobial agents. Bollettino Chimico Farmaceutico, 2002b, 141, 461-465.

8. El-Sayed, O. A., Al-Turki, T. M., Al-Daffiri, H. M., Al-Bassam, B. A., Hussein, M. E. Tetrazolo[1,5-a] quinoline derivatives as anti-inflammatory and antimicrobial agents. Bollettino Chimico Farmaceutico, 2004, 143, 227-238.
9. Kulaichev, A. P. Methods and tools for integrated data analysis. Moscow: FORUM: INFA-M, 2006.

10. Lakin, G. F. Biometry. Moscow: Higher School, 1990.

11. Marjani, A. P., Khalafy, J., Ebrahimlo, A. M. R. Facile Synthesis of Some New Pyrimidoquinolines. Synthetic Commun, 2011, 41 (16), 2475-2482. doi: 10.1080/00397911.2010.505701

12. Major retardants (chlorcholine chloride, alar, and ethephon). URL: http: // www.valleyflora.ru/53-1.html (Acceced 12.01.2017).

13. Nikolaenko, N. P. Handbook of the florist. Moscow: Kolos, 1971.

14. Ostroshenko, V. V., Ostroshenko, L. Yu. Influence of the seed pretreatment with growth stimulators on their sowing qualities. Bulletin of Krasnoyarsk State Agrarian University, 2011, 5, 12-15.

15. Sherer, V. A., Gadiev, R. Sh. Using growth regulators in vine growing and nursery gardens. Kiev: Urozhai, 1991.

16. Shujiang, T. U., Fang, F., Tuanjie, L., Songlei, Z., Xiaojing, Z. An efficient onepot synthesis of novel pyrimidoquinoline derivative under microwave irradiation without catalyst. J. Heterocycl. Chem., 2005, 42, 707-710.

17. Vasin, A. V., Darmin, A. V., Brezhnev, V. V. Using growth stimulators for corn and barley growing. Fodder Production, 2009, 2, 17-18.

18. Vasin, V. G., Darmin, A. V., Vasin, A. V. Effective use of growth stimulators for corn growing. Proceedings of Samara State Agrarian University, 2008, 4, 22-24.

19. Vostrikova, T. V., Kalaev, V. N., Potapov, A. Yu., Shikhaliev, H. S. The effect of new synthesized chemical compounds of a number of pyrimidine carboxylic acids on the growth activity of Tagetes patula $L$. Bulletin of Voronezh State University. Ser. Chemistry. Biology. Pharmacy, 2012, 2, 132-135.

20. Trivedi, A., Dodiya, D., Surani, J., Jarsania, S., Mathukiya, H., Ravat N., Shah, V. Facile one-pot synthesis and antimycobacterial evaluation of pyrazolo[3,4 d]pyrimidines. Archiv Pharmazie, 2008, 341, 435-439. 
Table 1. The height of Salvia splendens seedlings after the pre-sowing seed treatment with the studied synthesized organic compounds

\begin{tabular}{c|c|c|c|c}
\hline Concentration, \% & $\begin{array}{c}\text { The average } \\
\text { height of the } \\
\text { plants, cm }\end{array}$ & $\begin{array}{c}\text { Max - } \\
\text { min, cm }\end{array}$ & Cv, \% & $\begin{array}{c}\text { Increase in the } \\
\text { height of the } \\
\text { plants, \% }\end{array}$ \\
\hline Control group & $15.8 \pm 0.6$ & $14-20$ & 12.7 & - \\
\hline \multicolumn{5}{c}{ 4-methyl-2-piperidin-1-yl-pyrimidine-5-carboxylic acid } \\
\hline $0,01 \%$ & $11.0 \pm 0.5^{* * *}$ & $9-13$ & 13.6 & 30.4 \\
$0,1 \%$ & $10.0 \pm 0.9^{* * *}$ & $3-13$ & 28.0 & 36.7 \\
\hline \multicolumn{6}{c}{ 4-methyl-2-morpholin-4-pyrimidine-5-carboxylic acid } \\
\hline $0,01 \%$ & $8.9 \pm 0.4^{* * *}$ & $7-11$ & 13.5 & 43.7 \\
$0,05 \%$ & $12.3 \pm 0.3^{* * *}$ & $11-14$ & 8.9 & 22.2 \\
$0,1 \%$ & $13.7 \pm 0.4^{* *}$ & $12-15$ & 8.8 & 13.3 \\
\hline
\end{tabular}

Reference: $\mathrm{Cv}$ - variation coefficient

** - differences with the control group are reliable $(p<0.01)$;

$* * *$ differences with the control group are reliable $(p<0.001)$.

Table 2. The power of influence (in \%) of the retardant on the height of Salvia splendens on the 42nd day of the experiment

\begin{tabular}{c|c|c}
\hline retardant & $\begin{array}{c}\text { as compared to } \\
\text { the control } \\
\text { group }\end{array}$ & as is \\
\hline $\begin{array}{c}\text { 4-methyl-2-piperidin-1-yl- } \\
\text { pyrimidine-5-carboxylic acid } \\
\text { 4-methyl-2-morpholin-4- } \\
\text { pyrimidine-5-carboxylic acid }\end{array}$ & $6.0^{* * *}$ & - \\
\hline
\end{tabular}

Reference: ${ }^{* * *}$ - the influence of the factor is reliable $(p<0.001)$.

The SOUTHERN BRAZILIAN JOURNAL OF CHEMISTRY (ISSN: 2674-6891; 0104-5431) is an open-access journal since 1993. Journal DOI: 10.48141/SBJCHEM. http://www.sbjchem.com. This text was introduced in this file in 2021 for compliance reasons.

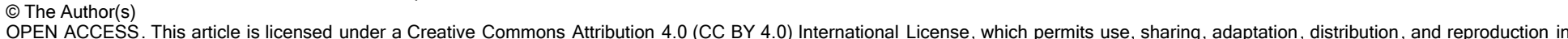

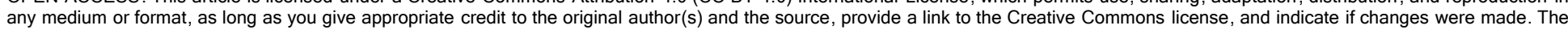

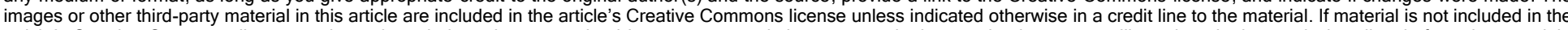

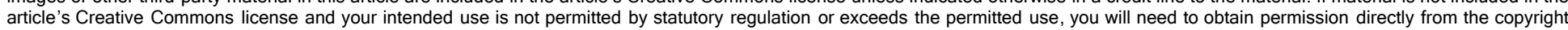
holder. To view a copy of this license, visit http://creativecommons.org/licenses/by/4.0/. 


\title{
SOUTHERN BRAZILIAN JOURNAL OF CHEMISTRY
}

\section{MISUSE AND ABUSE OF DRUGS: A CROSS-SECTIONAL SURVEY AMONG PHARMACY PROFESSIONALS IN SAUDI ARABIA}

\author{
ALSHAYBAN, Dhafer ${ }^{1}$; JOSEPH, Royes ${ }^{1 *}$; LUCCA, Jisha ${ }^{1}$; ALJISHI, Fatimah ${ }^{1} ;$ ALSADIQ, \\ Yara $^{2}$
} ${ }^{1}$ Department of Pharmacy Practice, College of Clinical Pharmacy, Imam Abdulrahman Bin Faisal University,
Dammam, Saudi Arabia

2PharmD student, College of Clinical Pharmacy, Imam Abdulrahman Bin Faisal University, Saudi Arabia

* Correspondence author

e-mail: rjchacko@iau.edu.sa

Received 19 March 2020; received in revised form 26 May 2020; accepted 23 June 2020

\begin{abstract}
Prescription and non-prescription medication misuse or abuse is a global problem that has a negative impact on all human life aspects, including health, social, economic, and security status. According to the United Nations Office on Drug and Crime reports, over $5 \%$ of adult people used drugs at least once in the year 2015, and 29.5 million of them were suffered from the consequences of inappropriate use of drugs. Information on the knowledge and perception among pharmacists regarding the misuse and abuse medications in Saudi Arabia are limited, and therefore, a study was conducted among pharmacy staff to assess their knowledge and awareness on drug misuse and abuse. A cross-sectional study was carried out in Eastern Province, Saudi Arabia. Pharmacy professionals with more than three months of experience were included in the study. A structured questionnaire was used to obtain the participant's responses. A Chi-square test was used to evaluate the association of sociodemographic factors with the participant's responses. Ninety pharmacy professionals were responded. Overall, $69(76.7 \%)$ participants agreed that misuse and abuse are two different terms. In addition, the study showed different responses for patients who suspected to be medication abusers. In conclusion, this study provides an initial picture of pharmacy staffs' knowledge and opinion regarding the misuse and abuse of medicines in Saudi Arabia. Participants' reactions toward such behaviors were different and not consistent. Therefore, there should be a clear policy to define the role of the pharmacy staff toward the misuse and abuse of medication in Saudi Arabia.
\end{abstract}

Keywords: Knowledge, Perception and Practice, misuse and abuse

\section{INTRODUCTION}

World Health Organization (WHO) defined the rational use of medications as where patients receive medications suitable to their clinical needs, in doses that are optimal for enough period, and at the lowest price. Inappropriate use of drugs can be classified into either misuse or abuse (World Health Organization (WHO), 2002). Drug misuse is defined as the use of medications in a way other than that is stated by a physician, while drug abuse is the use of a substance for a purpose not consistent with legal or medical guidelines (Sadia, 2015).

Although the terms 'abuse' and 'misuse' are interchangeably used when talking about illegal medications, the terms have to be differentiated when it comes to prescription or over-the-counter (OTC) medications (Sadia, 2015). The issue of misuse and abuse of medications has become a serious concern afflicting all countries, owing to the crucial dangers triggered to health, social, economic, and security (Ali, et al., 2011).

According to the United Nations Office on Drug and Crime reports, over $5 \%$ of adult people used drugs at least once in 2015, and 29.5 million of them were suffering from drug use disorders (United nations office on drugs and crime, 2017). The magnitude of the impairment triggered by drug use is underlined by the estimated 28 million years of "healthy" life lost worldwide in 2015 (United 
nations office on drugs and crime, 2017). There is a lack of data regarding the abuse of medications in Saudi Arabia. However, one study concluded that substance abuse could be a public health issue in Saudi Arabia, that was also linked to many psychiatric diseases (Bassiony, 2013).

Pharmacists are front-line health care providers, most accessible members of a health care team, the sentinel of the country's Schedule $X$ drugs, dispenser of addictions pharmacotherapy, and drug educator (Lafferty, et al., 2006). The American Society of HealthSystem Pharmacists (ASHP) clearly states, "ASHP believes that pharmacists have unique knowledge, skills, and responsibilities for assuming an important role in substance abuse prevention, education, and assistance" (American society of health-system pharmacist (ASHP), 2003). However, in Saudi Arabia, data pertaining to the knowledge and awareness of pharmacists and other pharmacy staff to problems related to drug abuse and misuse are limited. The aim of this study is to investigate the understanding of pharmacy professionals about the difference between words 'misuse and abuse' of medications, in addition to investigating pharmacists' belief about the misuse/abuse of medications in Saudi Arabia. We also evaluated the pharmacy staff's practice regarding dispensing medications to customers suspicious for misuse or abuse of the medications.

\section{MATERIALS AND METHODS}

\subsection{Study setting, recruitment and data collection}

A cross-sectional study was conducted from January-May 2017 among pharmacy professionals, working in different public sectors hospital and community pharmacies in Dammam and Al Khobar regions, Eastern Province, Saudi Arabia. A convenient sample of 13 pharmacies, including three hospital pharmacies and ten community pharmacies, in the region was selected. All pharmacy professionals, including pharmacists (having a bachelor's degree in pharmacy) and pharmacy technicians (not having a bachelor's degree in pharmacy) from the selected pharmacies, were considered for screening. Pharmacy professionals with less than three months of experience are most likely to be under training, and thus, they were not included in the study. Pharmacy professionals working in more than one pharmacy outside the sector were also excluded from the study. A study researcher visited the participated pharmacies and encouraged the participants to fill up a study questionnaire on the spot. Each pharmacy's director and the participants were briefed about the aim and the objectives of the study. A total of 100 pharmacy professionals agreed to participate in the study. Informed consent letters were obtained from the participants before completing the questionnaire. Participants were assured about the confidentiality of their personal information and response.

\subsection{Study instrument}

A questionnaire was developed through the review of literature and researches available in this field and was used to obtain participants' socio-demographic information and their response. The primary draft of the questionnaire was distributed to members of the research team for their feedback, and modifications were carried out as per the suggestions. Based on a pilot study, which was carried out on 20 pharmacists before the definitive study, some questions were modified. The questionnaire had three sections; the first section was about participants sociodemographic details. The second section was discussing pharmacy professionals' understanding of the difference between word misuse and abuse of medications and their belief about the misuse/abuse of medications in Saudi Arabia. The participants were also asked to list the name of commonly abused or misused drugs from their experience. The final section was about pharmacy professionals' practice regarding dispensing medications to customers suspicious for misuse or abuse of the medications.

\subsection{Ethical approval}

The study was approved by the Institutional Review Board of Imam Abdulrahman Bin Faisal University, Saudi Arabia (IRBUGS201805210).

\subsection{Data processing and analysis}

Participants'

socio-demographic

information and their response to the questionnaire items were presented using frequencies and percentages. Chi-square test was used to test the association of gender, age, place of work, nationality, and years of experience of pharmacy professionals with their responses. A 2tailed significance test was set at the 0.05 level for 
all analyses. All statistical analyses were performed using SPSS Statistics version 24.

\section{RESULTS AND DISCUSSION:}

\subsection{Results}

Among the 100 pharmacy professionals who agreed to participate, 90 had returned filled questionnaires. The refusal for participation was due to either pressure of time or administrative commitments. The socio-demographic characteristics of the participants were summarized in (Table 1). The sample was comprised of $61.1 \%$ males, $43.3 \%$ aged less than 30 years, $62.2 \%$ Saudi nationals, $72.2 \%$ with a bachelor's degree or more, $77.8 \%$ from hospital pharmacies, and $34.4 \%$ with more than ten years of experience.

Table 1. Socio-demographic characteristics of participants

\begin{tabular}{|c|c|c|}
\hline $\begin{array}{l}\text { Socio-demographic } \\
\text { variables }\end{array}$ & $\mathbf{N}$ & $\%$ \\
\hline \multicolumn{3}{|l|}{ Gender } \\
\hline Male & 55 & $61.1 \%$ \\
\hline Female & 35 & $38.9 \%$ \\
\hline \multicolumn{3}{|l|}{ Age } \\
\hline $20-30$ years & 39 & $43.3 \%$ \\
\hline $31-40$ years & 31 & $34.4 \%$ \\
\hline 41 years or older & 20 & $22.2 \%$ \\
\hline \multicolumn{3}{|l|}{ Nationality } \\
\hline Saudi & 56 & $62.2 \%$ \\
\hline Other & 34 & $37.8 \%$ \\
\hline \multicolumn{3}{|l|}{ Educational qualification } \\
\hline Pharmacy technicians* & 25 & $27.8 \%$ \\
\hline Bachelor's degree & 55 & $61.1 \%$ \\
\hline Master's degree or higher & 10 & $11.1 \%$ \\
\hline \multicolumn{3}{|l|}{ Graduated from } \\
\hline Saudi university & 46 & $51.7 \%$ \\
\hline Non-Saudi university & 43 & $48.3 \%$ \\
\hline \multicolumn{3}{|l|}{ Working place } \\
\hline Hospital pharmacy & 70 & $77.8 \%$ \\
\hline Community pharmacy & 20 & $22.2 \%$ \\
\hline \multicolumn{3}{|l|}{ Years of experience } \\
\hline $1-5$ years & 31 & $34.4 \%$ \\
\hline $6-10$ years & 28 & $31.1 \%$ \\
\hline $11-15$ years & 13 & $14.4 \%$ \\
\hline 16 years or more & 18 & $20.0 \%$ \\
\hline Overall & 90 & $100 \%$ \\
\hline
\end{tabular}

SOUTHERN BRAZILIAN JOURNAL OF CHEMISTRY.

ISSN 0104-5431. vol.28, $\mathrm{n}^{\circ} 28$. 2020. Downloaded from www.sbjchem.com

Established in 1993.
The participants were asked about their understanding of the difference between terms of misuse and abuse of medications (Figure 1). Overall, $69(76.7 \%)$ participants agreed that there is a difference between these terms. As shown in Figure 1, the agreement was less than $70 \%$ among pharmacy technicians or among those who aged less than 30 years; whereas the agreement was $80 \%$ or more among the participants aged more than 30 years, graduated from Saudi universities, having a bachelor's degree or more, or having 11-15 years of experience.

Importantly, $75.6 \%(n=68)$ think that both narcotics and non-narcotics medications are misused/abused in the country while remaining responded that either only narcotic medications $(12.2 \%)$ or only non-narcotic medications $(12.2 \%)$ are misused/abused.

Participants practices at pharmacies was also discussed, (Figure 2) and (Table 2) summarize practice at a pharmacy regarding dispensing medications to customers suspicious for misuse or abuse of the medications. The key finding is that three-quarter $(n=68)$ of participants claimed that they never dispensed medication to customers if misuse/abuse was suspected. Among the remaining 22 participants, nearly half of participants claimed that they had reacted to situations where misuse/abuse of medications was suspected before dispensed the medications. That is, in total, $87 \%$ of participants had reacted to customers suspicious for misuse or abuse of the medications. Importantly, 12 (13.3\%) participants accepted that they had failed to react before dispensing medications to suspicious customers. In details, the proportion of the non-reacted pharmacy professionals, a high percentage was reported among female (26\%), aged less than 40 years $(16 \%)$, Saudi nationals $(14 \%)$, pharmacy technicians $(36 \%)$, graduated from a Saudi university $(17 \%)$, working in a hospital pharmacy (14\%), and having experience $6-10$ years $(25 \%)$ (Table 2). Importantly, more females and pharmacy technicians tended to dispense medication without reacting to suspicious situations $(P<0.05)$. However, the study did not show a statistical association between other sociodemographic characters and this practice $(P$ $>0.05$ ).

Participants were also asked about the possible effective solution from their experience that can limit misuse/abuse of medications. Overall, $83.3 \% \quad(n=75)$ think that awareness programs to both pharmacy professionals and 
customers may limit the misuse/abuse of medications. In addition, implementation of punishment $(50.0 \%, n=45)$ and limit easy access to medications $(47.8 \%, n=43)$ were also effective solutions to control the misuse/abuse of medications from the pharmacist point of view.

\subsection{Discussion}

Pharmacists and pharmacy technicians in retail and hospital pharmacies are important stakeholders for the dispensing of medicines. Thus, they share equal responsibility for substance abuse/misuse detection and prevention (American society of health-system pharmacist, 2003). Being aware of this problem, having sufficient knowledge to identify medication abuse/misuse and playing a crucial role in educating individuals with substance abuse problems are important points that pharmacists should consider.

Previous studies revealed that pharmacists
receive scant information on substance abuse/misuse during their undergraduate courses, and few professionals from this area can be considered experts in the area of misuse or abuse (American society of health-system pharmacist, 2003; Tomko and Giannetti, 2013). However, study results showed that pharmacists' and pharmacy technicians' knowledge in this area was respectable; more than three-quarters of participants agreed that they are aware of the differences of abuse and misuse terminologies. Though it wasn't statistically significant. Young ages (20-30 years old) were unaware of the difference in the terminology compared to higher ages (more than 40 years) (33\% vs. $15 \%$ respectively). The possible reason for the increased understanding among higher ages might be due to the existence of well-established practice-based-knowledge. It is well documented that pharmacists will gain knowledge by focused training or more often gained through personal experience (Wagner, 2010). Similarly, a higher proportion of pharmacy staffs having fewer years of experience were also unaware of the difference in the terminology compared to those having higher years of experience. This could be due to the reasons that pharmacists in the country are periodically undergoing continuous medical education. Also, over the last few decades, an extensive change was observed in the medical education and medical services in the Arabian countries, and it has been reflected in medical research activities that pertains to substancerelated issues also (Jon, 2010). A substantial proportion of pharmacy technicians were unaware of the difference in terminology, possibly because of the lack of education and training offered to the technicians. Another reason could be due to the un-offered courses that could help in understanding the medication misuse during their study. Interestingly, high percentages of Saudi graduates were aware of the difference than those who graduated from non-Saudi universities.

National Institute of Health (NIH) reports that nearly one-fifth of people in the United States have used prescription medicines for non-medical reasons (Sweileh, et al., 2014). The issue is substantial in the Middle East, and it could be a matter for serious concern in Saudi Arabia (Khalifeh, et al., 2017; Sammon, 2017). With regards to our participants' knowledge about which type of medications can be abused or misused, a majority $(88 \%)$ of them stated that narcotics and/or non-narcotic medications could have the chance to be misused or abused. This finding is consistent with the results of a previously published study (Abood and Wazaify, 2016). More specifically, study participants enlisted the common substance that can be misused or abused, such as Pregabalin, Gabapentin, Benzodiazepines, Tricyclic Antidepressants, Tramadol, and other Analgesics, Trihexyphenidyl, Metformin, and Antibiotics. Similarly, over the counter medications like Mentex Syrup (Ammonium Chloride, Dextromethorphan, Diphenhydramine, Menthol, Pseudoephedrine, and Sodium Citrate) Lactulose Syrup, Bisacodyl, Solpadine (Paracetamol, ibuprofen, caffeine, and codeine), and Caffeine can be abused or misused. Some of the medications listed are consistent with a recent study that reported the top 10 medications that are used between 2010 and 2015 (AlKhamees, et al., 2018). Most of the study participants believe that misuse and abuse issues can have significant economic as well as clinical consequences. Globally, a total of $\$ 35$ billion spending is used to treat the drug users annually (AlKhamees, et al., 2018). A recent published study reported that analgesics abuse by adult patients in primary care settings is associated with around $\$ 53.4$ billion in costs every year (International Narcotics Control Board, 2014; Sheree, 2017).

Pharmacies have a critical role in preventing and protect patients from drug misuse or abuse problem (American society of healthsystem pharmacist, 2016). Pharmacists must use 
their professional judgment to screen patients for drug misuse or abuse, intentionally ignoring a dubious prescription, when there is a concern over its legitimacy, may not be ethical and acceptable (American society of health-system pharmacist, 2016). Pharmacists reaction towards customers' suspicious requests for medications were different based on gender. A quarter of female pharmacy staff, compared to $5 \%$ among male staffs, were reluctant to respond to the situation. The cultural, religious, and gender-specific differences in the country may have been influenced the attitude. Most of the male participants affirm that they would deny prescriptions if they had a serious concern about a prescription, and they would never dispense medication to a customer suspicious to be a misuser. More than one-third of pharmacy technicians claimed that they would not have the chance to face such a situation, and the reason might be the fact that they have limited access to talk directly to the patients when they come to the pharmacy.

Lack of responsibility, the dearth of effective communication between the health care providers and patient and their family, missing follow-ups with doctors, wrong information about the euphoric effects of drugs, multiple prescribers and lack of restriction of prescription of drugs by physicians were all possible reasons reported for abusing or misusing medications, which was consistent with the findings observed in a recently published study (Alshomrani, et al., 2017). A recently published report reveals that unemployment, lack of physical activity, selftreatment of depression, and simply boredom are also the reasons for drug abuse (Nazaraliev Medical Center, 2015). In addition to implementation of education programs and punishment, participants recommended different solutions such as restrictions in prescribing of medication based on the prescribers disciplines, increasing the price of the medication or including them in the insurance plan, restriction on quantity prescribed, implementing good unified electronic networking of records and tracking system of substance abusers, more involvement of health care providers including physicians and pharmacists in this sensitive issue. Moreover, according to American society of health-system pharmacist, pharmacists should be enrolled to limit substance abuse problems as this is their responsibilities as healthcare providers either by preventing, educating or assisting through performing different activities such as providing and participating in substance abuse prevention and assistance programs, initiating educational programs for patients, technicians, colleges, other healthcare providers, under graduated students and community. In addition, the referral of patients and their families to support groups, contributing to identifying patients who may suffer from substance abuse and providing optimum counseling sessions for those patients.

\subsubsection{Limitations}

The present study was done in Eastern Province, and thus results of the study could not be generalized to all the regions of Saudi Arabia. A similar study on the national level can give a clearer picture of whether medication abuse or misuse is a serious issue in Saudi Arabia or not. Other participants from different backgrounds should have been included in this study, such as physicians and nurses. Knowing the differences can give a clear picture of the level of the knowledge and awareness of pharmacists. Another research should be conducted in this regard and compare the differences in knowledge and awareness among health care providers in Saudi Arabia.

\section{CONCLUSIONS:}

This study provides an initial picture of pharmacists and other pharmacy staffs' knowledge and opinion regarding the misuse and abuse of medicines in Saudi Arabia. There is still a lack of knowledge among some participants about the differences between misuse and abuse of medications. Abuse and misuse can involve both OTC and prescription medications, and the participants' reactions toward such behavior were different and not consistent. Therefore, there should be a clear policy to define the role of the pharmacist toward the misuse and abuse of medication in Saudi Arabia.

\section{REFERENCES:}

1. Abood, E.A., Wazaify, M., Abuse and Misuse of Prescription and Nonprescription Drugs from Community Pharmacies in Aden City-Yemen. Subst Use Misuse, 2016, 51(7), 942-7.

2. Ali, S.F., Onaivi E.S., Dodd, P.R., et al., Understanding the Global Problem of Drug Addiction is a Challenge for IDARS 
Scientists. Curr Neuropharmacol, 2011, 9(1), 2-7.

3. AlKhamees, O.A., AINemer, K.A., Bin Maneea, M.W., et al., Top 10 most used drugs in the Kingdom of Saudi Arabia 2010-2015. Saudi Pharm J, 2018, 26(2), 211-6.

4. Alshomrani, A.T., Khoja, A.T., Alseraihah, S.F., et al., Drug use patterns and demographic correlations of residents of Saudi therapeutic communities for addiction. J Taibah Univ Sci, 2017, 12(4), 304-12.

5. American society of health-system pharmacist (ASHP), statement on the pharmacist's role in substance abuse prevention, education, and assistance. $\mathrm{Am}$ J Health Syst Pharm. 2003, 60(19),1995-8.

6. American society of health-system pharmacist (ASHP), Statement on the Pharmacist's Role in Substance Abuse Prevention, Education, and Assistance. Am J Health Syst Pharm. 2016, 73(9), e267-70.

7. Bassiony, M., Substance use disorders in Saudi Arabia: review article. Journal of Substance Use. 2013,18, 450-66.

8. Jon W., Is Pharmacy a Knowledge-Based Profession? Am J Pharm Educ, 2010, 74(3), 50.

9. Khalifeh, M.M., Moore, N.D., Salameh, P.R., Self-medication misuse in the Middle East: a systematic literature review. Pharmacol Res Perspect, 2017, 5(4).

10. Lafferty, L., Hunter, T.S., Marsh, W.A., Knowledge, attitudes and practices of pharmacists concerning prescription drug abuse. J Psychoactive Drugs. 2006, 38(3), 229-32.

11. Nazaraliev Medical Center. Why does the number of drug addicts grow in the Saudi Arabia: MCN Nazaraliev Medical Center; 2015 [Available from: https://nazaraliev.com/en/why-doesnumber-drug-addicts-grow-saudi-arabia. Acessed on 10 May 2019]

12. International Narcotics Control Board. Report of the International Narcotics Control Board for 2013. United Nations,
2014

[Available

from:

https://www.incb.org/documents/Publicati ons/AnnualReports/AR2013/English/AR_2 013_E.pdf. Acessed on 10 May 2019].

13. Sadia, S., Pharmacists' Knowledge, Attitudes and Beliefs Regarding Intervention for Prescription Medicines Abuse. 2015, 2, 1-6.

14. Sammon, P.J., Prescription Drug Misuse and Abuse: A National Health Crisis. J Okla Dent Assoc, 2017,108(1), 34-5.

15. Sheree, L., Provider based interventions to mitigate risk for opioid pain medication abuse among adult patients in a primary care setting. graduate school university of southern mississippi, 2017.

16. Sweileh, W.M., Zyoud, Se.H., Al-Jabi, S.W., Sawalha, A.F., Substance use disorders in Arab countries: research activity and bibliometric analysis. Subst Abuse Treat Prev Policy. 2014, 9(1), 33.

17. Tomko, J.R., Giannetti, V.J., Knowledge, attitudes, and professional practices versus personal beliefs of pharmacists regarding chemically dependent patients. MHC, 2013, 3(6), 302-8.

18. United nations office on drugs and crime. World drug report 2017. United Nations. 2017 [Available from: https://www.unodc.org/wdr2017/field/Book let_1_EXSUM.pdf. Acessed on 10 May 2019].

19. Wagner, G.A., Andrade, A.Gd., Pharmacist professionals in the prevention of drug abuse: updating roles, and opportunities, 2010, 46(1).

20. World Health Organisation. Promoting rational use of medicines: core components. WHO Policy Perspectives on Medicines. 2002. [Available from: http://archives.who.int/tbs/rational/h3011e. pdf. Acessed on 10 May 2019]. 


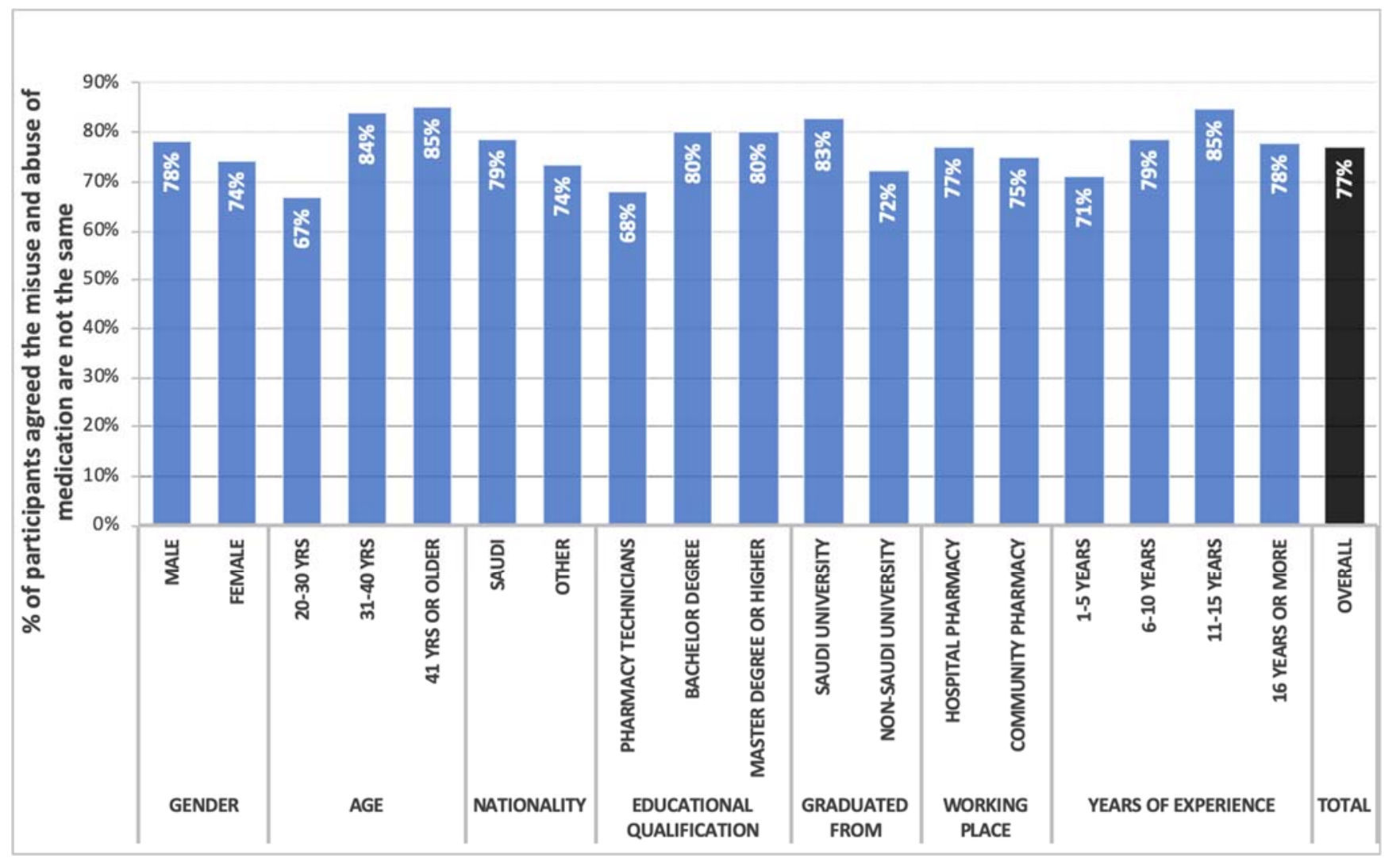

Figure 1. Pharmacy professionals' understanding of the difference between word misuse and abuse of medications.

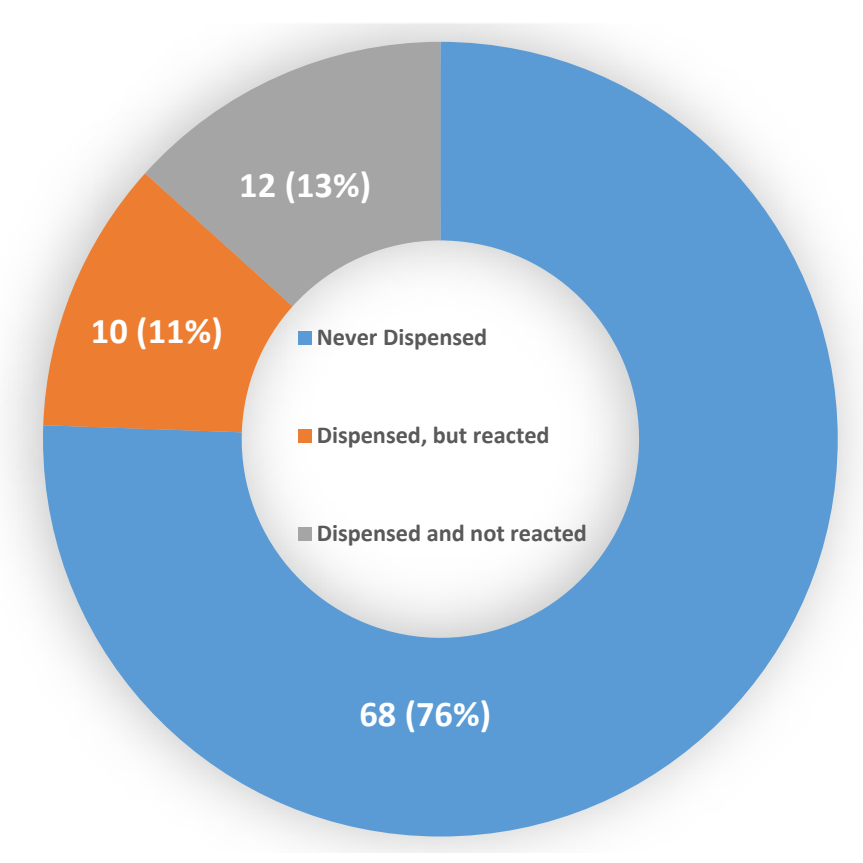

Figure 2. Pharmacy professionals' response to dispensing medications to customers suspicious for misuse or abuse of the medications. 
Table 2: Pharmacy professionals' practice on dispensing medications to customers suspicious for misuse or abuse of the medications.

\begin{tabular}{|c|c|c|c|c|}
\hline \multirow[t]{2}{*}{ Socio-demographic variables } & \multicolumn{4}{|c|}{$\begin{array}{l}\text { Practice on dispensing medication if } \\
\text { misuse/abuse was suspected }\end{array}$} \\
\hline & $\begin{array}{l}\text { Never } \\
\text { Dispensed } \\
(n=68)\end{array}$ & $\begin{array}{l}\text { Dispensed, } \\
\text { but } \\
\text { reacted } \\
(n=10)\end{array}$ & $\begin{array}{l}\text { Dispensed and } \\
\text { not reacted }{ }^{1} \\
(\mathbf{n = 1 2})\end{array}$ & P-value \\
\hline \multicolumn{5}{|l|}{ Gender } \\
\hline Male & $44(80 \%)$ & $8(15 \%)$ & $3(5 \%)$ & $0.02^{*}$ \\
\hline Female & $24(69 \%)$ & $2(6 \%)$ & $9(26 \%)$ & \\
\hline \multicolumn{5}{|l|}{ Age } \\
\hline 20-30 years & $31(80 \%)$ & $2(5 \%)$ & $6(15 \%)$ & 0.22 \\
\hline $31-40$ years & $23(74 \%)$ & $3(10 \%)$ & $5(16 \%)$ & \\
\hline 41 years or older & $14(70 \%)$ & $5(25 \%)$ & $1(5 \%)$ & \\
\hline \multicolumn{5}{|l|}{ Nationality } \\
\hline Saudi & $40(71 \%)$ & $8(14 \%)$ & $8(14 \%)$ & 0.44 \\
\hline Other & $28(82 \%)$ & $2(6 \%)$ & $4(12 \%)$ & \\
\hline \multicolumn{5}{|l|}{ Educational qualification } \\
\hline Pharmacy technicians ${ }^{2}$ & $13(52 \%)$ & $3(12 \%)$ & $9(36 \%)$ & $0.004^{*}$ \\
\hline Bachelor's degree & $46(84 \%)$ & $6(11 \%)$ & $3(5 \%)$ & \\
\hline Master's degree or higher & $9(90 \%)$ & $1(10 \%)$ & $0(0 \%)$ & \\
\hline \multicolumn{5}{|l|}{ Graduated from } \\
\hline Saudi university & $31(67 \%)$ & $7(15 \%)$ & $8(17 \%)$ & 0.21 \\
\hline Non-Saudi university & $36(84 \%)$ & $3(7 \%)$ & $4(9 \%)$ & \\
\hline \multicolumn{5}{|l|}{ Working place } \\
\hline Hospital pharmacy & $50(71 \%)$ & $10(14 \%)$ & $10(14 \%)$ & 0.18 \\
\hline Community pharmacy & $18(90 \%)$ & $0(0 \%)$ & $2(10 \%)$ & \\
\hline \multicolumn{5}{|l|}{ Years of experience } \\
\hline $1-5$ years & $25(81 \%)$ & $3(10 \%)$ & $3(10 \%)$ & 0.19 \\
\hline $6-10$ years & $20(71 \%)$ & $1(4 \%)$ & $7(25 \%)$ & \\
\hline $11-15$ years & $10(77 \%)$ & $3(23 \%)$ & $0(0 \%)$ & \\
\hline 16 years or more & $13(72 \%)$ & $3(17 \%)$ & $2(11 \%)$ & \\
\hline
\end{tabular}

"Based on Fisher's Exact Test; * statistically significant at 5\% level

${ }^{1}$ Reaction defined as either talking or expressing the issue to a concerned patient, doctor, or pharmacy director.

${ }^{2}$ not having bachelor's degree in pharmacy

The SOUTHERN BRAZILIAN JOURNAL OF CHEMISTRY (ISSN: 2674-6891; 0104-5431) is an open-access journal since 1993. Journal DOI: 10.48141/SBJCHEM. http://www.sbjchem.com. This text was introduced in this file in 2021 for compliance reasons.

(C) The Author(s)

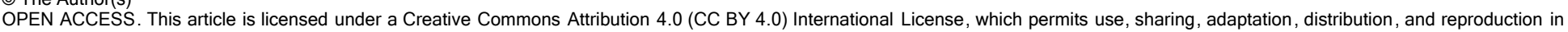

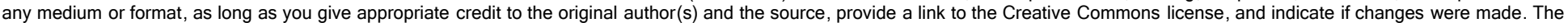

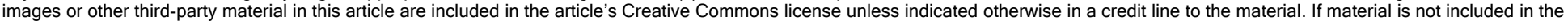

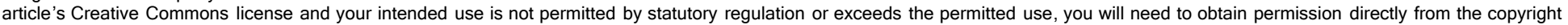
holder. To view a copy of this license, visit http://creativecommons.org/ licenses/by/4.0/. 


\title{
SOUTHERN BRAZILIAN JOURNAL OF CHEMISTRY
}

\section{CLINICAL AND LABORATORY TESTING OF A NEW MODIFICATION OF TWO-LAYER "SILEP" DENTURES USED IN PROSTHETIC DENTISTRY}

\author{
TIMOSHIN, Anton'; MITIN, Nikolay²; OLEYNIKOV, Alexander2; TIMOSHINA, Maria'; MITINA, \\ Evgeniya $^{2}$ \\ 1 I.M. Sechenov First Moscow State Medical University (Sechenov University) \\ ${ }^{2}$ Ryazan State Medical University named after academician I.P. Pavlov
}

\author{
* Correspondence author \\ e-mail: sbjchem@gmail.com
}

Received 13 March 2020; received in revised form 16 June 2020; accepted 23 June 2020

\begin{abstract}
Dentistry is a part of medicine, where various polymer materials were used for the first time. Many factors forced researchers to find more stable, versatile, and hygienic materials for the manufacture of dental products. It is important to note that the search for the ideal polymer dental material is still ongoing. This is because modern polymers, in some cases, do not meet the specified requirements for chemical, physical, strength, and elastic properties. Based on the data on the method of creating and using silicone material for the base of the removable prosthesis "Gossil", an improved silicone material for two-layer dentures "Silep" was developed, as well as a special primer for better connection of the lining with the rigid acrylic base of the prosthesis. To evaluate the most suitable compound, materials were tested for several parameters, such as tensile strength, elongation, and shore hardness. In addition to selecting a suitable material for modification, the selection and testing of an adhesive that allows the chemical bonding of the acrylate surface to the siloxane surface were carried out.
\end{abstract}

Keywords: GosSil, SilEP, polymeric material, prosthetic dentistry.

\section{INTRODUCTION}

Dentistry is a part of medicine, where various polymer materials were used for the first time. One of these materials was rubber, as the most convenient in terms of molding and elastic properties. However, this natural material had significant disadvantages in the form of porosity and chemical instability (Evstratenko et al., 2018; Mazzeo et al., 2013). These and many other factors forced researchers to find more stable, versatile, and hygienic materials for the manufacture of dental products. It is important to note that the search for the ideal polymer dental material is still ongoing.

This is because modern polymers, in some cases, do not meet the specified requirements for chemical, physical, strength, and elastic properties. The first artificial polymer materials appeared in the XIX century.
The chemical structure of acrylates consists of molecules of polymer compounds constructed from repeated links and connected by covalent bonds that form macromolecules (Voloshina et al., 2018; Silva et al., 2019). The chemical formula of acrylate can be represented by the example of methylacrylate (Figure 1) and methyl methacrylate (Figure 2).<smiles>C=CC(=O)OC</smiles>

Figure 1. The chemical formula of methyl acrylate 


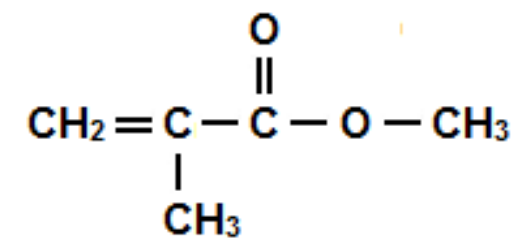

Figure 2. The chemical formula of methyl methacrylate

Currently, polymers are used for dental, orthopedic structures that are macromolecules with a molecular weight of several thousand to several million, consisting of two or more different components (Dukić et al., 2013; Vehkalahti et al., 1996).

The synthesis of polymers takes place using a polymerization or polycondensation reaction. The essence of this reaction is that molecules of low-molecular substances that are monomers by nature join the active centers of polymers that are high-molecular substances (Girardin et al., 2019; Timoshin et al., 2018, 2019). In the course of this reaction, the above-mentioned macromolecular links are formed, which differ in composition from the original monomers and are formed by their sequential "cross-linking" with the release of low-molecular-weight by-products (Sevbitov et al., 2018). An example of a polymerization reaction is a reaction from monomers that do not include an aromatic ring. For example, obtaining acrylic or methacrylic acids by polymerization (Figures $3 a$ and $3 b$ ).

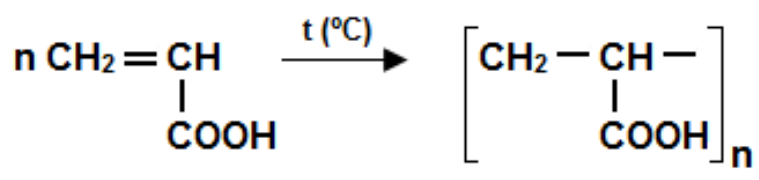

Acrylic acid

A)<smiles>C=C(C)C(=O)O</smiles>

Methacrylic acid B)

Poly(methacrylic acid)

Figure. 3. Polymerization of acrylic acid (A) and methacrylic acid (B)

Knowledge of the physical and chemical nature of polymer synthesis allows us to identify the positive and negative properties of materials- acrylates used to create acrylic dental plastics.

The positive properties include the existing high modulus of elasticity, which allows some dental polymer materials to have the ability to reverse deformations at a relatively low load, as well as a favorable factor for dental production and operation is the low brittleness of crystalline polymers, which allows dental plastic to withstand chewing load and physical and mechanical impact during processing and fitting (Kolodkina et al., 2018; Gozha et al., 2010).

Positive features of polymer solutions and their chemical nature provide high manipulative qualities in plastic molding and the ability to dramatically change their physical and mechanical properties when using catalysts and initiators (Zholudev et al., 2004, 2005) of the polymerization reaction, which speeds up and simplifies the process of manufacturing orthopedic structures.

Despite the high level of physical and chemical indicators that characterize the resistance of polymers to various destructive factors, for use in dentistry, in particular in dental and maxillofacial prosthetics using partially removable or full removable plate acrylic prostheses, the structure of polymers needs to be embedded in various components (Kasatkina, 2010; Kalyvradzhiyan et al., 2010). This is due to the fact the operation of the polymer prosthesis occurs under constant physical and mechanical stress in an aggressive, constantly changing chemical environment. The combination of these factors actively affects the structure and properties of polymers, causing the so-called "aging" of the prosthesis, in which there is a loss of the complex of useful properties of the product material (Lepilin et al., 2003).

Additional components embedded in the chemical composition of the polymer that improves its natural properties and slows down the process of operational wear include fillers, plasticizers, stabilizers, dyes, cross-agents, etc. (Nartikova et al., 1977; Paschina et al., 1968). The arrangement of additional substances with polymers allows us today to produce bioinert and technological dentures that meet high performance, quality, medical and technical characteristics, aesthetic and functional requirements.

However, despite the fact that modern manufacturing methods allow you to achieve highquality polymer prosthesis, they are not ideal, and the positive properties have a number of disadvantages. Primary negative qualities of 
dental polymers occur already during the polymerization reaction and are characterized by a part of the original monomer that is not embedded in the polymer molecules, which determines the degree of biocompatibility of the material and affects the allergization factors when using a polymer prosthesis (Kuznetsova et al., 2018; Platonova et al., 2018). Another physical and chemical disadvantage of polymers is their water absorption. it can be assumed that this process is associated with the uncompensated polarity of the dipole links of the polymer, which characterizes their hydrophilic properties (Sevbitov et al., 1999; 2004).

From a physical point of view, this property of affinity for water molecules is more obvious because the free hypothetical space in the polymer structure is saturated with water during a prolonged stay in a humid environment (Mamedov et al., 2019; Yumashev et al., 2019). This effect of water absorption adversely affects the geometry of the polymer prosthesis base, as well as its optical and mechanical parameters. To the changes in optical properties, we can also add that in addition to saturation with water, the porous micro-surface of the polymer is able to accumulate molecules of various substances, including those that are dyed by their chemical nature, which leads to a deterioration in the aesthetic properties of the polymer orthopedic product. In addition to physical and chemical changes within the polymer structure, polymer prostheses themselves are a factor of influence, in particular on the surrounding tissue natural formations of the prosthetic bed, which is subjected to mechanical pressure due to a much higher modulus of polymer hardness than that of the oral mucosa.

Long-term use of a removable prosthesis leads to a number of changes in trophic processes, physiology, and microcirculation of the soft tissues of the mucous membrane, as well as the underlying bone tissue of the jaw (Saxena et al., 2019; Rech-Ortega et al., 2019).

The rigidity of the polymeric denture base has a significant impact on the usability of this orthopedic designs, so, if you have to thin of the mucous membrane in the oral cavity, natural and abnormal bony prominences in the area of prosthetic bed dental patients do not have the ability to comfortable use of the prosthesis, are faced with painful sensations and also the difficult phase of adaptation to the prosthesis.

These disadvantages of removable polymer prostheses, in particular those made of acrylates, were a prerequisite for the use of other polymer compounds that can be used in medicine. The leading factor in the medical scientific and technical search for a suitable material is obtaining the safest, technologically accessible, acceptable material in the manufacture and operation, from which it is possible to create an anatomical orthopedic structure that meets the physiological requirements as much as possible.

It is important to understand that synthetic polymer compounds that do not contain carbon atoms in the main chain are inherently inorganic and foreign to the body (Utyuzh et al., 2019; Mironov et al., 2020). In this regard, when creating dental products made of polymers, it is necessary to observe all the maximum possible technological conditions and physiological restrictions that allow full and effective use of plastic prostheses in the treatment of dental patients without harming them.

Acrylic polymer prostheses containing in their chemical composition acrylic resin, which is a derivative of the product of polymerization of acrylic and methacrylic acids (Enina et al., 2019; Turgaeva et al., 2020), have various restrictions on use. First of all, they are due to the extreme rigidity of this material, which exerts mechanical pressure on the soft tissues of the oral cavity, also included in the composition of acrylate acids, esters and their derivatives with the content of a lowmolecular compound (monomer) that is not embedded in the structure can cause an allergic reaction or be intolerant for the patient. An alternative to this group of polymers can serve as other synthetic materials-elastomers, such as silicones, copolymers of polychlorinated vinyl and butylacrylate, nylons, polyoxymethylenes, polypropylene, ethylene-vinyl acetate (Sevbitov et al., 2005; Ergesheva et al., 2018).

These materials are mostly elastic plastics, and this is not provided by the acrylic base of their chemical composition. During prosthetics, orthopedic prostheses made entirely of elastomers, thermoplastic masses, or acrylic prostheses created in combination with elasticplastic, for example, an acrylic prosthesis with a rubber or polymethylmethacrylate, plasticized with salicylic acid, are the most common (Sevbitov et al., 2018; 2019).

However, early developments on creating two-layer acrylic removable prostheses with lining materials were not widely used in practice. For example, rubber linings in the base of the prosthesis due to the porosity of their structure had a high level of water absorption, quickly polluted, and had low adhesion to acrylates. Polymethylmethacrylates, which are close to them 
in chemical nature, had a stronger bond with acrylates, but the content of a low-molecular plasticizer in their composition was actively subjected to washing out, which caused the porosity of the lining, which made the latter hard (Sevbitov et al., 2018; 2019; 2020).

Various other materials, such as PVC, silicone, and others, were used to create linings, but most of these elastomers did not meet the necessary requirements for strength and adhesion to the acrylic base of the prosthesis (Sevbitov et al., 2019; 2020).

The decrease in adhesion, as the most common lack of linings, is due to the fact that the surfaces of the two materials are uneven at the atomic level, and if they come into contact with each other during loading, the contacts will appear only in the places of the largest protrusion, which will lead to frictional wear of the material. Thus, only the densest intermolecular contact of materials of different phases can cause optimal adhesion.

As an alternative to the two-layer bases of removable polymer prostheses, prostheses made of thermoplastic masses can be used. The creation of this material involves the use of biologically neutral thermoplastics with a crystalline linear or branched structure. the characteristic difference from inorganic polymers is that this group of materials does not have a three-dimensional cross-linked structure and contains tertiary carbon atoms (Sevbitov et al., 2018; 2019, 2020).

Another important difference is the ability of the thermoplastic to reversibly transition to a highly elastic or viscous state when the temperature increases, which favorably affects the plasticity and shape change of the material in accordance with the anatomy of the prosthetic bed when using thermoplastic removable prostheses.

The competitive advantage of this material over acrylates is the absence of a monomer, which eliminates the toxic effect on the body and allows the use of thermoplastic prostheses in patients with hyper sensibilization or allergic reactions. This group of materials includes nylon, polypropylene, polyurethane, and others. thus, removable prostheses made of nylon have high flexibility, allow you to optimize the load on the soft tissues of the prosthetic bed, and are more durable in comparison with acrylic polymer prostheses (Sevbitov et al., 2018; 2019, 2020).

However, this group of materials for the manufacture of dental, orthopedic products has its own disadvantages, for example, the rapid occurrence of micro-scratches, where a plaque is formed when coloring products are ingested, which reduces the aesthetic appearance of the prosthesis. A more important adverse factor, in this case, is the higher contamination of the microrough surface of the prosthesis by microorganisms, which potentially reduces the level of oral hygiene, complicates hygienic measures for cleaning the prosthesis, and creates prerequisites for the development of infectious agents.

Another negative technological property of thermoplastics is the lack of chemical compatibility with acrylic polymer materials. This is reflected in the increased probability of breaking off artificial teeth of the prosthesis, made mainly from acrylic plastics. But, despite these disadvantages, the creation of prostheses made of thermoplastic materials is an actual and promising direction in the development of dental, orthopedic removable prosthetics, which is confirmed by the works of a number of authors of modern research in this area, and indicates that the positive qualities of polymer materials made of thermoplastic offset the negative ones (Sevbitov et al., 2018; 2019, 2020).

In addition to polymer materials for the manufacture of solid bases of orthopedic removable prostheses that do not carry acrylate molecular substances in their structure, the development of the direction of combining acrylate or other materials with materials for linings is also continuing. So, in the last decade, prostheses with pads made of various modern materials have been introduced into clinical practice. Polymer elastic plastics and silicones are used as such linings.

One of the promising developments is the use of silicone material for elastic linings "GosSil". This material is based on monolithic silicon, which in its chemical structure, is an oxygen-containing high-molecular-weight organosilicon compound. The synthesis of this compound is carried out by standard methods of polymer chemistry, including the polymerization reaction. The issue of adhesion to acrylates in this material is resolved by adding a special adhesive that can be chemically bonded to both components in a two-phase connection.

According to the results of the author's research, this material is acceptable and effective in use in combination with the polymer acrylic base of a removable orthopedic prosthesis, since silicone polymers are chemically stable substances and do not undergo destruction in their molecular structure when exposed to a humid environment. The presence of a soft silicone pad 
in the prosthesis provides a more reliable fixation of the prosthesis in the oral cavity, precisely corresponds to the anatomical structures, and significantly reduces the pain sensitivity of areas with developed bone formations.

All these indicators may indicate an improvement in the quality of life of patients using this two-phase combination of dental, orthopedic polymer materials.

\section{MATERIALS AND METHODS}

Based on the above advantages of the silicone lining technology in a removable acrylate orthopedic prosthesis, we give an example of manufacturing and using a soft silicone rubber lining combined with an acrylate prosthesis.

Based on the data on the method of creating and using silicone material for the base of the removable prosthesis "GosSil", an improved silicone material for two-layer dentures "SilEP" was developed, as well as a special primer for better connection of the lining with the rigid acrylic base of the prosthesis.

The essence of this material for creating a lining is that it is created from high-elasticity silicone rubber and is chemically inert. The chemical composition of this polymer is characterized by the fact that it is obtained from organic substances containing silicon, by its nature it is a high-molecular substance: silicone rubber combines the structure of carbon and silicon high-molecular compounds. The chemical formula of this compound is presented below:

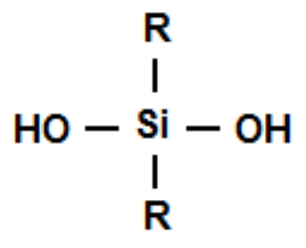

Figure 4. Structure of carbon and silicon

where $\mathrm{R}$ - is hydrocarbon radicals, for example $\mathrm{CH}_{3}$, $-\mathrm{C}_{2} \mathrm{H}_{5}$. The synthesis of this substance occurs through a polycondensation reaction, and this reaction is shown in Figure 5.

Thus, from a chemical point of view, this polymer is a compound of a linear structure that can combine the property of elasticity with heat resistance, which has found application in clinical practice when creating a lining for a removable denture. From the point of view of the practical application of this material in an environment with constant mechanical and physical stress, as well as under the action of various chemically aggressive substances, silicone rubber, which is the main component of the material for the elastic lining of "SilEP", provides acceptable results for long-term use in combination with an acrylate denture.

The physical and chemical characteristics of silicone rubber allow us to predict its qualitative state during operation. The most significant characteristics of the material, when used in dentistry, are presented in Table 1.

For the visual application of these values for practical use, you can compare the characteristics of silicone rubber with the characteristics of rubber, which was also used for linings for the basis of a removable prosthesis. The most significant characteristics of the rubber material, when used in dentistry, are presented in Table 2.

Based on these characteristics, we can conclude that the rubber is superior in some respects to those found in silicone rubber, but the most critical indicators for operation in the oral cavity, indicated earlier in the list of disadvantages of pads for the basis of the prosthesis, such as water resistance and tear resistance, are higher in silicones. Thus, silicone rubber, used as a lining for the basis of an orthopedic prosthetic product, is a more suitable polymer material from a practical point of view.

In addition to selecting a suitable polymer material, the necessary criterion for the quality of its use is the selection of the optimal adhesive technology and filler, which allow for reliable "bonding" in the two-phase connection of the surface of the acrylate with the surface of siloxane (silicone). To solve this problem, the filler was chemically modified in the "GosSil" material by treating the surface of the Aerosil with substances that can chemically interact with reactive groups on the surface of the filler. When developing a modification to improve the strength characteristics of a two-phase connection, the creators of the "SilEP" material selected several different compounds:
1. Amyltrichlorosilane
$\mathrm{CH}_{3}(\mathrm{CH})_{4} \mathrm{Si}\left(\mathrm{OC}_{2} \mathrm{H}_{5}\right)(\mathrm{APEC})$
2. Chloropropyltrimethoxysilane
$\mathrm{Cl}\left(\mathrm{CH}_{2}\right)_{3} \mathrm{Si}\left(\mathrm{OCH}_{3}\right)_{3}(\mathrm{HPTMS})$ 
3. Vinyltriethoxysilane

$\mathrm{CH}_{2}=\mathrm{CHSi}\left(\mathrm{OC}_{2} \mathrm{H}_{5}\right)_{3}$ (VTES)

4. Dimethyldimethoxysilane

$\left(\mathrm{CH}_{3}\right)_{2} \mathrm{Si}\left(\mathrm{OCH}_{3}\right)_{2}$ (DMLS)

To evaluate the most suitable compound, materials were tested for several parameters, such as tensile strength, elongation, and shore hardness. The test results obtained are shown in table 3 . In addition to selecting a suitable material for modification, the selection and testing of an adhesive that allows the chemical bonding of the acrylate surface to the siloxane surface were carried out. The following compounds were studied as adhesives:

\section{Tetrabutoxide (TBT)}

2. Tetraethoxysilane (TEOS)

3. y-aminopropyltriethoxysilane (as)

4. Vinyltriethoxysilane (VTES)

5. y-glycidoxypropyltrimethoxysilane (GTS)

6. The product of the interaction of vinyltriethoxysilane with 1.6 hexamethylene diisocyanate (VHC).

The test evaluated the bond strength of the materials during peeling. The data obtained are presented in the "Results and discussions" in Table 5.

\section{RESULTS AND DISCUSSION}

The greatest effect in improving the strength characteristics of the resulting vulcanizates is achieved when using vinyltriethoxysilane as a modifier. Based on the research, the authors developed a composition based on siloxane rubber to produce vulcanizates with low hardness and high physical and mechanical properties (utility model patent No. 71249 of 13.06.2007). Thus, the results obtained indicate a high level of strength of the two-phase connection of materials when using vinyl triethoxysilane in the "SilEP" material, which is superior to the "GosSil" material in these indicators. The comparative characteristics of "SilEP" and "GosSil" for these indicators are presented in table 4 below.

Based on the data in table 4, you should pay attention to the index of resistance to tearing, which is significantly higher in the material "SilEP" in comparison with the material "GosSil". As it was established earlier, siloxanes themselves have a fairly high level of this indicator in comparison with rubber, and the use of a modifier allows you to increase the level of this characteristic almost 4 times in conjunction with a material of another physical and chemical phase, which potentially improves the strength properties of the product created using this technology.

Based on the table 5 data, it is noted that the use of an adhesive (primer) can significantly increase the adhesion of the silicone lining to the acrylate base. In this case, the most effective product in this combination was the interaction of vinyltriethoxysilane with 1,6-hexamethylene diisocyanate. From the point of view of chemical analysis, the obtained high strength of the compound is provided by the presence in $\mathrm{VHC}$ of active functional groups that interact with unreacted active groups in the siloxane polymer, the functional groups on the surface of the acrylate react in the same way. It was found that this combination of a primer to improve the connection of the silicone lining "SilEP" with acrylate allows for a 14-fold increase in the degree of adhesion to the base of the denture.

\section{CONCLUSIONS}

Thus, based on the above review, can conclude that all methods of using polymer compounds in orthopedic dentistry are still relevant, and the development of modern technologies and approaches to dental materials allows us to successfully combine traditional methods of using acrylate polymers with other newer polymers for successful orthopedic treatment.

The most relevant and promising methods are the use of advanced silicone material for twolayer dentures "Silep" as a lining for the acrylic base of the prosthesis, as well as a special primer of vinyltriethoxysilane in combination with 1,6 hexamethylene diisocyanate for better connection of the silicone lining with a rigid acrylic base of the prosthesis.

This composition allows to increase the degree of adhesion to the basis of the denture by 14 times, thereby extending the service life and increasing the comfort of using the denture. 


\section{ACKNOWLEDGMENTS:}

This work was done at Sechenov University with supported by the "Russian Academic Excellence Project 5-100".

\section{REFERENCES}

1. Evstratenko, V., Sevbitov, A., Platonova, V., Selifanova, E., Dorofeev, A. The characteristics of crystallization of mixed saliva in patients using heroin and methadone. Klin. Lab. Diagn, 2018, 63(4), 223.

2. Mazzeo, M., Linares, J., López, M. Analysis of saliva samples from oncological patients treated with 5fluorouracil and leucovorin calcium by scanning electron microscopy with energy dispersive system. J. Oral Pathol. Med, 2013, 42(10), 788.

3. Voloshina, I., Borisov, V., Sevbitov, A., Davidiants, A., Mironov, S., Kuznetsova, M., Ergesheva, E. Distinctive features of microcrystallization of mixed saliva in children with different levels of activity of carious process. Asian J. Pharm, 2018, 12(3), S1017.

4. Silva, P., Santos, B., Soares, G. AntiCandida albicans activity of the association of citronelal with anfotericin B or with cetoconazole. Periodico Tche Química, 2019, 16(31), 223.

5. Dukić, W., Dobrijević, T., Katunarić, M. Caries prevalence in chronic alcoholics and the relationship to salivary flow rate and $\mathrm{pH}$. Cent. Eur. J. Public Health, 2013, 21(1), 43.

6. Vehkalahti, M., Nikula-Sarakorpi, E., Paunio, I. Evaluation of salivary tests and dental status in the prediction of caries increment in caries-susceptible teenagers. Caries Res, 1996, 30(1), 22.

7. Girardin, F., Hearmon, N., Negro, F. Increasing hepatitis $C$ virus screening in people who inject drugs in Switzerland using rapid antibody saliva and dried blood spot testing: A cost-effectiveness analysis. J. Viral Hepat, 2019, 26(2), 236.

8. Timoshin, A., Sevbitov, A., Ergesheva, E., Mironov, S., Kozhemov, S., Pustokhina, I., Danshina, S. Experience in the use of collagen phytoplates in the treatment of gingivitis. Opcion, 2019, 35(21), 582.

9. Timoshin, A., Sevbitov, A., Drobot, G., Yumashev, A., Timoshina, M. Use of bioresorbable plates on the basis of collagen and digestase for treatment of diseases of oral mucosa (review of clinical cases). Int. J. Green Pharm, 2018, 12(1), 290.

10. Sevbitov, A., Dorofeev, A., Davidiants, A., Ershov, K., Timoshin, A. Assessment of pain perception of elderly patients with different levels of dentophobia during surgical dental appointment. Asian J. Pharm, 2018, 12(3), S1012.

11. Timoshin, A., Sevbitov, A., Ergesheva, E., Boichuk, A., Sevbitova, M. Experience of treatment of aphthous lesions of oral mucosa by preparations on the basis of collagen and digestase. Asian J. Pharm, 2018, 12(1), 284.

12. Kolodkina, V., Arutyunov, A., Sirak, S., Andriutsa, N., Tsymbalov, O. Cytological characteristics of oral cavity tissues of experimental animals when using photo polymeric material. Med. News North Cauc, 2018, 13(4), 637.

13. Gozha, L., Talalai, T., Arunov, T. Functional disorders of saliva in toxicchemical stomatitis caused by metal prostheses. Dentistry for all, 2010, 3, 53 .

14. Zholudev, S., Zhmakin, I. Treatment and prevention of prosthetic stomatitis in persons older than 55 years, that use removable plate prostheses. Dentist, 2004, 9, 21.

15. Zholudev, S. Ways to improve the adaptation in people with problems of tolerability of removable denture materials. Maes. Dent, 2005, 19, 5.

16. Kasatkina, E. lodine deficiency diseases in children and adolescents. Eligible Doctor, 2010, 10, 14

17. Kalyvradzhiyan, E., Podoprigora, A., Komarova, Yu. Clinical and experimental substantiation of the use of modified adhesive composition based on polysaccharides to improve the period of adaptation to removable denture plate prosthesis. Modern Orthop. Dentistry, 2010, 13, 31.

18. Lepilin, A., Rubin, V., Proshin, N. The effect of removable plate prostheses made of acrylic plastics on the structural and functional properties of the cellular membranes of the oral mucosa. Stomatology, 2003, 1, 51.

19. Nartikova, V., Oglobina, O. Modern methods in biochemistry, M. 1977.

20. Paschina, T., Egorova, G. Modern methods in biochemistry, M. 1968. 
21. Kuznetsova, M., Nevdakh, A., Platonova, V., Sevbitov, A., Dorofeev, A. Evaluation of effectiveness of a preparation on the basis of phytoecdysteroids for treatment of traumatic injuries of oral mucosa in orthodontic patients. Int. J. Green Pharm, 2018, 12(S1), 297.

22. Platonova, V., Sevbitov, A., Shakaryants, A., Dorofeev, A. Experimental and clinical justification for the treatment of patients with odontogenic phlegmon of the maxillofacial region using dalargin in the complex therapy. Clin. lab. diagn, 2018, 63(5), 293.

23. Sevbitov, A., Persin, L., Slabkobskaia, A., Pankratova, N. The morphological status of the maxillodental system in children living in an area contaminated by radionuclides as a result of the accident at the chernobyl atomic electric power station. Stomatologiya, 1999, 78(6), 41.

24. Sevbitov, A. V. Remote effects of the Chernobyl accident: evaluation of the maxillodental status of the children. Stomatologiya, 2004, 83(1), 44.

25. Mamedov, A., Morozova, N., Yumashev, A., Dybov, A., Nikolenko, D. Criteria for provisional restorations used in preparation for comprehensive orthodontic and orthopedic rehabilitation. Periodico Tche Quimica, 2019, 16(32), 647.

26. Yumashev, A., Semenycheva, I., Rakhadilov, B. Development of biocompatible coatings for dental implants based on transition metal nitrides. $J$. Global Pharma Technol, 2019, 11(5), 22.

27. Yumashev, A., Koneva, E., Borodina, M. Electronic apps in assessing risk and monitoring of patients with arterial hypertension. Prensa Medica Argentina, 2019, 105(4), 235.

28. Saxena, N., Habelitz, S., Marshall, G. Remineralization of demineralized dentin using a dual analog system. Orthodon. Craniofac. Res, 2019, 22(S1), 76.

29. Rech-Ortega, C., Fernández-Estevan, L., Solá-Ruíz, M. Comparative in vitro study of the accuracy of impression techniques for dental implants: Direct technique with an elastomeric impression material versus intraoral scanner. Med. Oral Patol. Oral Cir. Bucal, 2019, 24(1), 89.

30. Utyuzh, A., Nikolenko, D., Yumashev, A., Volchkova, I., Samusenkov, V. Adhesion of periodontal pathogens to materials used for long-term temporary crowns. Periodico Tche Quimica, 2019, 16(33), 60.
31. Sevbitov, A., Kuznetsova, M., Dorofeev, A., Borisov, V., Mironov, S., lusupova, I. Dental anomalies in people living in radionuclide-contaminated regions. $J$. Environ. Radioact, 2020, 216, 106190.

32. Sevbitov, A., Davidyants, A., Kuznetsova, M., Dorofeev, A., Mironov, S. Analysis of electronic microscopy results based on combining the infiltration method with different restoration technologies and in vitro investigation of enamel focal demineralization treatment at the defect stage. Periodico Tche Quimica, 2019, 16(33), 53.

33. Sevbitov, A., Brago, A., Enina, Y., Dorofeev, A., Mironov, S. Experience in the application of hybrid ceramic restorations in the cervical region. Asian J. Pharm, 2018, 12(3), S1106.

34. Sevbitov, A., Dorofeev, A., Kuznetsova, M., Timoshin, A., Ershov, K. Comparative characteristics of the crystallogram of the oral fluid in patients who use heroin and methadone. Periodico Tche Quimica, 2019, 16(33), 94.

35. Sevbitov, A., Timoshin, A., Dorofeev, A., Davidyants, A., Ershov, K., Kuznetsova, M. Comparative characteristics of the state of hard dental tissues in drug-dependent patients who use heroin, and methadone as replacement therapy. Periodico Tche Quimica, 2020, 17(34), 135.

36. Sevbitov, A., Ergesheva, E., Sirak, S., Enina, Yu., Mallkov, S., Kuznetsova, M. Clinical and laboratory analysis of the efficiency of hirudotherapy in complex treatment of endodontal diseases. J. Global Pharma Technol, 2020, 12(1), 253.

37. Mironov, S., Emelina, E., Troitskii, V., Yablokova, N., Kuznetsov, I. The Impact of Smoking, Including Hookah, on the Human Body. J. Global Pharma Technol, 2020, 12(1), 211.

38. Enina, Yu., Sevbitov, A., Dorofeev, A., \& Pustokhina, I. Experimental substantiation of the choice of the restoration method in the cervical area of teeth with abfraction defects. Int. J. Mechan. Eng. Technol, 2019, 10(5), 41.

39. Sevbitov, A., Mitin, N., Kuznetsova, M., Dorofeev, A., Ershov, K. A new modification of the dental prosthesis in the postoperative restoration of chewing function. Opcion, 2020, 36(S26), 864.

40. Sevbitov, A., Zhadko, S., Dorofeev, A., Ershov, K., Enina, Yu., Pustokhina, I. Rationale for the preservation of vital pulp 
in the use of fixed dentures in the experiment. Opcion, 2020, 36(S26), 953.

41. Sevbitov, A., Danshina, S., Platonova, V., Usatova, G., Borisov, V., Kuznetsova, M. Icon as a method of choice for injectable treatment of initial caries in patients with fibrodysplasia ossificans progressive: a clinical case. J. Global Pharma Technol, 2020, 12(2), 270.

42. Sevbitov, A., Ershov, K., Dorofeev, A., Borisov, V., Mironov, S., Enina, Yu. Analysis of the quality of life of elderly patients with removable orthopedic constructions during rehabilitation. Prensa Medica Argentina, 2020, 106(4), 226.

43. Turgaeva, A., Kashirskaya, L., Zurnadzhyants, Yu., Latysheva, O., Pustokhina, I., Sevbitov, A. Assessment of the financial security of insurance companies in the organization of internal control. Ent. Sust Issues, 2020, 7(3), 2243.

44. Sevbitov, A., Emelina, G., Kuznetsova, M., Dorofeev, A., Emelina, E. A study of the prevalence of non-carious dental lesions related to production factors in residents of the city of penza. Georgian Med News, 2019, 295, 42.

45. Sevbitov, A., Borisov, V., Davidyants, A., Timoshin, A., Ershov, K., Enina, Yu., Pustokhina, I. Prevention of injuries of the maxillofacial area in contact sports using sports caps. Indo Am. J. Pharm. Sci, 2018, 5(11), 12322.

46. 46. Sevbitov, A., Enina, Yu., Dorofeev, A., Kamenskov, P., Kozhemov, S., Nikonova,
A. Study of the impact of various abrasive factors on the microrelief of the surface of hybrid ceramic orthopedic structures. Opcion, 2019, 35(S24), 598.

47. Sevbitov, A., Zhadko, S., Ershov, K., Borisov, V., Mironov, S. Rationale for the use of therapeutic and prophylactic complex to prevent intolerance to acrylates in patients with hyperfunction of the thyroid glands. Periodico Tche Quimica, 2019, 16(33), 266.

48. Sevbitov, A. Dental characteristics of clinical manifestations of delayed effects of radiation exposure. Abstract of the dissertation for the degree of doctor of medicine. Central research Institute of dentistry of the Ministry of health of the Russian Federation. Moscow, 2005.

49. Ergesheva, E., Davidiants, A., Dorofeev, A.., Sevbitova, M., Timoshina, M. Evaluation of effectiveness of an alternative method in complex treatment of diseases of endodont. Asian J. Pharm, 2018, 12(3), S933.

50. Sevbitov, A., Kuznetsova, M., Dorofeev, A., Borisov, V., Davidyants, A., Mironov, S., Timoshin, A., Paperno, A., Limonjan V. Introduction to Cariology and Periodontology, 2020, 120.

Table 1. Physical characteristics of silicone rubber.

\begin{tabular}{c|c}
\hline Specifications & Values \\
\hline Density, $\mathrm{kg} / \mathrm{m}^{3}$ & $960-980$ \\
Glass transition temperature, ${ }^{\circ} \mathrm{C}$ & 130 \\
Thermal conductivity, W/m.K & 1,32 \\
Water resistance, $\%$ & $<1$ \\
Tear resistance, $\mathrm{kgf} / \mathrm{cm}$ & 20 \\
\hline
\end{tabular}

Table 2. Physical characteristics of rubber.

\begin{tabular}{c|c}
\hline Specifications & Values \\
\hline Density, $\mathrm{kg} / \mathrm{m}^{3}$ & 1200 \\
Glass transition temperature, 0c & 73 \\
Thermal conductivity, W/m.K & 0,368 \\
Water resistance, \% & $>1$ \\
Tear resistance, $\mathrm{kgf} / \mathrm{cm}$ & 8 \\
\hline
\end{tabular}


Table 3. Influence of the modifier nature on the physical and mechanical properties of vulcanizates.

\begin{tabular}{c|c|c|c|c|c|c}
\hline \multirow{2}{*}{ № } & \multirow{2}{*}{ Indicators } & \multicolumn{5}{|c}{ Symbol modifier } \\
\cline { 3 - 7 } & & APEC & HPTMS & VTES & DMLS & Unmodified \\
\hline 1 & TS $^{\text {a }}(\mathrm{MPa})$ & $4,0 \pm 0.2$ & $4,2 \pm 0.21$ & $5,6 \pm 0.28$ & $3,2 \pm 0.16$ & $3,8 \pm 0.19$ \\
2 & Elongation $(\%)$ & $220 \pm 11$ & $360 \pm 18$ & $550 \pm 27.5$ & $360 \pm 18$ & $200 \pm 10$ \\
3 & Hardness $^{\text {b }}$ & $30 \pm 1.5$ & $28 \pm 1.4$ & $22 \pm 1.1$ & $32 \pm 1.6$ & $42 \pm 2.1$ \\
\hline
\end{tabular}

a Tensile strength

${ }^{b}$ by Shore $A$, conventional unit

Table 4. The physical and mechanical properties of siloxane compositions.

\begin{tabular}{|c|c|c|c|c|}
\hline \multirow{2}{*}{ № } & \multirow{2}{*}{ Indicators } & \multirow{2}{*}{ Method (SSc) } & \multicolumn{2}{|c|}{ Value of the index } \\
\hline & & & SilEP & GosSil \\
\hline 1 & $\mathrm{CTS}^{\mathrm{a}}(\mathrm{MPa})$ & $270-75$ & 5.6 & 5.1 \\
\hline 2 & Elongation at break (\%) & $270-75$ & 550 & 436 \\
\hline 3 & Hardness ${ }^{b}$ & $263-75$ & 22 & 32 \\
\hline 4 & Tear resistance $(\mathrm{kN} / \mathrm{m})$ & $262-93$ & 31 & 12 \\
\hline 5 & Permanent elongation (\%) & $270-75$ & 3 & 3.6 \\
\hline
\end{tabular}

a Conditional Tensile Strength

${ }^{b}$ by Shore $A$, conventional unit

c State Standard

Table 5. The effect of the primer on the strength of the connection of the "SilEP" lining with the acrylic base of the prosthesis.

\begin{tabular}{|c|c|c|}
\hline № & Primer & Bond strength during exfoliation ( $\mathrm{M} \pm \mathrm{M})$ \\
\hline 1 & WPa & $0.3 \pm 0.05$ \\
\hline 2 & TBT & $1.3 \pm 0.03$ \\
\hline 3 & TEOS & $1.8 \pm 0.06$ \\
\hline 4 & AS & $1.7 \pm 0.04$ \\
\hline 5 & VTES & $1.3 \pm 0.05$ \\
\hline 6 & VHC & $4.3 \pm 0.04$ \\
\hline
\end{tabular}

a Without a primer

The SOUTHERN BRAZILIAN JOURNAL OF open-access journal since 1993, Journal DOI: 10 . 48141/SBJCHEM. http://www.sbjchem.com. This text was introduced in this file in 2021 for compliance reasons.

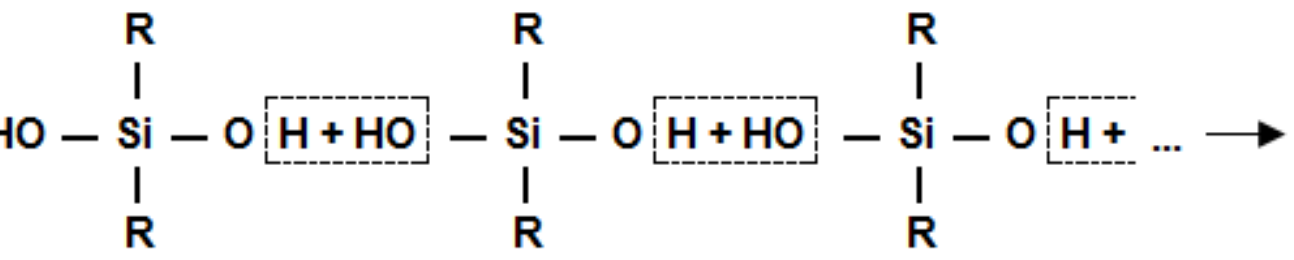

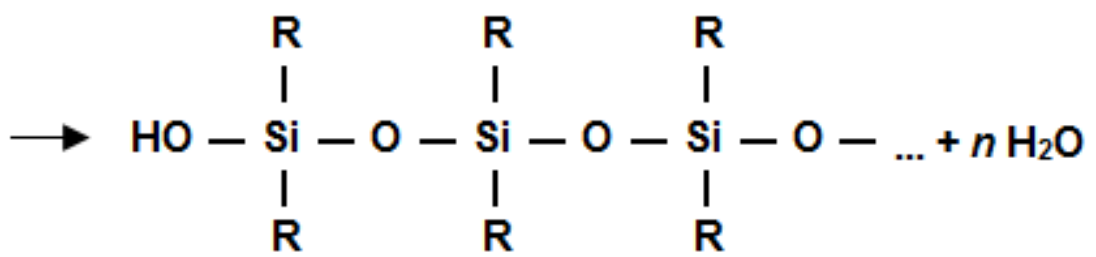

Figure 5. The chemical structure of the synthesized silicone rubber. 